\title{
Automated versus non-automated weaning for reducing the duration of mechanical ventilation for critically ill adults and children (Review)
}

Rose L, Schultz MJ, Cardwell CR, Jouvet P, McAuley DF, Blackwood B

Rose L, Schultz MJ, Cardwell CR, Jouvet P, McAuley DF, Blackwood B.

Automated versus non-automated weaning for reducing the duration of mechanical ventilation for critically ill adults and children.

Cochrane Database of Systematic Reviews 2014, Issue 6. Art. No.: CD009235.

DOI: 10.1002/14651858.CD009235.pub3. 
TABLE OF CONTENTS

ABSTRACT

PLAIN LANGUAGE SUMMARY

SUMMARY OF FINDINGS

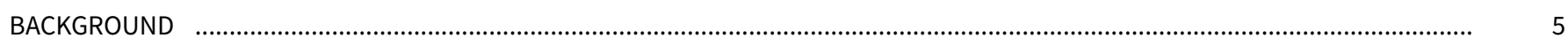

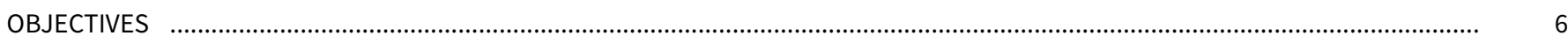

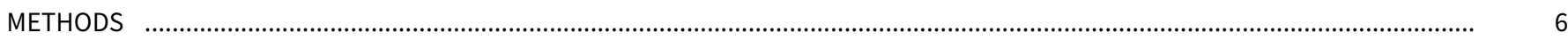

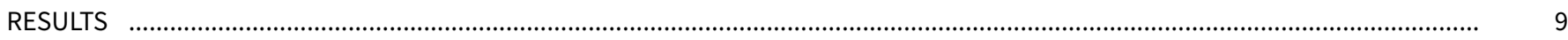

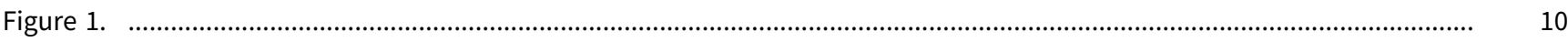

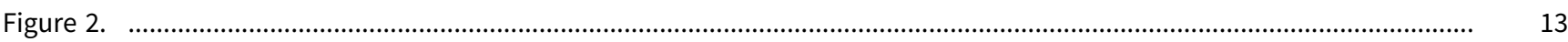

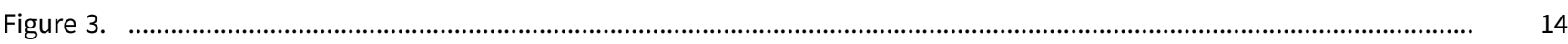

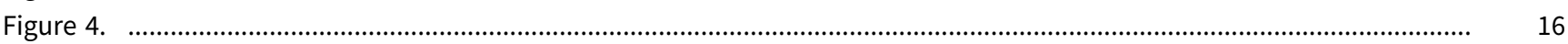

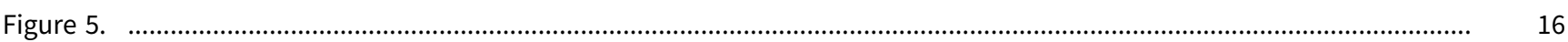

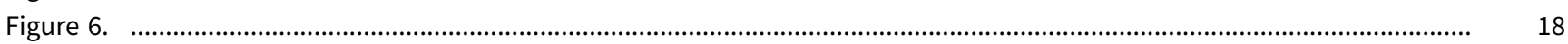

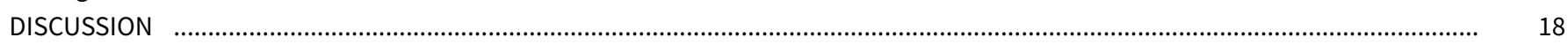

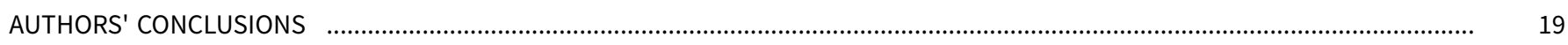

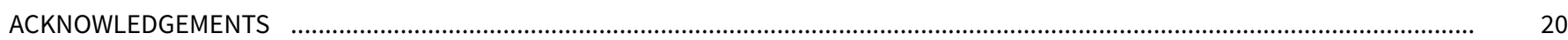

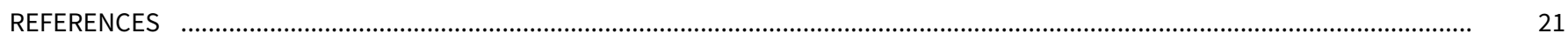

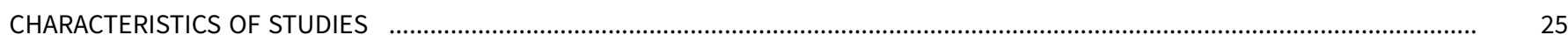

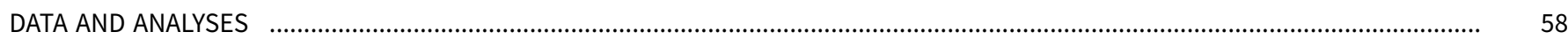

Analysis 1.1. Comparison 1 Primary analysis: automated closed loop system versus non-automated system, Outcome 1 Total 60 weaning duration by study population.

Analysis 1.2. Comparison 1 Primary analysis: automated closed loop system versus non-automated system, Outcome 2 Total weaning duration by automated system.

Analysis 1.3. Comparison 1 Primary analysis: automated closed loop system versus non-automated system, Outcome 3 Total weaning duration by non-automated strategy (control arm).

Analysis 1.4. Comparison 1 Primary analysis: automated closed loop system versus non-automated system, Outcome 4 Randomization to first extubation.

Analysis 1.5. Comparison 1 Primary analysis: automated closed loop system versus non-automated system, Outcome 5 Ventilation duration by study population.

Analysis 1.6. Comparison 1 Primary analysis: automated closed loop system versus non-automated system, Outcome 6 Ventilation duration of by automated system.

Analysis 1.7. Comparison 1 Primary analysis: automated closed loop system versus non-automated system, Outcome 7 Ventilation duration of by non-automated strategy (control arm).

Analysis 1.8. Comparison 1 Primary analysis: automated closed loop system versus non-automated system, Outcome 8 Intubation to randomization.

Analysis 1.9. Comparison 1 Primary analysis: automated closed loop system versus non-automated system, Outcome 9 Secondary outcome 5.1: mortality.

Analysis 1.10. Comparison 1 Primary analysis: automated closed loop system versus non-automated system, Outcome 10 Hospital length of stay.

Analysis 1.11. Comparison 1 Primary analysis: automated closed loop system versus non-automated system, Outcome 11 ICU length of stay by ICU population.

Analysis 1.12. Comparison 1 Primary analysis: automated closed loop system versus non-automated system, Outcome 12 ICU length of stay by automated system.

Analysis 1.13. Comparison 1 Primary analysis: automated closed loop system versus non-automated system, Outcome 13 Reintubation.

Analysis 1.14. Comparison 1 Primary analysis: automated closed loop system versus non-automated system, Outcome 14 Selfextubation.

Analysis 1.15. Comparison 1 Primary analysis: automated closed loop system versus non-automated system, Outcome 15 Non invasive ventilation.

Analysis 1.16. Comparison 1 Primary analysis: automated closed loop system versus non-automated system, Outcome 16 Prolonged mechanical ventilation.

Analysis 1.17. Comparison 1 Primary analysis: automated closed loop system versus non-automated system, Outcome 17 Tracheostomy. 
Analysis 2.1. Comparison 2 Sensitivity analysis: automated closed loop system versus non-automated system, un-logged data duration of weaning, Outcome 1 Weaning duration by ICU population.

Analysis 2.2. Comparison 2 Sensitivity analysis: automated closed loop system versus non-automated system, un-logged data duration of weaning, Outcome 2 Weaning duration by automated system [hours].

Analysis 2.3. Comparison 2 Sensitivity analysis: automated closed loop system versus non-automated system, un-logged data duration of weaning, Outcome 3 Weaning duration by non-automated strategy (control arm).

Analysis 2.4. Comparison 2 Sensitivity analysis: automated closed loop system versus non-automated system, un-logged data duration of weaning, Outcome 4 Randomization to first extubation.

Analysis 2.5. Comparison 2 Sensitivity analysis: automated closed loop system versus non-automated system, un-logged data duration of weaning, Outcome 5 Ventilation duration.

Analysis 2.6. Comparison 2 Sensitivity analysis: automated closed loop system versus non-automated system, un-logged data duration of weaning, Outcome 6 Intubation to randomization.

Analysis 2.7. Comparison 2 Sensitivity analysis: automated closed loop system versus non-automated system, un-logged data duration of weaning, Outcome 7 Hospital length of stay.

Analysis 2.8. Comparison 2 Sensitivity analysis: automated closed loop system versus non-automated system, un-logged data duration of weaning, Outcome 8 ICU length of stay.

Analysis 3.1. Comparison 3 Sensitivity analysis: automated closed loop system versus non-automated system excluding high risk of bias studies, Outcome 1 Weaning duration.

APPENDICES

WHAT'S NEW

HISTORY

CONTRIBUTIONS OF AUTHORS

DECLARATIONS OF INTEREST

SOURCES OF SUPPORT

INDEX TERMS 
[Intervention Review]

\title{
Automated versus non-automated weaning for reducing the duration of mechanical ventilation for critically ill adults and children
}

\author{
Louise Rose ${ }^{1}$, Marcus J Schultz² ${ }^{2}$ Chris R Cardwell ${ }^{3}$, Philippe Jouvet ${ }^{4}$, Danny F McAuley, 5 , Bronagh Blackwood 5
}

1Department of Critical Care Medicine, Sunnybrook Health Sciences Centre and Sunnybrook Research Institute, Toronto, Canada. 2Laboratory of Experimental Intensive Care and Anesthesiology, Academic Medical Center, University of Amsterdam, Amsterdam, Netherlands. ${ }^{3}$ Centre for Public Health, Queen's University Belfast, Belfast, UK. ${ }^{4}$ Department of Pediatrics, Sainte-Justine Hospital, University of Montreal, Montreal, Canada. ${ }^{5}$ Centre for Experimental Medicine, School of Medicine, Dentistry and Biomedical Sciences, Queen's University Belfast, Belfast, UK. ${ }^{6}$ Regional Intensive Care Unit, Royal Victoria Hospital, Belfast, UK

Contact: Louise Rose, Department of Critical Care Medicine, Sunnybrook Health Sciences Centre and Sunnybrook Research Institute, Toronto, Canada. louise.rose@utoronto.ca.

Editorial group: Cochrane Emergency and Critical Care Group.

Publication status and date: Edited (no change to conclusions), published in Issue 12, 2018.

Citation: Rose L, Schultz MJ, Cardwell CR, Jouvet P, McAuley DF, Blackwood B. Automated versus non-automated weaning for reducing the duration of mechanical ventilation for critically ill adults and children. Cochrane Database of Systematic Reviews 2014, Issue 6. Art. No.: CD009235. DOI: 10.1002/14651858.CD009235.pub3.

Copyright @ 2018 The Cochrane Collaboration. Published by John Wiley \& Sons, Ltd.

\section{A B S T R A C T}

\section{Background}

Automated closed loop systems may improve adaptation of mechanical support for a patient's ventilatory needs and facilitate systematic and early recognition of their ability to breathe spontaneously and the potential for discontinuation of ventilation. This review was originally published in 2013 with an update published in 2014.

\section{Objectives}

The primary objective for this review was to compare the total duration of weaning from mechanical ventilation, defined as the time from study randomization to successful extubation (as defined by study authors), for critically ill ventilated patients managed with an automated weaning system versus no automated weaning system (usual care).

Secondary objectives for this review were to determine differences in the duration of ventilation, intensive care unit (ICU) and hospital lengths of stay (LOS), mortality, and adverse events related to early or delayed extubation with the use of automated weaning systems compared to weaning in the absence of an automated weaning system.

\section{Search methods}

We searched the Cochrane Central Register of Controlled Trials (CENTRAL) (The Cochrane Library 2013, Issue 8); MEDLINE (OvidSP) (1948 to September 2013); EMBASE (OvidSP) (1980 to September 2013); CINAHL (EBSCOhost) (1982 to September 2013); and the Latin American and Caribbean Health Sciences Literature (LILACS). Relevant published reviews were sought using the Database of Abstracts of Reviews of Effects (DARE) and the Health Technology Assessment Database (HTA Database). We also searched the Web of Science Proceedings; conference proceedings; trial registration websites; and reference lists of relevant articles. The original search was run in August 2011, with database auto-alerts up to August 2012.

\section{Selection criteria}

We included randomized controlled trials comparing automated closed loop ventilator applications to non-automated weaning strategies including non-protocolized usual care and protocolized weaning in patients over four weeks of age receiving invasive mechanical ventilation in an ICU. 


\section{Data collection and analysis}

Two authors independently extracted study data and assessed risk of bias. We combined data in forest plots using random-effects modelling. Subgroup and sensitivity analyses were conducted according to a priori criteria.

\section{Main results}

We included 21 trials (19 adult, two paediatric) totaling 1676 participants (1628 adults, 48 children) in this updated review. Pooled data from 16 eligible trials reporting weaning duration indicated that automated closed loop systems reduced the geometric mean duration of weaning by $30 \%$ (95\% confidence interval $(\mathrm{Cl}) 13 \%$ to $45 \%)$, however heterogeneity was substantial $(\mathrm{I}=87 \%, \mathrm{P}<0.00001)$. Reduced weaning duration was found with mixed or medical ICU populations $(42 \%, 95 \% \mathrm{Cl} 10 \%$ to $63 \%)$ and Smartcare/PS $\mathrm{PS}^{\mathrm{TM}}(28 \%, 95 \% \mathrm{Cl} 7 \%$ to $49 \%)$ but not in surgical populations or using other systems. Automated closed loop systems reduced the duration of ventilation (10\%, $95 \% \mathrm{Cl} 3 \%$ to $16 \%)$ and ICU LOS (8\%, 95\% Cl $0 \%$ to $15 \%)$. There was no strong evidence of an effect on mortality rates, hospital LOS, reintubation rates, self-extubation and use of non-invasive ventilation following extubation. Prolonged mechanical ventilation $>21$ days and tracheostomy were reduced in favour of automated systems (relative risk (RR) $0.51,95 \% \mathrm{Cl} 0.27$ to 0.95 and $\mathrm{RR} 0.67,95 \% \mathrm{Cl} 0.50$ to 0.90 respectively). Overall the quality of the evidence was high with the majority of trials rated as low risk.

\section{Authors' conclusions}

Automated closed loop systems may result in reduced duration of weaning, ventilation and ICU stay. Reductions are more likely to occur in mixed or medical ICU populations. Due to the lack of, or limited, evidence on automated systems other than Smartcare/PS ${ }^{\mathrm{TM}}$ and Adaptive Support Ventilation no conclusions can be drawn regarding their influence on these outcomes. Due to substantial heterogeneity in trials there is a need for an adequately powered, high quality, multi-centre randomized controlled trial in adults that excludes 'simple to wean' patients. There is a pressing need for further technological development and research in the paediatric population.

\section{PLAIN LANGUAGE SUMMARY}

\section{Do ventilators that manage the reduction of ventilator support (weaning) reduce the duration of weaning compared to strategies managed by clinicians?}

\section{Background and importance}

Critically ill patients receiving assistance from breathing machines (ventilators) may be restored to normal breathing using clinical methods (collectively termed weaning) that require both expertise and continuous monitoring. Inefficient weaning may result in a prolonged time on a ventilator, putting patients at risk of lung injury, pneumonia and death. At times, delivery of the most effective and efficient care can be difficult due to organizational constraints. Computerized weaning systems may provide a solution to inefficient weaning methods. In this Cochrane review we evaluated if computerized weaning systems were more effective than clinical methods used by clinicians for reducing inappropriate delays in weaning, the overall duration of ventilation, and the length of intensive care unit (ICU) and hospital stays.

\section{Findings}

We identified 21 studies that provided information on a total of 1676 people including 1628 adults and 48 children. The evidence was current to 30th September 2013. Studies were conducted in people with medical reasons such as pneumonia and other infections for needing admission to ICU, people admitted following trauma, and people admitted after heart or other forms of surgery. As well, various commercially available computerized weaning systems were studied. We found that computerized weaning systems resulted in a reduced weaning duration as well as reduced overall time on the ventilator and stay in an ICU. The average time required for a person to be weaned off the ventilator was reduced by $30 \%$. The overall time on the ventilator was reduced by $10 \%$ and the length of stay in ICU by $8 \%$. Not all studies demonstrated these reductions. Studies conducted only in people admitted to ICU following surgery did not demonstrate reductions in weaning, overall time on a ventilator or ICU stay.

\section{Limitations}

Because of differences in the methods and results of some studies included in this review, further large scale research is warranted. There is also a need for more studies that examine the effect of computerized weaning systems in children. 


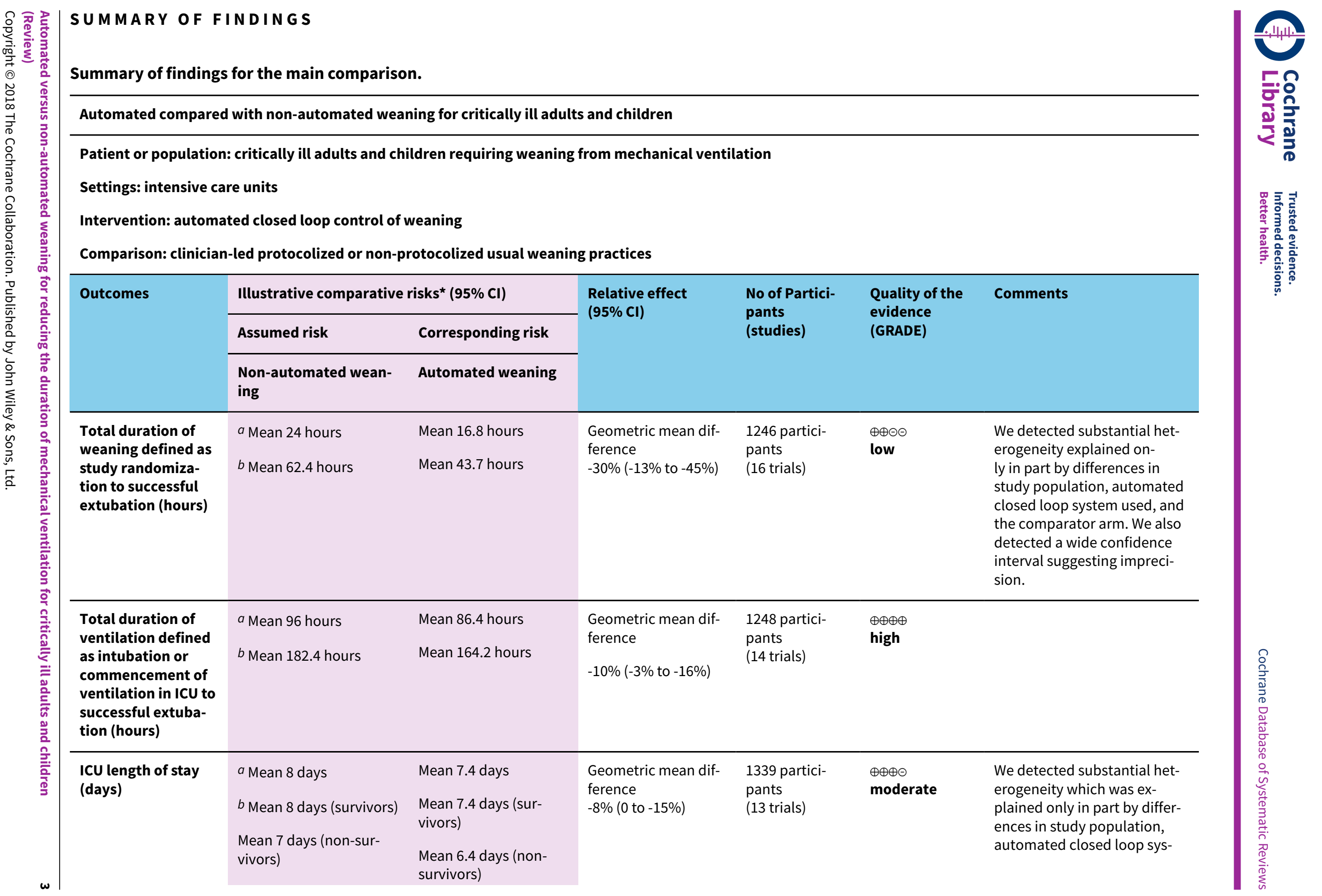




\begin{tabular}{|c|c|c|c|c|c|c|}
\hline \multirow[b]{2}{*}{$\begin{array}{l}\text { Hospital length of } \\
\text { stay (days) }\end{array}$} & & & & & & \multirow[t]{2}{*}{$\begin{array}{l}\text { tem used, and the compara- } \\
\text { tor arm. }\end{array}$} \\
\hline & $\begin{array}{l}a_{\text {Mean }} 17 \text { days } \\
b \text { Mean } 17 \text { days (sur- } \\
\text { vivors) } \\
\text { Mean } 11.5 \text { days (non- } \\
\text { survivors) }\end{array}$ & $\begin{array}{l}\text { Mean } 15.3 \text { days } \\
\text { Mean } 15.3 \text { days (sur- } \\
\text { vivors) } \\
\text { Mean } 10.3 \text { days (non- } \\
\text { survivors) }\end{array}$ & $\begin{array}{l}\text { Geometric mean dif- } \\
\text { ference } \\
-10 \%(-19 \% \text { to } 2 \% \text { in- } \\
\text { crease) }\end{array}$ & $\begin{array}{l}749 \text { partici- } \\
\text { pants } \\
\text { ( } 7 \text { trials) }\end{array}$ & $\begin{array}{l}\oplus \oplus \oplus \oplus \\
\text { high }\end{array}$ & \\
\hline $\begin{array}{l}\text { Mortality (ICU, hos- } \\
\text { pital) (days) }\end{array}$ & $\begin{array}{l}a \text { ICU } 31 \% \text {, hospital } 37 \% \\
\text { (adults) } \\
b \text { ICU } 15 \% \text {, hospital } 18 \% \\
\text { (children) }\end{array}$ & $\begin{array}{l}\text { ICU } 38 \% \\
\text { hospital 35\% } \\
\text { (adults) } \\
\text { ICU } 18 \% \\
\text { hospital 17\% (chil- } \\
\text { dren) }\end{array}$ & $\begin{array}{l}\text { Risk ratio } \\
\text { ICU } \\
1.23 \text { ( } 0.58 \text { to } 2.60) \\
\text { Hospital } \\
0.95 \text { ( } 0.62 \text { to } 1.45 \text { ) }\end{array}$ & $\begin{array}{l}1128 \text { partici- } \\
\text { pants } \\
\text { (12 trials) }\end{array}$ & $\begin{array}{l}\oplus \oplus \oplus \oplus \\
\text { high }\end{array}$ & \\
\hline Reintubation rate & $\begin{array}{l}a_{11} \% \text { (adults) } \\
b_{10 \%} \text { (children) }\end{array}$ & $\begin{array}{l}9 \% \text { (adults) } \\
8 \% \text { (children) }\end{array}$ & $\begin{array}{l}\text { Risk ratio } \\
0.80 \text { (0.61 to } 1.05)\end{array}$ & $\begin{array}{l}1081 \text { partici- } \\
\text { pants } \\
\text { (13 trials) }\end{array}$ & $\begin{array}{l}\oplus \oplus \oplus \oplus \\
\text { high }\end{array}$ & \\
\hline
\end{tabular}

${ }^{\star}$ The basis for the assumed risk (e.g. the mean control group risk) is provided in footnotes. The corresponding risk is based on the assumed risk in the comparison group and the relative effect of the intervention.

Cl: Confidence interval

GRADE Working Group grades of evidence

High quality: Further research is very unlikely to change our confidence in the estimate of effect.

Moderate quality: Further research is likely to have an important impact on our confidence in the estimate of effect and may change the estimate.

Low quality: Further research is very likely to have an important impact on our confidence in the estimate of effect and is likely to change the estimate.

Very low quality: We are very uncertain about the estimate.

a Assumed risk for adults is derived from large international cohort study of mechanical ventilation and weaning by Esteban and colleagues (Esteban 2008). Reported medians are used as an approximation for the means used for illustrative comparisons of all continuous variables.

${ }^{b}$ Assumed risk for children is derived from international cohort study of mechanical ventilation and weaning by Farias and colleagues (Farias 2004 ). The mean duration of weaning and ventilation are reported in the paper and have been used in this illustrative comparison. Reported medians for survivors and non-survivors are used as an approximation for the mean ICU and hospital length of stay used for illustrative comparisons. 


\section{B A C K G R O U N D}

\section{Description of the condition}

Serious physiological and psychological sequelae are associated with protracted use of invasive mechanical ventilation, necessitating efficient processes to safely reduce and remove ventilator support, termed weaning. Physiological complications include ventilator associated pneumonia, large airway injury and ventilator associated lung injury. Mechanical ventilation can damage both injured and healthy lungs by perpetuating alveolar and systemic inflammatory response systems (Kuipers 2011). Psychological sequelae include post-traumatic stress disorder (Cuthbertson 2004; Jones 2001; Jubran 2010a); anxiety and depression (Jubran 2010b); delirium (Ely 2001a; Girard 2010); and cognitive deficits (Hopkins 2005; Jackson 2011).

Weaning may account for more than $40 \%$ of the duration of mechanical ventilation depending on the definition of when weaning commences (Esteban 2008; Rose 2009). Greater than $50 \%$ of critically ill ventilated children will be extubated within 48 hours, however the remainder frequently require prolonged mechanical ventilation (Newth 2009). Adult patients that require prolonged mechanical ventilation account for $40 \%$ of intensive care unit (ICU) bed days and $50 \%$ of ICU costs (Carson 2006). Evidence-based consensus guidelines for weaning, published in 2001 (Maclntyre 2001) and 2007 (Boles 2007), emphasize the importance of preventing unnecessary delays to the weaning process. The same tenets of weaning apply to children and adults (Leclerc 2010). Mortality increases as the duration of ventilation is extended (Esteban 2008) and extubation is delayed (Coplin 2000). Determining weaning readiness and the most appropriate weaning method have traditionally been based on clinician 'judgement and experience' (Sahn 1973), resulting in variable practice. Tools such as weaning protocols and automated closed loop systems have been developed to facilitate systematic and early recognition of a patient's ability to breathe spontaneously and so the potential for discontinuation of ventilation. These tools may reduce variation in practice and improve efficiency by removing subjectivity and applying objectivity (Murtagh 2007). A previous Cochrane review evaluated the efficacy of protocolized versus non-protocolized weaning for reducing the duration of mechanical ventilation (Blackwood 2010a). Despite evidence indicating the deleterious effects of unnecessary prolongation of mechanical ventilation, weaning continues to be delayed (Ely 1996; Esteban 2008; Kollef 1997). Recent surveys indicate inconsistent implementation of weaning protocols (Burns 2009a; Santschi 2007) and infrequent adoption of automated closed loop systems (Blackwood 2010b), suggesting a lack of consensus in their utility.

\section{Description of the intervention}

Weaning traditionally occurs via clinician-directed adjustments to the level of breathing support provided by the ventilator, which culminates in a spontaneous breathing trial (SBT) comprising either low level pressure support or a T-piece trial. Automated closed loop systems may improve the adaptation of mechanical support to the ventilatory needs of patients. These systems continuously monitor changes in ventilation, interpret real-time physiological changes, and adapt ventilation in response to these changes (Lellouche 2009a). Complex closed loop systems consist of an input that activates the system, an output, which is the product of the system, and a protocol linking the two (Chatburn 2011).
Several systems have been developed and are now commercially available. Examples of commercially automated systems or modes using complex closed loops include Mandatory Minute Ventilation (MMV), Adaptive Support Ventilation (ASV) (Hamilton Medical AG, Bonaduz, Switzerland), SmartCare ${ }^{\mathrm{TM}} / \mathrm{PS}$ (Dräger Medical, Lübeck, Germany), Proportional Assist Ventilation (PAV), Neurally Adjusted Ventilatory Assist (NAVA) (Maquet, Solna, Sweden), and Automode ${ }^{\circledR}$ (Maquet, Solna, Sweden).

\section{How the intervention might work}

Automated closed loop systems have been proposed to optimize decision-making, reduce variation amongst clinicians, and to assist with interpretation of clinical information (Morris 2002). Through continuous monitoring and real-time interventions, automated weaning applications theoretically provide improved adaptation of ventilatory support to the patients' needs when compared to clinician-directed weaning. Automation of the weaning process has the potential to reduce avoidable delays in weaning as it is less reliant on clinician recognition of changes in the patient's weaning status, which in turn is influenced by clinician availability, work load, and unit adoption of processes of care such as weaning protocols and guidelines.

\section{Why it is important to do this review}

There is a pressing imperative to identify efficiencies in the weaning process to prevent associated morbidity and mortality, and also to offer solutions to constraints in the provision of critical care services. The number of patients receiving mechanical ventilation is increasing and is predicted to continue to increase due to improved patient survival and an aging population (Needham 2006; Zilberberg 2012). The cost of providing care to these patients is substantial (Wunsch 2010). This increased demand is occurring alongside a reduced supply of healthcare professionals qualified and skilled in the management of mechanical ventilation and its weaning (Fink 2006; Zolnierek 2010). If efficacious, automated weaning applications could enable management of weaning despite predicted staffing shortages.

In the Cochrane review comparing protocolized weaning to usual care (Blackwood 2010a) it was evident that trials of automated systems were becoming more frequent. Compared to other weaning methods, automated weaning applications have been shown to either reduce the duration of mechanical ventilation (Lellouche 2006; Petter 2003; Sulzer 2001) or have no effect (Dongelmans 2009; Rose 2008). Automated weaning applications have also been shown to be well tolerated in the paediatric population (Jouvet, 2007). Given the increasing availability of these applications, and the moderate number of trials with discordant results, there is a need to provide consumers, clinicians and policy makers with evidence of their effectiveness and their safety.

A Cochrane systematic review comparing the effectiveness of automated weaning and SBT systems with non-automated weaning in postoperative adults identified one high quality trial of SmartCare ${ }^{\mathrm{TM}} / \mathrm{PS}$ reporting no effect on ventilation discontinuation time (Burns 2014). Another review specific to SmartCare ${ }^{\mathrm{TM}} / \mathrm{PS}$ is underway for all critically ill adults (Burns 2010). Given that other automated systems are used in adult and paediatric populations, a review evaluating the effectiveness of all systems is warranted in both populations. 


\section{O B JECTIVES}

The primary objective for this review was to compare the total duration of weaning from mechanical ventilation, defined as the time from study randomization to successful extubation (as defined by study authors), for critically ill ventilated patients managed with an automated weaning system versus no automated weaning system (usual care).

Secondary objectives for this review were to determine differences in the duration of ventilation, ICU and hospital lengths of stay (LOS), mortality, and adverse events related to early or delayed extubation with the use of automated weaning systems compared to weaning in the absence of an automated weaning system.

\section{METHOD S}

\section{Criteria for considering studies for this review Types of studies}

We included randomized controlled trials (RCTs) that compared automated closed loop ventilator applications to non-automated weaning strategies including standard or usual care (as described by the authors) and protocolized weaning (as described by the authors).

\section{Types of participants}

We included patients over four weeks of age receiving invasive mechanical ventilation in a high intensity care setting. We included adults and children as the same tenets of weaning apply to children and adults (Leclerc 2010).

\section{Types of interventions}

In our search strategy we included all automated ventilator modes and modalities that aim to reduce the level of support provided by the ventilator based on continuous monitoring of changes in the patient tolerance and interpretation of real-time physiological changes. Several commercially available examples are described below.

1. Smartcare/PS ${ }^{\mathrm{TM}}$ (Dräger Medical, Lübeck, Germany) performs closed loop control of pressure support (increases, decreases, or leaves it unchanged) in response to data on the patient's current respiratory status (respiratory rate, tidal volume $\left(\mathrm{V}_{\mathrm{T}}\right)$, and endtidal carbon dioxide $\left.\left(\mathrm{ETCO}_{2}\right)\right)$ and its time-course to maintain the patient in a 'respiratory zone of comfort'. The SmartCare/PS ${ }^{\text {TM }}$ system divides weaning into three phases: 1 . stabilizing the patient within the respiratory zone of comfort; 2 . decreasing pressure support without the patient leaving the comfort zone; 3 . testing for extubation readiness by monitoring the patient at the lowest level of pressure support. As opposed to other systems that make breath by breath changes, Smartcare/PS ${ }^{\mathrm{TM}}$ changes settings every couple of minutes.

2. Adaptive support ventilation (ASV) (Hamilton Medical, Bonaduz, Switzerland) is a closed loop controlled mode of ventilation that adjusts inspiratory pressure and mandatory breath rate on a breath by breath basis to maintain a preset minimum minute ventilation with an optimal respiratory pattern (Sulzer 2001). Ideal body weight, percentage of minute ventilation desired, and maximal inspiratory pressure are selected by the clinician on initiation of ASV. Following assessment of the patient's respiratory compliance and resistance via five test breaths, ASV is delivered as pressurecontrolled ventilation (PCV) and calculates optimal tidal volume and respiratory rate targets using the Otis formula (Otis 1950) and based on the pre-set minimum minute ventilation, theoretical dead space calculated from the ideal body weight, and the expiratory time constant. When the patient makes an inspiratory effort, ASV switches from PCV to pressure support ventilation (PSV). Pressure support is continuously adapted to the patient's respiratory rate and $V_{T}$ to achieve the desired minute ventilation.

3. Automode (Siemens, Solna, Sweden) uses an algorithm to switch from a controlled mode, for example PCV, to a support mode such as PSV based on detection of patient triggering of two consecutive breaths. The mode is switched from support to control when the patient experiences prolonged apnoea ( $>12$ seconds) (Roth 2001). Other possible mode switches are from volume controlled ventilation to volume support ventilation (VSV) or from pressure regulated volume control to VSV.

4. Proportional assist ventilation $\left(\mathrm{PAV}^{+}\right)$automatically adjusts airway pressure based on measurement of compliance and resistance throughout the inspiratory cycle to maintain an appropriate degree of support. There are no set targets for pressure, volume or flow, rather airway pressure is increased or decreased in proportion to patient effort via a positive feedback control using respiratory elastance and resistance as feedback signals (Branson 2004). The patient's respiratory drive determines the respiratory rate and inspiratory time.

5. Mandatory minute ventilation (MMV) (Dräger Medical, Lübeck, Germany) uses closed loop control of the mandatory breath rate while considering the patient's spontaneous breath rate based on a clinician predetermined minute ventilation. All other ventilator parameters are clinician selected. The mandatory breath rate is variable, dependent on the patient's respiratory drive. Patients able to breath spontaneously above the predetermined minute ventilation essentially receive PSV, patients experiencing apnoea receive controlled ventilation.

6. Proportional pressure support (PPS) (Dräger Medical, Lübeck, Germany) is based on the same principals as PAV. In conventional PSV, pressure support is delivered as a fixed pressure during each inspiratory phase. In PPS, pressure support is provided proportionately to the work of breathing that alters due to changes in airway resistance and lung compliance.

7. Neurally adjusted ventilatory assist (NAVA) (Maquet, Solna, Sweden) delivers partial ventilatory support via a feedback loop generated through monitoring of neural inspiratory activity using continuous oesophageal recording of the diaphragmatic electromyogram. Ventilatory support is delivered in proportion to the signal's intensity and is cycled on and off according to its time course (Schmidt 2010).

8. Intellivent-ASV ${ }^{\circledR}$ (Hamiltom Medical, Rhäzüns, Switzerland) is a relatively new extension of ASV that uses closed loop control to adjust minute ventilation based on the $\mathrm{ETCO}_{2}$ and oxygenation by automatically adjusting the fraction of inspired oxygen $\left(\mathrm{FiO}_{2}\right)$ and positive end-expiratory pressure (PEEP) in combination based on the acute respiratory distress syndrome network (ARDSnet) PEEP$\mathrm{FiO}_{2}$ table (Arnal 2012).

Automated versus non-automated weaning for reducing the duration of mechanical ventilation for critically ill adults and children 
9. Mandatory rate ventilation (MRV) (Taema-Horus Ventilator ${ }^{\circledR}$ Air Liquide, France) uses closed loop control to adjust pressure support based on a respiratory rate target. The ventilator compares the average respiratory rate over four respiratory cycles to the target. If the average respiratory rate is higher than the target, pressure support is increased by $1 \mathrm{cmH}_{2} \mathrm{O}$, if lower the pressure support is decreased by $1 \mathrm{cmH}_{2} \mathrm{O}$ (Taniguchi 2009).

We included studies describing commercial and non-commercial automated ventilator applications. We excluded modes such as pressure regulated volume control (PRVC) (Siemens, Solna, Sweden) and pressure augmentation (Bear Medical Systems, Yorba Linda, United States), also known as volume assured pressure support (VAPS) (Bird Product Corporation, Yorba Linda, United States), which use closed loops to minimize inspiratory pressure while guaranteeing volume as opposed to reducing the level of support based on patient tolerance.

\section{Types of outcome measures}

\section{Primary outcomes}

The total duration of ventilator weaning, where weaning was defined as the time in hours from study randomization to successful extubation or discontinuation of invasive and noninvasive mechanical ventilation (defined as no requirement for either reintubation or recommencement of mechanical ventilation (in the case of tracheostomy) for 24,48 , or 72 hours, or as defined by study authors), or death

\section{Secondary outcomes}

1. Time from study randomization to first extubation

2. Total duration of mechanical ventilation (from intubation to successful extubation)

3. Time from intubation to study randomization

4. Time from satisfying extubation criteria (as defined by the study authors) and actual extubation

5. Mortality (ICU, 28 or 30 day, 60 day, 90 day, and hospital)

6. ICU and hospital LOS

7. Number of adverse events (reintubation, self-extubation, postextubation non-invasive ventilation, and prolonged ventilation defined as requirement for mechanical ventilation for $\geq 21$ days)

\section{Search methods for identification of studies}

\section{Electronic searches}

Two authors (LR and PJ) searched the Cochrane Central Register of Controlled Trials (CENTRAL) (The Cochrane Library 2013, Issue 8); MEDLINE (OvidSP) (1948 to September 2013); EMBASE (OvidSP) (1980 to September 2013); CINAHL (EBSCOhost) (1982 to September 2013); and the Latin American and Caribbean Health Sciences Literature (LILACS). Relevant published reviews were sought using the Database of Abstracts of Reviews of Effects (DARE) and the Health Technology Assessment Database (HTA Database). The original search was run in August 2011, with database auto-alerts to August 2012.

In MEDLINE we combined our search terms with the Cochrane highly sensitive search strategy for identifying RCTs (Appendix 1). We adapted our MEDLINE search strategy to other selected databases (EMBASE: Appendix 2; CENTRAL: Appendix 3; DARE:
Appendix 4; HTA: Appendix 5; CINAHL: Appendix 6; LILACS: Appendix 7).

We limited our searches to RCTs, systematic reviews and metaanalyses, and we applied a filter to limit the search to human studies.

We did not impose language or other restrictions.

\section{Searching other resources}

We searched conference proceedings using the Web of Science Conference Proceedings Citation Index - Science and Social Science and Humanities (1990 to September 2013).

We also searched the conference proceedings of the annual congresses of the European Society of Intensive Care Medicine, Society of Critical Care Medicine, Australian New Zealand Intensive Care Society, and American Thoracic Society (each searched from January 2005 to October 2013).

We searched for unpublished studies and ongoing trials on the following websites:

1. www.clinicaltrials.gov/;

2. www.controlled-trials.com/mrct/; and

3. www.who.int/trialsearch.

We searched for prospectively registered systematic reviews using PROSPERO at www.crd.york.ac.uk/prospero/.

We handsearched the reference lists of retrieved studies and review papers as well as contacted the identified corresponding authors of eligible trials and content experts to identify additional potentially relevant studies.

\section{Data collection and analysis}

\section{Selection of studies}

We developed a tool to perform study screening (Appendix 8). Two authors (LR, PJ) independently examined the titles and abstracts of articles retrieved though the electronic and manual searches to determine eligibility using the inclusion and exclusion criteria, which were listed on the screening tool. The full-texts of articles selected for inclusion by either review author, from the review of the title and abstract, were obtained and examined for eligibility. We resolved any disagreements though discussion and were able to achieve consensus without referring to an independent arbiter (DM).

\section{Data extraction and management}

Two authors (BB, MS) independently extracted study data from the selected studies using a standardized data extraction form (Appendix 9). Where an author was a member of the study team, he or she was excluded from data extraction and this task was assigned to a third author (LR). We piloted the form on a random sample of five studies prior to its use. Information was extracted on the study design and setting, participant demographic characteristics, study inclusion and exclusion criteria, weaning methods in the intervention and control arms of the selected studies, sedation strategies, and study outcomes. As well, randomization methods, allocation concealment, blinding, frequency and handling of missing data, adherence to intention-to- 
treat analysis, and selective reporting of outcomes were described. We contacted the corresponding authors of selected studies to seek further clarification on issues of reporting or to obtain additional outcome data. Data extractors were not blinded to the study citations.

\section{Assessment of risk of bias in included studies}

The quality of the included studies was independently assessed by two authors (BB, MS) and verified by a third (LR). Study quality was assessed using the domain-based evaluation recommended by The Cochrane Collaboration (Higgins 2011). These domains include:

1. random sequence generation,

2. allocation concealment,

3. blinding,

4. incomplete outcome data,

5. selective reporting,

6. other bias.

For each domain, we assigned a judgment regarding the risk of bias as 'high risk of bias', 'low risk of bias', or 'unclear risk of bias' (Higgins 2011). We attempted to contact the trial corresponding author for clarification when insufficient detail was reported to assess the risk of bias. A priori, we anticipated that no eligible trials would be blinded to the weaning intervention. Once we achieved consensus on the quality assessment of the six domains for eligible studies, we assigned them to the following categories.

1. Low risk of bias: describes studies for which all domains are scored as 'low risk of bias'.

2. High risk of bias: two or more domains are scored as 'No', indicating high risk of bias.

3. Unclear risk of bias: one or more domains are scored as unclear.

We constructed a 'Risk of bias' table in RevMan 5.2 to present the results. We used the assessment of risk of bias to perform sensitivity analyses based on methodological quality.

\section{Measures of treatment effect}

We calculated the difference in means, 95\% confidence interval $(\mathrm{Cl})$ and the standard error of that difference for continuous outcomes. For dichotomous data we described the treatment effects using risk ratios (RR) and $95 \% \mathrm{Cls}$. The pooled estimate was calculated using the random-effects model as heterogeneity was anticipated and this model makes adjustments for the heterogeneity and produces a more conservative estimate of treatment effect (DeMets 1987).

\section{Unit of analysis issues}

Individual participants in each trial arm comprised the unit of analysis. All trials had a parallel group design and thus no adjustment was necessary for crossover or clustering.

\section{Dealing with missing data}

We contacted the corresponding authors of selected trials to obtain missing data.

\section{Assessment of heterogeneity}

We evaluated the clinical heterogeneity in selected studies by qualitative assessment of study differences in terms of study population, ICU type, the type of clinician involvement in decision- making for the weaning process, and implementation of weaning and extubation processes. Statistical heterogeneity was informally evaluated from forest plots of the study estimates, and more formally using the $\mathrm{Chi}^{2}$ test $(\mathrm{P}<0.05$, significant heterogeneity) and $I^{2}$ statistic $\left(I^{2}>50 \%\right.$, moderate to substantial heterogeneity) (Higgins 2011).

\section{Assessment of reporting biases}

Reporting bias occurs due to an increased likelihood of positive trials being published compared to trials with negative findings. We constructed a funnel plot (graphical display) of the treatment effect for the primary outcome against trial precision (standard error) using RevMan 5.2. We visually inspected the funnel plot for asymmetry. We identified sufficient studies $(\geq 10)$ to formally test for asymmetry using the test proposed by Egger 1997 (linear regression of the intervention effect estimate against its standard error, weighted by the inverse of the variance of the intervention effect estimate) because of the continuous nature of our primary outcome variable.

\section{Data synthesis}

Findings are presented in the 'Summary of findings for the main comparison'. Two authors (CC, LR) organized the data, conducted analyses and reported summary statistics when data were available, similar and of good quality. We identified sufficient studies to perform meta-analyses using RevMan 5.2. When pooling was appropriate, we used a random-effects model which incorporates variation both within and between studies. Continuous data for our primary and secondary outcomes were skewed, therefore we log transformed the data for the primary analysis. This was done by obtaining the raw data from the corresponding authors of the selected studies, which we then log transformed. When unable to obtain data from the corresponding authors we log transformed the mean and SD using the method described by Higgins 2011. If the mean (SD) was not available we used the median and interquartile range (IQR) of the unlogged data to approximate the mean using the method described by Hozo and colleagues (Hozo 2005) and calculated an approximate SD on the log scale from the IQR on the log scale (Higgins 2011). We performed a sensitivity analysis examining the standardized mean difference on the unlogged data.

The exponential of the difference in the mean of a variable on the log scale between the intervention and the control groups was determined to give the ratio of geometric means on the unlogged scale. We reported the percentage change and 95\% confidence interval $(\mathrm{Cl})$ (reduction or increase) in the geometric mean for the treatment group compared to control for ease of understanding (Bland 1996).

\section{Subgroup analysis and investigation of heterogeneity}

We planned to perform the following subgroup analyses to assess the impact on weaning duration, total duration of mechanical ventilation, ICU length of stay, and rate of reintubation:

1. type of patient i.e., medical, surgical, or trauma;

2. weaning classification (simple, difficult, or prolonged (Boles 2007));

3. adult versus paediatric populations;

4. the automated weaning application evaluated;

Automated versus non-automated weaning for reducing the duration of mechanical ventilation for critically ill adults and children (Review) 
5. the non-automated weaning strategy used (protocolized versus non-protocolized weaning); and

6. type of sedation strategy used (targeted to sedation score, daily interruption, no formal sedation strategy).

Due to limited numbers we collapsed patient types in to medical or mixed ICU populations and surgical ICU populations. We were unable to perform subgroup analyses according to weaning classification as no trials have been conducted using this taxonomy. We were unable to perform a subgroup analysis in trials of adult versus paediatric populations as we only identified one trial that recruited children. We did not perform a subgroup analysis based on the type of sedation strategy used as this was inadequately reported in most trials.

\section{Sensitivity analysis}

We performed a sensitivity analysis to investigate the effect on the primary outcome of excluding trials with high risk of bias.

\section{Summary of finding tables}

We assessed the quality of the evidence associated with the total duration of ventilator weaning, other relevant durations of invasive mechanical ventilation listed as secondary outcomes, mortality, ICU and hospital lengths of stay and adverse events using the principles of the GRADE system (Guyatt 2008). We presented our findings using a 'Summary of findings for the main comparison' (SoF) constructed in RevMan 5.2. The GRADE system assesses within study risk of bias (methodological quality), directness of evidence, data heterogeneity, precision of effect estimates and risk of publication bias.

\section{RES U L T S}

\section{Description of studies}

(See: Characteristics of included studies; Characteristics of excluded studies; Characteristics of ongoing studies; Characteristics of studies awaiting classification)

We identified eligible RCTs with intervention arms that comprised one of the following commercially available closed loop systems: Smartcare/PS ${ }^{\mathrm{TM}}$, ASV, Automode, MMV, MRV, or PAV+; and one study of a non-commercial closed loop system. The control arms of the included studies comprised weaning from mechanical ventilation using either written protocols or the usual methods within the study sites.

\section{Results of the search}

Our search of the electronic databases, described above, retrieved 1249 citations including 175 from our updated search (August 2012 to September 2013). In addition, we received four citations recommended by experts. After reviewing the citation titles and abstracts retrieved from the electronic databases and expert referrals we retrieved 40 potentially relevant studies, nine from our updated search. Of these, 11 were abstracts of eligible studies later published as full-text reports. Three were available in abstract form only, two met our inclusion criteria and are pending classification, and the second was an abstract reporting interim findings from a trial previously included in our list of ongoing trials. We excluded six studies as they did not meet our inclusion criteria. We identified a further 91 citations to review from trials databases and conference abstracts. Of these we identified five potentially relevant abstracts that are pending classification (two from the updated search) and 10 ongoing trials (six from the updated search) (see Figure 1). 
Figure 1. Study flow diagram.

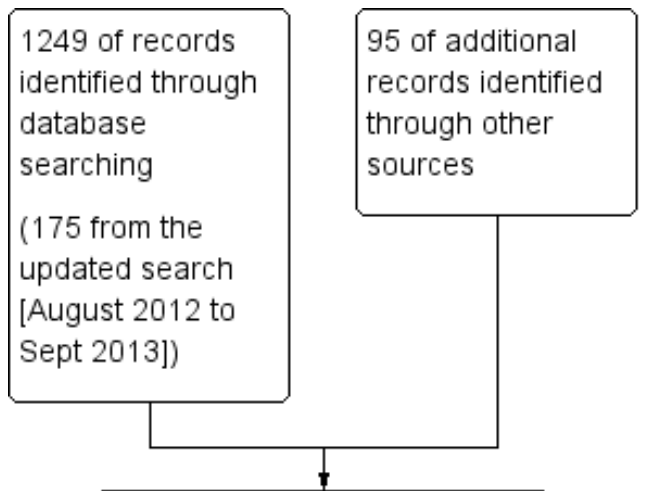

1192 of records after
duplicates removed

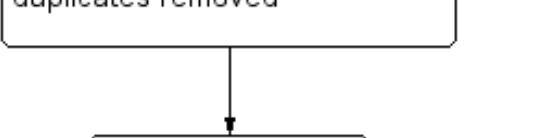

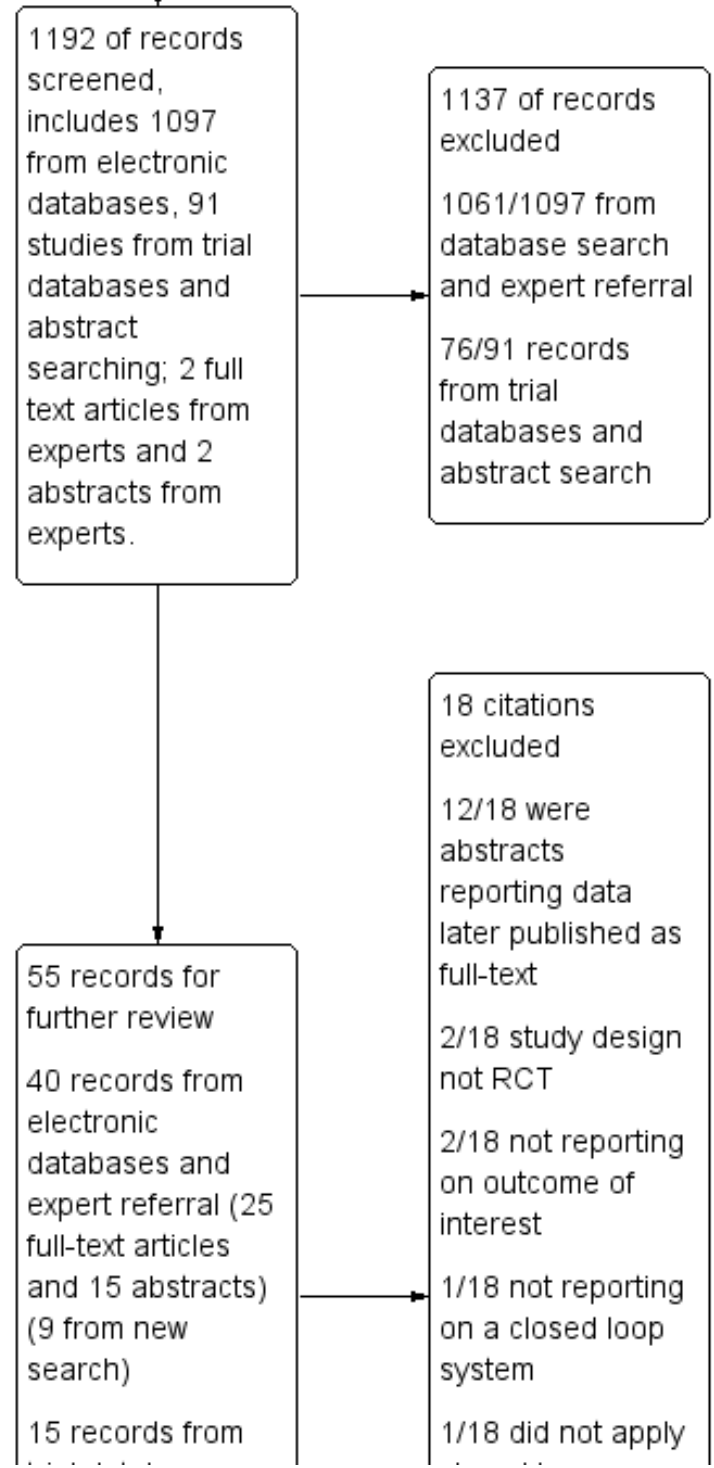


Figure 1. (Continued)

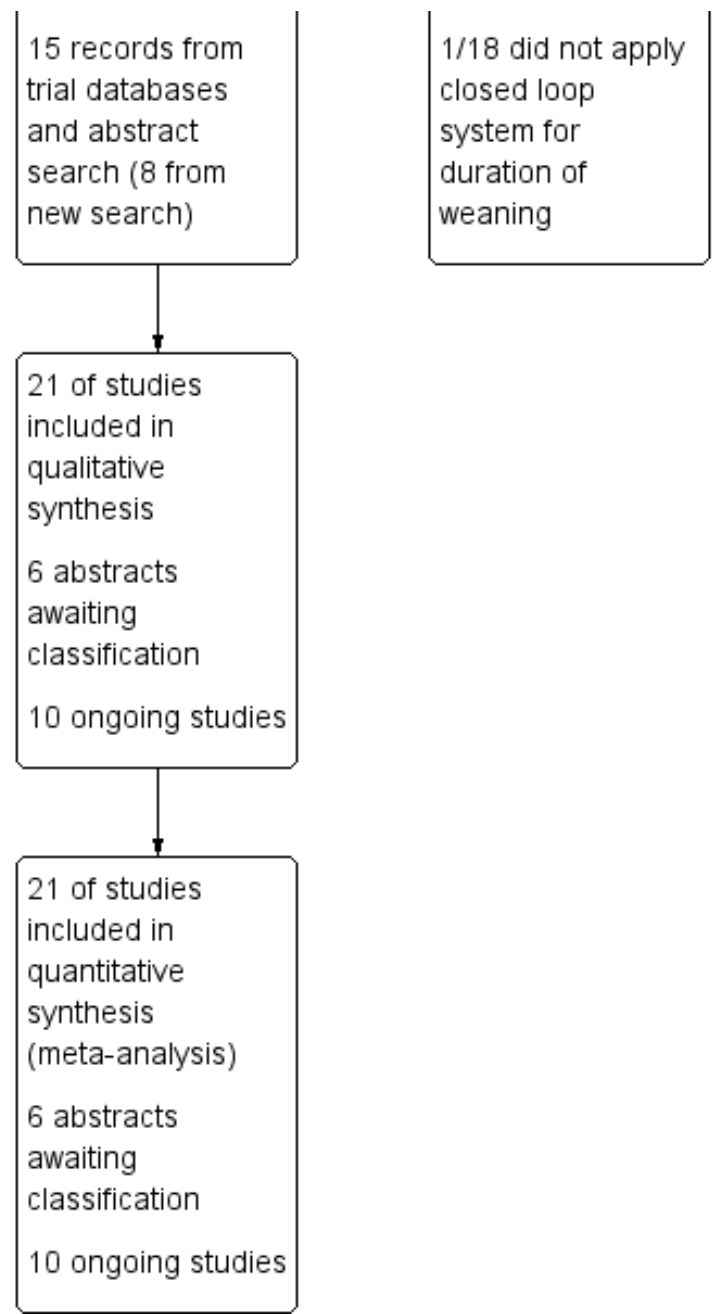

\section{Included studies}

In our original review we included 15 trials (Rose 2013). In this updated review we included an additional six studies (Agarwal 2013; Aghadavoudi 2012; Burns 2013; Liu 2013; Ramet 2002; Xirouchaki 2008). We included 21 trials with a total of 1676 participants in this updated review; 19 adult and two paediatric (see Characteristics of included studies). Sample sizes of individual studies ranged from 13 to 300 participants receiving mechanical ventilation in an ICU. Twelve trials were conducted in mixed or medical ICU populations ( $n=871,52 \%$ ) (Agarwal 2013; Burns 2013; Davis 1989; Jouvet 2013; Kirakli 2011; Lellouche 2006; Liu 2013; Ramet 2002; Rose 2008; Strickland 1993; Walkey 2011; Xirouchaki 2008) and nine trials were conducted in the surgical ICU population ( $\mathrm{n}=805,48 \%$ ) (Aghadavoudi 2012; Dongelmans 2009; Hendrix 2006; Petter 2003; Roth 2001; Schädler 2012; Stahl 2009; Sulzer 2001; Taniguchi 2009). We included eight trials of Smartcare/PS ${ }^{\text {TM }}$ ( $n=800,48 \%$ ) (Burns 2013; Jouvet 2013; Lellouche 2006; Liu 2013; Rose 2008; Schädler 2012; Stahl 2009; Walkey 2011); six trials of ASV ( $n=424,25 \%$ ) (Agarwal 2013; Aghadavoudi 2012; Dongelmans 2009; Kirakli 2011; Petter 2003; Sulzer 2001) ; three trials of Automode (Hendrix 2006; Ramet 2002; Roth 2001); one trial of MMV (Davis 1989); one trial of MRV (Taniguchi 2009); one trial of PAV+ (Xirouchaki 2008); and one trial describing a non-commercial automated closed loop system comprising modification of a Puritan Bennett 7200 ventilator to allow direct control of the ventilator settings by an external PC-compatible computer (Strickland 1993). The computer monitored patient and ventilator data through the serial digital outputs of a pulse oximeter and the ventilator. The computer sampled respiratory rate and oxygen saturation $\left(\mathrm{SpO}_{2}\right)$ every five minutes, and calculated a moving average of $V_{T}$ using the average of the last five one minute $\mathrm{V}_{\mathrm{T}}$ samples. The computer decreased the synchronized intermittent mandatory ventilation (SIMV) rate by two every hour until a rate of two was reached. The computer then decreased the pressure support (PS) by $2 \mathrm{cmH}_{2} \mathrm{O}$ every hour as long as the $\mathrm{V}_{\mathrm{T}}$ and respiratory rate limits were met.

\section{Excluded studies}

We excluded six studies; two studies of Smartcare/PS ${ }^{\text {TM }}$ (Jiang 2006; Ma 2010) that were determined not to be RCTs, one trial that evaluated a system that monitored real-time data but did not close the loop by making automated changes (Maloney 2007), one trial that did not apply the closed loop mode for the duration of weaning (Lellouche 2013), and two studies that evaluated a non-commercial computerized decision support system for management of patients with acute respiratory distress syndrome that offered therapeutic 
and diagnostic suggestions according to a protocol but did not close the loop by making automated changes to the ventilator (East 1999; McKinley 2001).

\section{Risk of bias in included studies}

Details regarding the performance of the studies against each domain are shown in the 'Risk of bias' tables for individual studies.
A summary of information is provided in the table 'Characteristics of included studies'. Additionally, a visual summary of judgements about each methodological quality item for each included trial is shown in Figure 2 and Figure 3. 
Figure 2. Risk of bias summary: review authors' judgements about each risk of bias item for each included study.

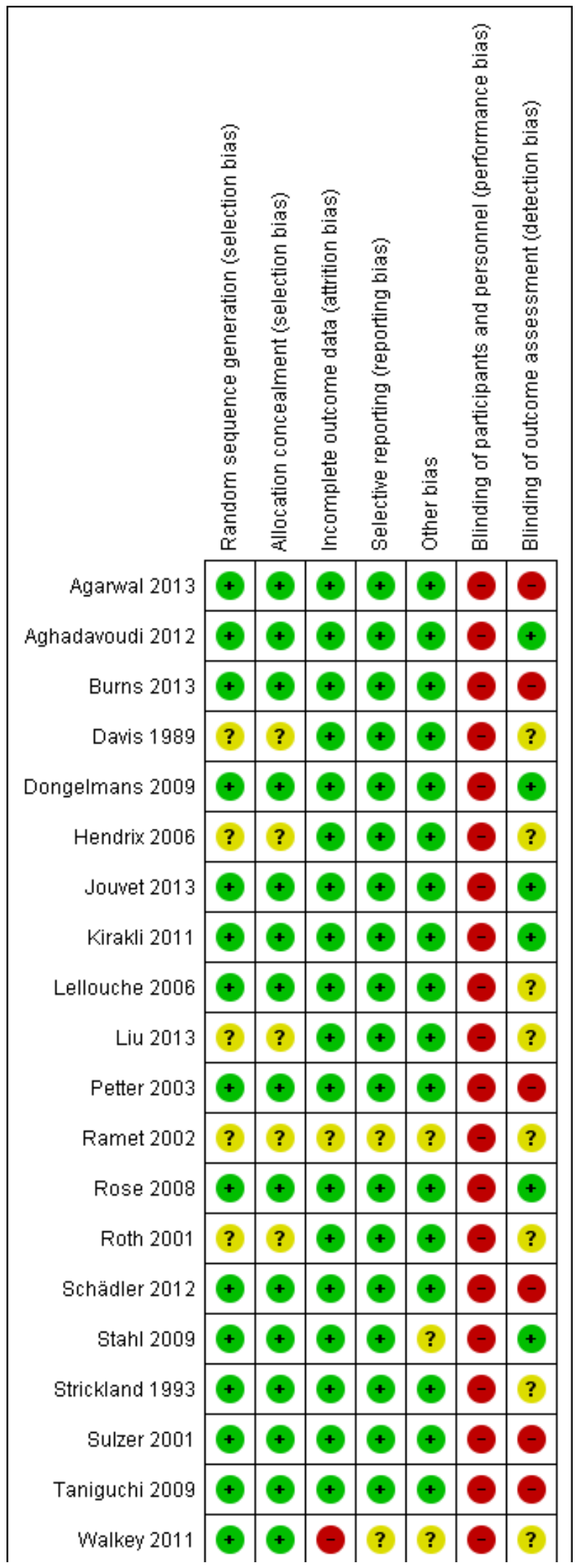

Automated versus non-automated weaning for reducing the duration of mechanical ventilation for critically ill adults and children 
Figure 2. (Continued)

\begin{tabular}{|l|l|l|l|l|l|l|l|} 
Walkey 2011 & + & + & - & $?$ & $?$ & - & $?$ \\
\hline
\end{tabular}

\begin{tabular}{ll|l|l|l|l|l|l|} 
Xirouchaki 2008 & $\odot$ & $\odot$ & $\odot$ & $\odot$ & $\odot$ & $\odot$ & - \\
\cline { 2 - 6 }
\end{tabular}

Figure 3. Risk of bias graph: review authors' judgements about each risk of bias item presented as percentages across all included studies.

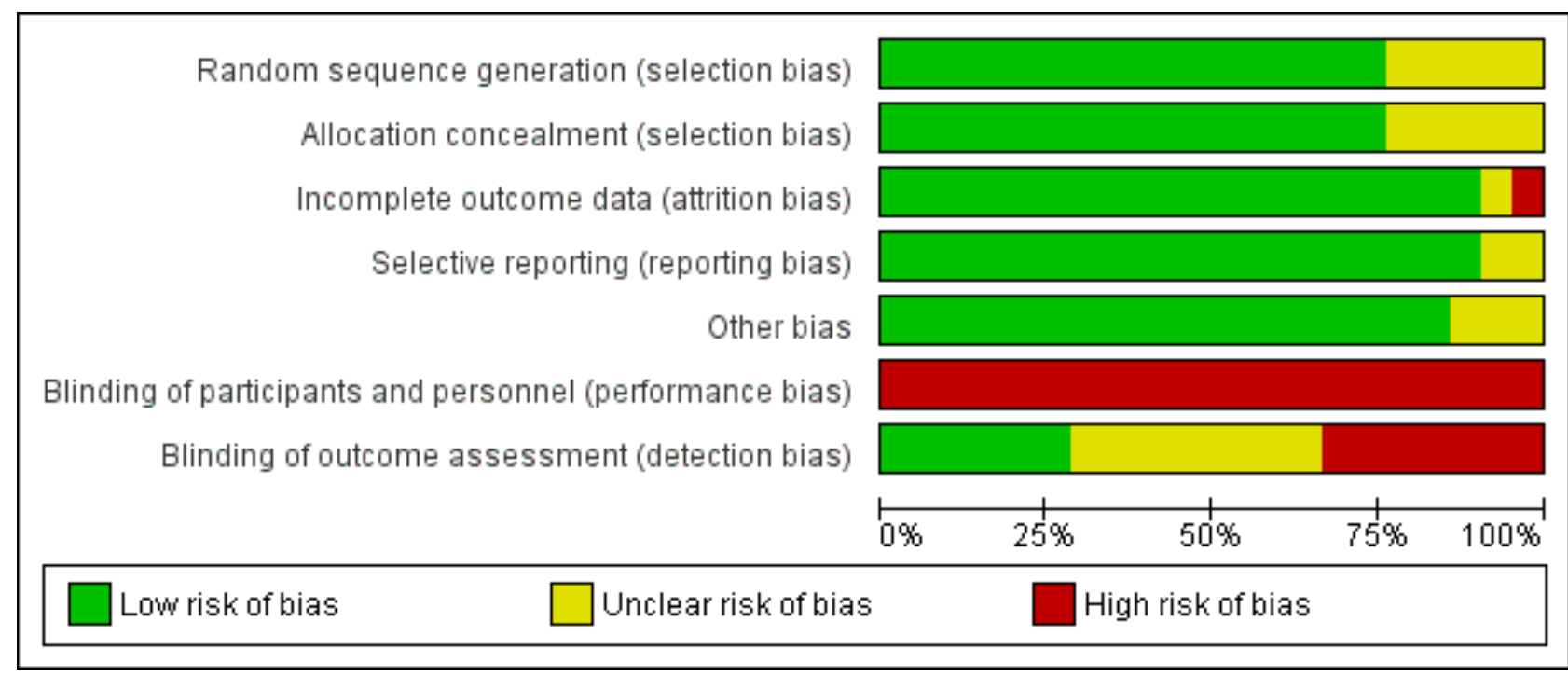

\section{Allocation}

We judged the risk of bias due to random sequence generation to be low for 16 trials and unclear for five trials. Of the 16 trials assessed to be at low risk of bias, 10 used computer generated randomization (Agarwal 2013; Aghadavoudi 2012; Burns 2013; Kirakli 2011; Lellouche 2006; Rose 2008; Schädler 2012; Stahl 2009; Walkey 2011; Xirouchaki 2008), one used a random number table (Strickland 1993), and five shuffled envelopes containing the allocation (Dongelmans 2009; Jouvet 2013; Petter 2003; Sulzer 2001; Taniguchi 2009). Of the five trials rated as unclear, four provided insufficient information to assess the adequacy of sequence generation (Davis 1989; Liu 2013; Roth 2001). In the remaining trial, due to limited availability of a ventilator with Automode function, only two patients could be randomized at a time. We were unable to determine if the two patients were randomly selected from all patients undergoing cardiac surgery on that day (Hendrix 2006).

We assessed the risk of bias due to allocation concealment methods to be low for 16 trials; three trials used central allocation (Burns 2013; Lellouche 2006; Schädler 2012) and 13 used sequentially numbered sealed opaque envelopes (Agarwal 2013; Aghadavoudi 2012; Dongelmans 2009; Jouvet 2013; Kirakli 2011; Petter 2003; Rose 2008; Stahl 2009; Strickland 1993; Sulzer 2001; Taniguchi 2009; Walkey 2011; Xirouchaki 2008). One trial (Hendrix 2006) was judged as unclear as it was not possible to assess if the allocation written on slips of paper was visible to the person selecting them. Four trials (Davis 1989; Liu 2013; Ramet 2002; Roth 2001) were judged as unclear as they did not present information regarding allocation concealment.

\section{Blinding}

Due to the nature of the intervention, blinding of clinicians involved in the delivery of mechanical ventilation and weaning would not have been feasible in all 21 trials. The extent to which this could have biased the results is unclear. However there is the potential that awareness of study allocation may have influenced the performance of clinicians managing ventilator weaning in study control arms. Additionally, awareness of study allocation potentially could influence the decision to extubate thus influencing the overall duration of weaning in either arm. Therefore, we have rated all 21 trials at high risk of bias due to lack of blinding of clinicians. For studies reporting primary and secondary outcomes such as duration of weaning, mechanical ventilation, ICU and hospital stay that are objective and not subject to interpretation by outcome assessors we considered the risk of detection bias as low if the outcome assessors were not involved in daily patient care (Aghadavoudi 2012; Dongelmans 2009; Jouvet 2013; Kirakli 2011; Rose 2008; Stahl 2009). Seven trials (Davis 1989; Hendrix 2006; Lellouche 2006; Liu 2013; Ramet 2002; Roth 2001; Strickland 1993) were rated as unclear as we were unable to determine if the outcome assessors were involved in daily patient care. Eight trials (Agarwal 2013; Burns 2013; Petter 2003; Schädler 2012; Sulzer 2001; Taniguchi 2009; Walkey 2011; Xirouchaki 2008) were judged at high risk of bias as some of the outcome assessors were also involved in patient care.

\section{Incomplete outcome data}

We judged 19 trials as being at low risk of attrition bias as they either had no missing data or performed analyses according to the intention-to-treat principal. We rated one trial (Ramet 2002) as

Automated versus non-automated weaning for reducing the duration of mechanical ventilation for critically ill adults and children 14

Copyright (c) 2018 The Cochrane Collaboration. Published by John Wiley \& Sons, Ltd. 
unclear risk as results were only available in abstract form. Limited results for one trial (Walkey 2011) that was stopped early due to slow recruitment were available via the trial registration database www.trials.gov and personal communication with the author, and thus we rated the trial as at high risk of bias.

\section{Selective reporting}

We did not find any evidence of reporting bias. Trial protocols or registrations were available for eight trials (Agarwal 2013; Burns 2013; Dongelmans 2009; Jouvet 2013; Kirakli 2011; Rose 2008; Schädler 2012; Xirouchaki 2008). Limited results were available for one trial (Walkey 2011) via the trial registration database www.trials.gov and personal communication with the author. One trial (Ramet 2002) was only available in abstract form. Although access to the trial protocols was not possible for the remaining 11 trials, reporting of the primary and secondary outcomes was consistent with those described in the methods section of each trial.

\section{Other potential sources of bias}

Eighteen trials appeared to be free of other sources of bias. Two trials were stopped early, one for futility (Stahl 2009) and one for failure to recruit participants (Walkey 2011). One trial (Ramet 2002) was only available in abstract form.

\section{Effects of interventions}

\section{See: Summary of findings for the main comparison}

All 21 trials presented data suitable for inclusion in the metaanalyses. We converted all reported durations to hours with the exception of ICU and hospital LOS, which are reported in days. We present our primary analysis, which comprised the durations of weaning, ventilation, ICU and hospital stay, using log-transformed data due to the skewed distribution of these outcomes. We were able to obtain means (SDs) on the log scale directly from trial investigators for six trials (Dongelmans 2009; Jouvet 2013; Kirakli 2011; Rose 2008; Schädler 2012; Xirouchaki 2008). For nine trials we calculated log-transformed means and SDs from unlogged data using the method described by Higgins 2011. For the remaining six trials (Agarwal 2013; Burns 2013; Liu 2013; Petter 2003; Stahl 2009; Sulzer 2001) we approximated the mean from the median using the method described in the data synthesis section above. We presented subgroup analyses according to ICU patient population, automated system used in the intervention arm, and weaning method used in the control arm. We also presented a sensitivity analysis of un-logged data for the continuous outcomes listed in the 'Methods' section above. A third sensitivity analysis of the primary outcome was presented that excluded data from two studies judged at high risk of bias (Ramet 2002; Walkey 2011).

\section{Duration of weaning}

\section{Total duration of weaning (randomization to successful extubation)}

Sixteen trials reported on the duration of weaning defined as from randomization to successful extubation. Using a random-effects model, due to statistically significant $(P<0.00001)$ and substantial $(12=87 \%)$ heterogeneity, pooled data from these 16 trials indicated a reduction in the duration of weaning when comparing automated closed loop systems to non-automated methods (mean log hours $-0.36,95 \% \mathrm{Cl}-0.59$ to $-0.14, \mathrm{P}=0.001$ ), which is equivalent to a $30 \%$ $(95 \% \mathrm{Cl} 13 \%$ to $45 \%)$ reduction in the geometric mean. Subgroup analyses according to ICU population demonstrated a different effect by population type ( $P$ value for subgroup differences was 0.04 ) with a reduction in weaning duration in studies including mixed or medical ICU patients: mean log hours $-0.55,95 \% \mathrm{Cl}-1.00$ to $-0.10, \mathrm{P}=0.02$, equivalent to a $42 \%(95 \% \mathrm{Cl} 10 \%$ to $63 \%)$ reduction in the geometric mean. No difference in weaning duration was found in studies including only surgical ICU patients: mean log hours $-0.07,95 \% \mathrm{Cl}-0.18$ to $0.04, \mathrm{P}=0.19$, equivalent to a $7 \%(95 \% \mathrm{Cl}$ $4 \%$ increase to $16 \%$ reduction) reduction in the geometric mean. Studies including mixed or medical ICU patients had significant $(\mathrm{P}<$ $0.00001)$ and substantial heterogeneity $(12=87 \%)$ whereas studies recruiting surgical ICU patients had minimal heterogeneity $\left(\mathrm{I}^{2}=\right.$ 29\%) (Analysis 1.1). A different effect was observed for automated system ( $P$ for subgroup differences $=0.03$ ) with a reduction in the duration of weaning using Smartcare/PS ${ }^{\mathrm{TM}}$ (mean log hours -0.33 , $95 \% \mathrm{Cl}-0.58$ to $-0.09, \mathrm{P}=0.008$, equivalent to a $28 \%(95 \% \mathrm{Cl} 7 \%$ to $49 \%$ ) reduction in the geometric mean). There was no difference in the duration of weaning in studies of ASV (mean log hours -0.03 , $95 \% \mathrm{Cl}-0.11$ to $0.05, \mathrm{P}=0.50$, equivalent to a $3 \%(95 \% \mathrm{Cl} 5 \%$ increase to $10 \%$ reduction) reduction in the geometric mean) or other systems (mean log hours $-0.54,95 \% \mathrm{Cl}-1.17$ to $0.08, \mathrm{P}=$ 0.09 , equivalent to a $42 \%(95 \% \mathrm{Cl} 8 \%$ increase to $69 \%$ reduction) reduction in the geometric mean) (Analysis 1.2) (Figure 4). There was no subgroup difference according to the weaning method used in the control arm with broadly overlapping subgroup Cls (Analysis 1.3). 
Figure 4. Forest plot of comparison: 1 Primary analysis: automated closed loop system versus non-automated system, outcome: 1.2 Total weaning duration by automated system (log hours).

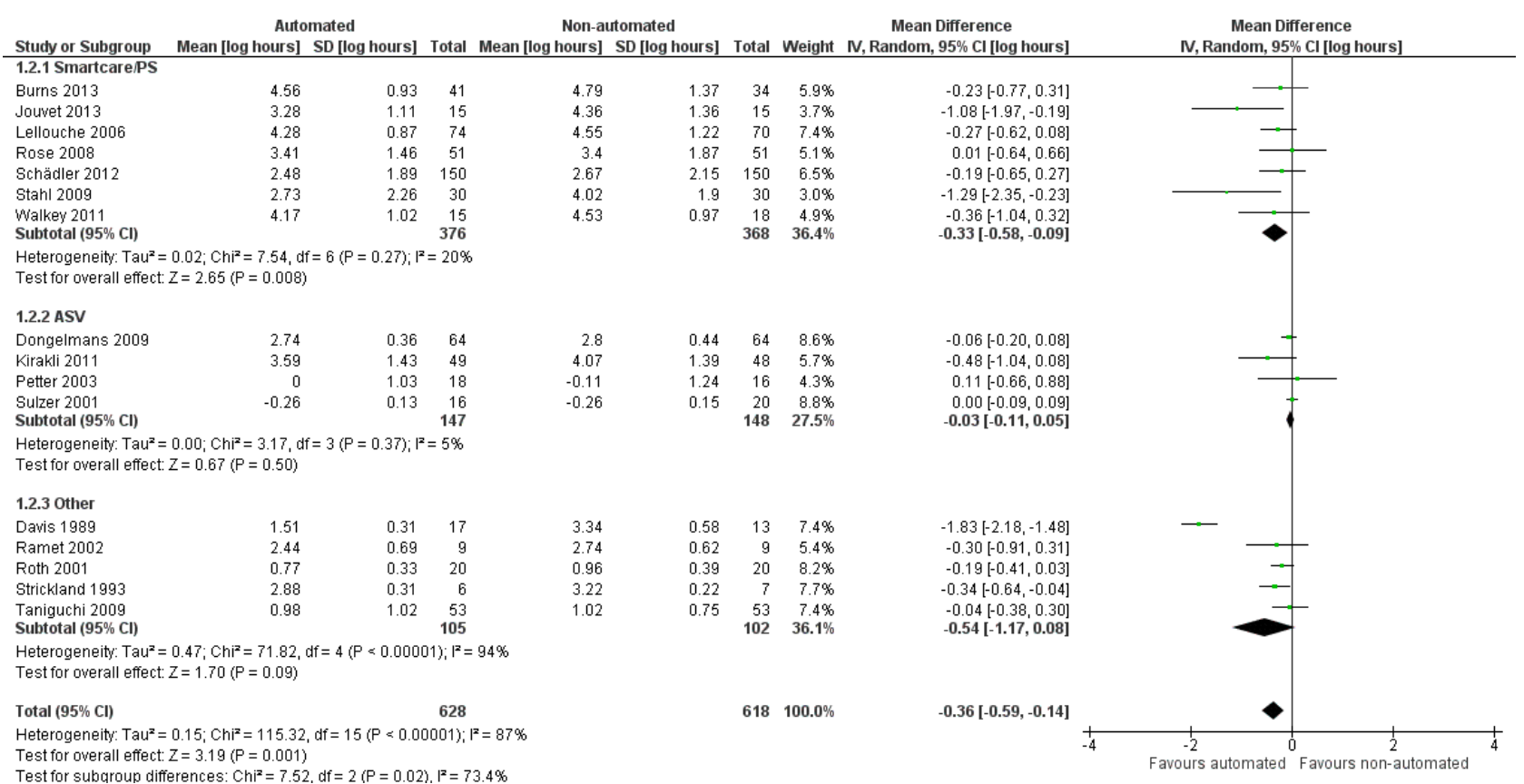

\section{Randomization to first extubation}

Eleven trials reported on the duration from study randomization to first extubation. Pooled data using a random-effects model demonstrated a reduction favouring use of an automated closed loop system (mean log hours $-0.20,95 \% \mathrm{Cl}-0.34$ to $-0.05, \mathrm{P}=0.04$, equivalent to an $18 \%(95 \% \mathrm{Cl} 5 \%$ to $29 \%)$ reduction in the geometric mean). Statistically significant $(P<0.0005)$ and substantial $(12=$ $68 \%$ ) heterogeneity was found for these 11 trials (Analysis 1.4).

\section{Duration of mechanical ventilation}

Fourteen trials reported on the total duration of ventilation. Pooled data using a random-effects model indicated a reduction in the total duration of ventilation favouring the use of an automated closed loop system (mean log hours $-0.11,95 \% \mathrm{Cl}-0.18$ to $-0.03, \mathrm{P}$ $=0.005$, equivalent to a $10 \%(95 \% \mathrm{Cl} 3 \%$ to $16 \%)$ reduction in the geometric mean) with no heterogeneity $(12=0 \%, P=0.87)$ (Analysis 1.5) (Figure 5). There were no subgroup differences according to ICU population, automated system, or the weaning method used in the control arm, with broadly overlapping subgroup Cls (Analysis 1.6; Analysis 1.7).

Figure 5. Forest plot of comparison: 1 Primary analysis: automated closed loop system versus non-automated system, outcome: 1.5 Ventilation duration by study population (log hours).

\begin{tabular}{|c|c|c|c|c|c|c|c|c|c|c|c|}
\hline Study or Subgroup & \multicolumn{2}{|c|}{ Automated } & Total I & \multicolumn{3}{|c|}{ Non-automated } & \multicolumn{2}{|c|}{$\begin{array}{c}\text { Mean Difference } \\
\text { Weight IV, Random, } 95 \% \mathrm{Cl}[\text { log hours] }\end{array}$} & \multicolumn{3}{|c|}{$\begin{array}{c}\text { Mean Difference } \\
\text { IV, Random, } 95 \% \text { CI [log hours] }\end{array}$} \\
\hline \multicolumn{12}{|c|}{ 1.5.1 Mixed and medical ICU population } \\
\hline Agarwal 2013 & 4.79 & 0.96 & 23 & 4.97 & 0.89 & 25 & $2.1 \%$ & $-0.18[-0.71,0.35]$ & & & \\
\hline Burns 2013 & 5.53 & 0.6 & 48 & 5.58 & 1.06 & 43 & $4.4 \%$ & $-0.05[-0.41,0.31]$ & & & \\
\hline Jouvet 2013 & 5.03 & 0.72 & 15 & 5.35 & 0.9 & 15 & $1.7 \%$ & $-0.32[-0.90,0.26]$ & & & \\
\hline Kirakli 2011 & 4.96 & 0.87 & 49 & 5.08 & 0.87 & 48 & $4.8 \%$ & $-0.12[-0.47,0.23]$ & - & - & \\
\hline Lellouche 2006 & 5.06 & 0.75 & 74 & 5.3 & 1.02 & 70 & $6.6 \%$ & $-0.24[-0.53,0.05]$ & & & \\
\hline Liu 2013 & 4.93 & 0.52 & 19 & 5.27 & 0.86 & 20 & $2.9 \%$ & $-0.34[-0.78,0.10]$ & & - & \\
\hline Ramet 2002 & 4.6 & 0.41 & 9 & 4.36 & 0.71 & 9 & $2.0 \%$ & $0.24[-0.30,0.78]$ & - & & \\
\hline Rose 2008 & 4.78 & 0.77 & 51 & 4.83 & 0.86 & 51 & $5.7 \%$ & $-0.05[-0.37,0.27]$ & & - & \\
\hline Xirouchaki 2008 & 5.31 & 0.82 & 108 & 5.45 & 0.82 & 100 & $11.5 \%$ & $-0.14[-0.36,0.08]$ & & & \\
\hline Subtotal $(95 \% \mathrm{Cl})$ & & & 396 & & & 381 & $41.7 \%$ & $-0.14[-0.25,-0.02]$ & $\Delta$ & & \\
\hline \multicolumn{12}{|c|}{$\begin{array}{l}\text { Heterogeneity: } \operatorname{Tau}^{2}=0.00 ; C \mathrm{Ch}^{2}=4.11, \mathrm{df}=8(\mathrm{P}=0.85) ; \mathrm{I}^{2}=0 \% \\
\text { Test for overall effect: } Z=2.29(P=0.02)\end{array}$} \\
\hline \multicolumn{12}{|c|}{ 1.5.2 Surgical ICU population } \\
\hline Aghadavoudi 2012 & 2.05 & 0.36 & 41 & 2.01 & 0.29 & 40 & $28.3 \%$ & $0.04[-0.10,0.18]$ & & & \\
\hline Hendrix 2006 & 2.02 & 0.3 & 10 & 2.27 & 0.19 & 10 & $11.8 \%$ & $-0.25[-0.47,-0.03]$ & 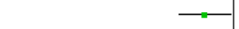 & & \\
\hline Petter 2003 & 0.99 & 0.51 & 16 & 1.16 & 0.29 & 18 & $7.1 \%$ & $-0.17[-0.45,0.11]$ & & & \\
\hline Schädler 2012 & 3.79 & 1.24 & 150 & 3.96 & 1.21 & 150 & $7.4 \%$ & $-0.17[-0.45,0.11]$ & & & \\
\hline Sulzer 2001 & 1.17 & 0.45 & 16 & 1.4 & 0.76 & 20 & $3.6 \%$ & $-0.23[-0.63,0.17]$ & & & \\
\hline Subtotal $(95 \% \mathrm{Cl})$ & & & 233 & & & 238 & $58.3 \%$ & $-0.12[-0.26,0.01]$ & $<$ & & \\
\hline \multicolumn{12}{|c|}{$\begin{array}{l}\text { Heterogeneity: } \mathrm{Tau}^{2}=0.01 ; \mathrm{Chi}^{2}=6.34, \mathrm{df}=4(\mathrm{P}=0.18) ; \mathrm{l}^{2}=37 \% \\
\text { Test for overall effect: } Z=1.74(\mathrm{P}=0.08)\end{array}$} \\
\hline Total $(95 \% \mathrm{Cl})$ & & & 629 & & & 619 & $100.0 \%$ & $-0.11[-0.18,-0.03]$ & • & & \\
\hline $\begin{array}{l}\text { Heterogeneity: Tau }= \\
\text { Test for overall effect: } \\
\text { Test for subqroup diff }\end{array}$ & $\begin{array}{l}0.00 ; \mathrm{Chi}^{2}=10.83 \\
\mathrm{Z}=2.81(\mathrm{P}=0.005) \\
\text { erences: } \mathrm{Chi}^{2}=0.03\end{array}$ & $\begin{array}{l}d f=13(P=0.62) \\
d f=1(P=0.87\end{array}$ & $\begin{array}{l}1^{2}=0 \% \\
1^{2}=0 \%\end{array}$ & & & & & & $\begin{array}{c}1 \\
-1 \\
\text { Favours }\end{array}$ & \begin{tabular}{|l|l} 
& \\
0 & 1 \\
Favours non-a
\end{tabular} & $\begin{array}{l} \\
1 \\
\text {-automated }\end{array}$ \\
\hline
\end{tabular}

Automated versus non-automated weaning for reducing the duration of mechanical ventilation for critically ill adults and children 


\section{Time from intubation to randomization}

Ten trials reported the time from intubation to randomization. Pooled data using a random-effects model, due to moderate heterogeneity $(12=46 \%)$, indicated no difference in this duration when comparing automated closed loop systems to nonautomated methods (mean log hours $-0.04,95 \% \mathrm{Cl}-0.14$ to $0.05, \mathrm{P}$ $=0.36$, equivalent to a $4 \%(95 \% \mathrm{Cl} 5 \%$ increase to $13 \%$ reduction) reduction in the geometric mean) (Analysis 1.8).

\section{Mortality}

Twelve trials reported mortality; six trials reported ICU mortality only, two trials reported 30-day mortality, one trial reported hospital mortality only, and four trials reported both ICU and hospital mortality. Due to relatively wide $\mathrm{Cls}$ the pooled data from 12 trials ( $R R 1.04,95 \% \mathrm{Cl} 0.83$ to $1.31, \mathrm{P}=0.72$ ) did not provide strong evidence that automated systems had an effect on mortality when compared to non-automated weaning. Minimal heterogeneity was noted $\left(I^{2}=3 \%\right)$. No strong evidence of effect was noted for ICU mortality (RR $1.23,95 \% \mathrm{Cl} 0.58$ to $2.60, \mathrm{P}=0.60$ ), 30-day mortality (RR $1.14,95 \% \mathrm{Cl} 0.75$ to $1.75, \mathrm{P}=0.53$ ) and hospital mortality (RR $0.95,95 \% \mathrm{Cl} 0.62$ to $1.45, \mathrm{P}=0.16$ ) (Analysis 1.9 ).

\section{Duration of hospital stay}

Hospital LOS was reported in seven trials. Pooled data using a random-effects model found no strong evidence of effect for automated closed loop systems when compared to non-automated methods (mean log days $-0.10,95 \% \mathrm{Cl}-0.21$ to $0.02, \mathrm{P}=0.10$, equivalent to a $10 \%(95 \% \mathrm{Cl} 2 \%$ increase to $19 \%$ reduction) reduction in the geometric mean) with no heterogeneity $(12=0 \%, P$ $=0.52$ ) (Analysis 1.10).

\section{Length of ICU stay}

The length of ICU stay was reported in 13 trials. Pooled data using a random-effects model, due to moderate heterogeneity $\left(I^{2}=49 \%, P\right.$ $=0.02$ ), demonstrated a reduction in ICU stay favouring automated closed loop systems (mean log days $-0.08,95 \% \mathrm{Cl}-0.16$ to -0.00 , $\mathrm{P}=0.05$, equivalent to a $8 \%(95 \% \mathrm{Cl} 0 \%$ to $15 \%)$ reduction in the geometric mean). Pooled analysis of studies conducted in the mixed and medical ICU population demonstrated a reduction in ICU stay (mean log days $-0.16,95 \% \mathrm{Cl}-0.29$ to $-0.04, \mathrm{P}=0.01$, equivalent to a $15 \%(95 \% \mathrm{Cl} 4 \%$ to $25 \%)$ reduction in the geometric mean) whereas those conducted in the surgical ICU population did not (mean log days $0.02,95 \% \mathrm{Cl}-0.02$ to $0.06, \mathrm{P}=0.29$, equivalent to a $2 \%(95 \% \mathrm{Cl} 2 \%$ reduction to $6 \%$ increase) increase in the geometric mean) (Analysis 1.11). Pooled analysis of trials conducted using the Smartcare/PS ${ }^{\mathrm{TM}}$ identified a reduction in ICU length of stay (mean $\log$ days $-0.26,95 \% \mathrm{Cl}-0.43$ to $-0.09, \mathrm{P}=0.003$, equivalent to a $23 \%$ (95\% $\mathrm{Cl} 9 \%$ to $35 \%)$ reduction in the geometric mean) whereas ASV trials did not (mean log days $0.02,95 \% \mathrm{Cl}-0.02$ to $0.06, \mathrm{P}=0.39$, equivalent to an $2 \%(95 \% \mathrm{Cl} 2 \%$ reduction to $6 \%$ increase) increase in the geometric mean) (Analysis 1.12).

\section{Adverse events associated with weaning}

We considered adverse events potentially related to the process of weaning to include reintubation, self-extubation, use of non-invasive ventilation after extubation, prolonged mechanical ventilation (defined as greater than 21 days of continuous ventilation) and tracheostomy. There was no strong evidence of effect on reintubation rates in the 13 trials reporting this outcome (RR $0.80,95 \% \mathrm{Cl} 0.61$ to $1.05, \mathrm{P}=0.1$ ). There was no strong evidence that automated systems had an effect on reintubation rates in trials comparing automated to usual weaning processes (RR $0.71,95 \% \mathrm{Cl}$ 0.27 to $1.88, \mathrm{P}=0.49$ ) or to protocolized weaning ( $\mathrm{RR} 0.81,95 \% \mathrm{Cl}$ 0.61 to $1.07, P=0.14$ ) (Analysis 1.13). Subgroup analyses according to ICU population or automated system were not reported due to the low number of events $(n=2)$ reported in a single trial. Similarly there was no strong evidence of effect on rates of self-extubation (RR 1.24, 95\% $\mathrm{Cl} 0.58$ to $2.67, \mathrm{P}=0.58,9$ trials) (Analysis 1.14) or noninvasive ventilation after extubation (RR $0.73,95 \% \mathrm{Cl} 0.53$ to $1.02, \mathrm{P}$ $=0.07,12$ trials) (Analysis 1.15). Prolonged mechanical ventilation (RR $0.51,95 \% \mathrm{Cl} 0.27$ to $0.95, \mathrm{P}=0.03,7$ trials) (Analysis 1.16) and rates of tracheostomy (RR $0.67,95 \% \mathrm{Cl} 0.50$ to $0.90, \mathrm{P}=0.008,9$ trials) were reduced in favour of automated systems (Analysis 1.17).

\section{Sensitivity analyses using un-logged data}

We conducted this sensitivity analysis to explore the effects of automated closed loop systems prior to log-transforming the data. We were able to obtain means (SDs) from either the published report or from communication with the author for 13 trials. For the remaining six trials (Agarwal 2013; Burns 2013; Liu 2013; Petter 2003; Stahl 2009; Sulzer 2001) the approximated means and SDs of study outcomes were calculated from the reported medians and IQRs using the methods described above.

Overall the pooled duration of weaning was not effected with the use of an automated system $(-0.75$ hours, $95 \% \mathrm{Cl}-1.85$ to $0.34, \mathrm{P}$ $=0.18)$, however statistically significant substantial heterogeneity was present $\left(\mathrm{I}^{2}=72 \%, \mathrm{P}<0.00001\right)$. Subanalyses according to ICU population demonstrated a reduction in the duration of weaning in the trials of the mixed and medical ICU population (mean hours $-18.75,95 \% \mathrm{Cl}-32.30$ to $-5.20, \mathrm{P}=0.007$ ) but not in trials of surgical ICU populations (mean hours $-0.15,95 \% \mathrm{Cl}-0.70$ to $0.39, \mathrm{P}=0.58$ ) (Analysis 2.1). Weaning duration was reduced in trials examining Smartcare/PS ${ }^{\text {TM }}$ (mean hours $-38.46,95 \% \mathrm{Cl}-58.11$ to $-18.81, \mathrm{P}=$ 0.0001 ) but not in trials of ASV (mean hours $-0.00,95 \% \mathrm{Cl}-0.07$ to $0.06, P=0.98$ ) or other automated systems (mean hours -3.89 , $95 \% \mathrm{Cl}-7.71$ to $0.07, \mathrm{P}=0.05$ ) (Analysis 2.2). In those studies that compared the automated system to non-protocolized usual care, there was a reduction in the duration of weaning (mean hours $-30.49,95 \% \mathrm{Cl}-60.63$ to $-0.35, \mathrm{P}=0.05, \mathrm{I}^{2}=52 \%$ ) whereas there was no difference when compared to a protocolized approach (Analysis 2.3). There was no difference in the time to first extubation (mean hours $-0.61,95 \% \mathrm{Cl}-1.61$ to $0.39, \mathrm{P}=0.23$ ) (Analysis 2.4), total duration of ventilation (mean hours $-0.55,95 \% \mathrm{Cl}-1.38$ to 0.28 ) (Analysis 2.5), time from intubation to randomization (mean hours $-0.16,95 \% \mathrm{Cl}-0.69$ to 0.36 ) (Analysis 2.6 ), hospital stay (mean days $-2.20,95 \% \mathrm{Cl}-4.91$ to 0.52 ) (Analysis 2.7 ) and ICU stay (mean days $0.01,95 \% \mathrm{Cl}-0.09$ to 0.11 ) (Analysis 2.8).

\section{Sensitivity analyses excluding studies with high risk of bias}

We conducted a sensitivity analysis to explore the effect of studies assessed as having high risk of bias for our primary outcome. Two studies (Ramet 2002; Walkey 2011) met this criterion. Pooled data from the 14 remaining trials continued to demonstrate a reduction in the duration of weaning using automated closed loop systems as opposed to non-automated methods (mean log hours $-0.37,95 \% \mathrm{Cl}$ -0.61 to $-0.13, \mathrm{P}=0.003$, equivalent to a $31 \%(95 \% \mathrm{Cl} 12 \%$ to $46 \%)$ reduction in the geometric mean) (Analysis 3.1). 


\section{Funnel plots}

A funnel plot of the primary outcome provided little indication of asymmetry suggestive of publication bias (Figure 6).

Figure 6. Funnel plot of comparison: 1 Primary analysis: automated closed loop system versus non-automated system, outcome: 1.2 Total weaning duration by automated system (log hours).

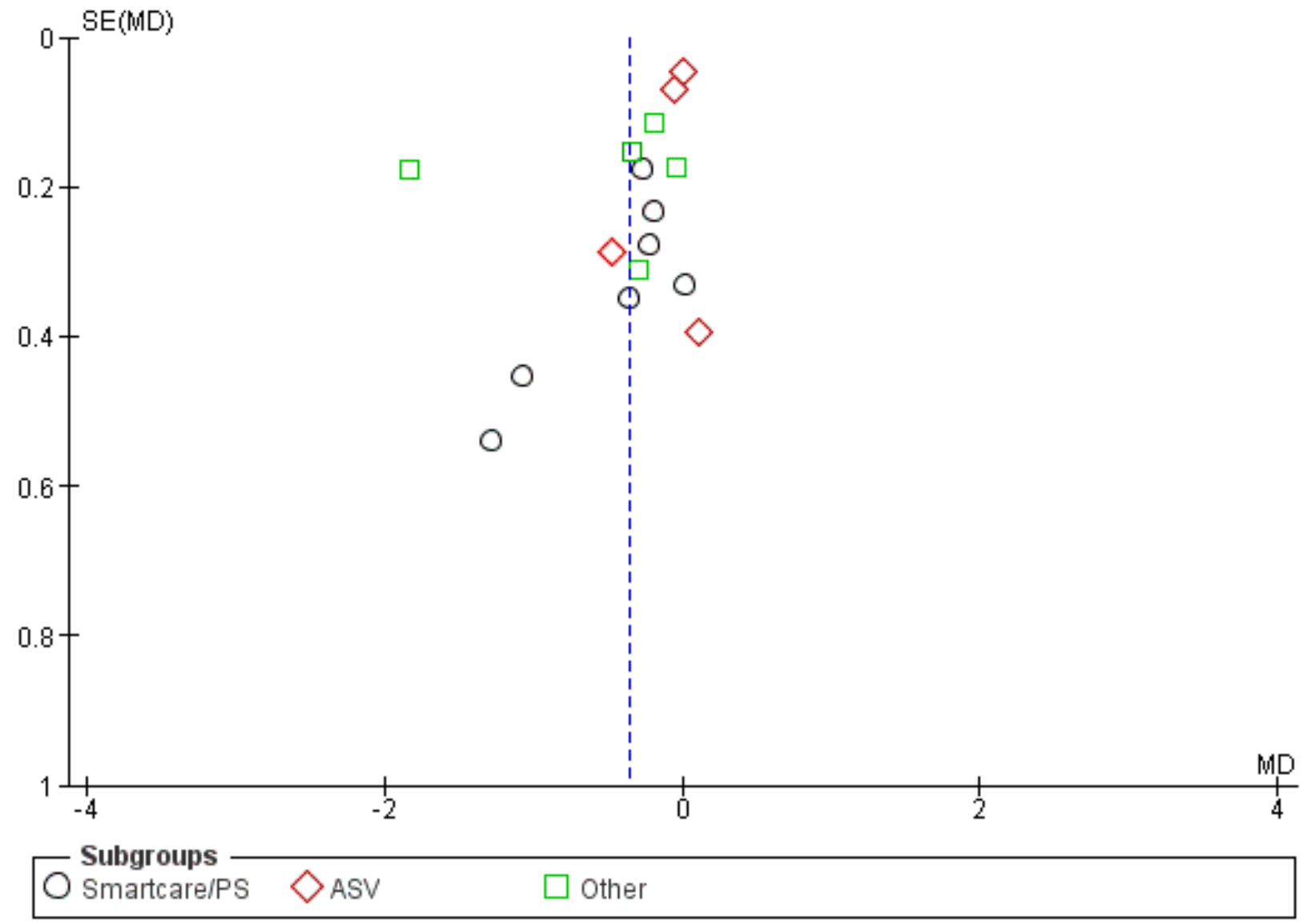

\section{DISCUSSION}

\section{Summary of main results}

Based on the pooled data from the eligible trials, automated closed loop systems reduced the duration of weaning, defined as from study randomization to successful extubation, by $30 \%$ in the geometric mean compared to weaning using either a protocol or non-protocolized usual care. Reduced duration of weaning was found in studies of mixed and medical ICU populations ( $42 \%$ in the geometric mean duration) and studies evaluating Smartcare/ $\mathrm{PS}^{\mathrm{TM}}$ (28\% in the geometric mean duration). Automated closed loop systems did not reduce the duration of weaning in surgical ICU populations or systems other than Smartcare/PS ${ }^{\mathrm{TM}}$. The method of weaning in the trial comparator arms (protocol or non-protocolized usual care) did not influence the effect of automated closed loop systems on the duration of weaning. Due to substantial heterogeneity $(12=87 \%)$ among studies reporting the primary outcome, the duration of weaning, caution must be used when interpreting these results. In our sensitivity analysis using unlogged data there was no difference in the duration of weaning between groups. However, a statistically significant and clinically meaningful difference in the duration of weaning was found in trials evaluating mixed and medical ICU populations only and in trials evaluating SmartCare/PS ${ }^{\mathrm{TM}}$. The reason for the disparate findings using logged and un-logged data for weaning duration when all studies were combined is due to the markedly lower SDs (that is less variation) in un-logged weaning duration in surgical ICU populations compared with mixed and medical ICU populations. Consequently the trials of surgical ICU populations, in which there is less evidence of a difference in weaning duration, receive much larger weights for the logged data than for the un-logged data. This means the overall conclusion for the difference in intervention and control groups for the logged data is much closer to zero than for the un-logged data. It is worth noting that the main conclusions for the logged and un-logged data in the surgical ICU population studies are similar and are the same for the logged and un-logged data in the mixed and medical ICU populations.

Automated closed loop systems also reduced the time from study randomization to first extubation ( $18 \%$ in the geometric mean), the duration of ventilation ( $10 \%$ in the geometric mean), and the length of ICU stay (8\% in the geometric mean). There was no strong evidence of an effect on mortality rates, hospital length

Automated versus non-automated weaning for reducing the duration of mechanical ventilation for critically ill adults and children 18 (Review)

Copyright (c) 2018 The Cochrane Collaboration. Published by John Wiley \& Sons, Ltd. 
of stay, reintubation, self extubation or the use of non-invasive ventilation (NIV) post-extubation. Automated closed loop systems reduced the rates of tracheostomy and the need for prolonged ventilation. A reduction in the duration of mechanical ventilation was found for all ICU populations as well as for studies examining Smartcare/PS ${ }^{\mathrm{TM}}$ and studies where the comparator arm comprised a weaning protocol. Reduced ICU stay was demonstrated only in mixed and medical ICU populations and trials of Smartcare/PS ${ }^{\mathrm{TM}}$. Trials reporting on the duration of ventilation and ICU stay had moderate heterogeneity and thus these findings may be considered more robust than the weaning duration outcome.

\section{Overall completeness and applicability of evidence}

Commercial availability of automated closed loop ventilation systems has led to a growing interest and enhanced feasibility in conducting trials such that 13 of the 21 eligible trials were published in the last five years. The most frequently evaluated systems were Smartcare/PS ${ }^{\top M}$ and ASV. A notable difference in these two systems is that the ASV automates the switching from controlled to spontaneous ventilation and thereby automates initiation of weaning whereas Smartcare/PS ${ }^{\mathrm{TM}}$ requires clinician recognition of a patient's ability to breathe spontaneously followed by activation of Smartcare/PS ${ }^{\mathrm{TM}}$. This difference is important when considering the potential impact on weaning and ventilation duration. Automated closed loop systems such as ASV, and its more recent extension Intellivent-ASV, which do not rely on clinician assessment to recognize weaning readiness and initiate weaning may have more influence on the overall duration of ventilation than those that rely on activation by a clinician. We did not detect an effect on the duration of ventilation in studies comparing ASV to usual methods, however this may be due to the inclusion of surgical ICU patients only who generally do not experience protracted weaning and ventilation.

We did not identify completed eligible trials of NAVA and only identified one trial of PAV+, two other commonly available commercial systems, though trials were identified in trial registration websites (Alander/Kontiokari 2010; Fernandez 2013; Liu/Qui 2010). While trials have been conducted in both surgical and mixed and medical ICU populations there is a need for more trials of ASV in mixed and medical ICU populations. Given the lack of efficacy of automated systems in the surgical population, trials of Smartcare/PS ${ }^{T M}$ are likely to be not required in this group. We were unable to conduct subgroup analyses according to the weaning classifications arising out of the 2005 consensus conference on weaning (Boles 2007) as these have not yet been widely adopted as trial inclusion criteria or a priori planned subgroup analyses. These classifications group patients in terms of difficulty in weaning and may enable better identification, particularly in mixed and medical ICU populations, of the patient population for which automated closed loop systems are more likely to be effective. Only two trials in a paediatric population were identified. The trial of SmartCare/PS ${ }^{\mathrm{TM}}$ was conducted in children older than two years, due to age and weight limits imposed by this system. More than $50 \%$ of the patients admitted to paediatric intensive care units (PICUs) are less than two years old (Payen 2012). The lag in development of automated systems capable of providing age appropriate ventilation and weaning to all children probably explains the lack of trials. Given the potential for reduced duration of weaning and ventilation, and the small sample size of the one identified trial, commercial industry and researchers should focus their efforts on further technological development of automated systems adapted to children and the accompanying research. Sedation and analgesic practices influence the duration of weaning and ventilation (Luetz 2012; Wanzuita 2012) and therefore should be described in detail in any trial with these as study outcomes. Seven trials did not describe sedation or pain assessment and implementation strategies, the amount of sedation and analgesia received, or level of sedation and analgesia achieved making the influence of this potentially confounding clinical practice difficult to assess.

\section{Quality of the evidence}

Overall the quality of the evidence was high with the majority of trials rated as low risk of bias across all six domains with the exception of performance bias. As discussed above, the nature of the intervention means blinding of clinicians involved in the delivery of mechanical ventilation and weaning is not feasible. In five trials the description provided for random sequence generation and allocation concealment was unclear and we were unable to obtain additional clarification from the study authors.

\section{Potential biases in the review process}

To minimize the introduction of bias in the review process, we strictly adhered to procedures outlined by The Cochrane Collaboration (Higgins 2011) including independent screening for trial inclusion, data extraction, and assessment of risk of bias by two review authors. We believe we have identified all relevant studies through the use of a comprehensive search strategy, developed in consultation with a senior librarian, in combination with a review of trial databases, conference abstracts, reference lists of relevant literature, and contact with experts and commercial ventilator companies.

\section{Agreements and disagreements with other studies or reviews}

This is the first published systematic review and meta-analysis of trials investigating automated closed loop ventilation systems.

\section{AUTHORS' CONCLUSIONS}

\section{Implications for practice}

Based on data from 21 trials totaling 1676 participants, utilization of an automated closed loop system may result in a reduction in the duration of weaning, ventilation and ICU stay. Potential reductions in weaning duration and ICU length of stay are more likely to occur in mixed and medical ICU populations as opposed to surgical ICU populations. All ICU populations may experience a reduction in the duration of ventilation using an automated closed loop system. The use of the automated closed loop system Smartcare/ $\mathrm{PS}^{\mathrm{TM}}$ resulted in reductions in weaning, ventilation duration and ICU length of stay whereas ASV and other automated systems including Automode, MMV, MRV, $\mathrm{PAV}^{+}$and a non-commercially available system did not influence these outcomes. Due to the lack of, or limited, evidence on automated systems other than Smartcare/PS ${ }^{\mathrm{TM}}$ and ASV no conclusions can be drawn regarding their influence on these outcomes. Automated closed loop systems compared favourably to a comparator arm comprising protocolization of the weaning process and existing usual care weaning practices that did not include a protocol for these outcomes. In the Cochrane review comparing protocolized weaning to usual care (Blackwood 2010a) 
use of a written professional-led protocol compared favourably to usual care when evaluating the duration of ventilation, whereas use of a computer-driven protocol via an automated closed loop system did not. The two trials of computer-driven protocols (Rose 2008; Stahl 2009) are included in our review. However, most trials comprised small to moderate sample sizes, the number of trials in subgroups were small and we found considerable heterogeneity for the primary outcome of weaning duration. Before an automated closed loop system is implemented in to clinical practice careful assessment is required of the local usual weaning practices including ICU organizational characteristics such as staffing ratios, hierarchical structure and ICU team functioning that may contribute to ICU performance and patient outcomes (Nguyen 2010).

\section{Implications for research}

Due to the high level of heterogeneity in trials reporting the duration of weaning we believe there is a need for an adequately powered, high quality, multi-centre randomized controlled trial in an adult patient population that excludes patients with the classification of 'simple to wean' based on our finding related to the lack of effect in surgical populations. This trial should include an economic analysis to determine the cost associated with the use of an automated system compared to usual care. Due to the lack of data on the performance of ASV in the difficult and prolonged weaning patient population, as well as minimal data on other closed loop systems such as $\mathrm{PAV}^{+}$and NAVA, we are cautious to recommend which automated system should be selected for investigation. The design of the comparator would need careful consideration. If a professional-led protocol is chosen it should be designed so that there are no time criteria that limit progression of weaning and may bias findings towards the automated closed loop system. If non-protocolized usual care is selected as the comparator arm for a multi-centre study, it should be documented in sufficient detail, both before and during the trial, so that an assessment of the influence of institutional culture and characteristics can be made. In addition, there is a pressing need for more development of and research on automated closed loop systems in the paediatric population.

\section{ACKNOWLEDGEMENTS}

We would like to acknowledge Elizabeth Uleryk, Director Hospital Library \& Archives, The Hospital for Sick Children, Toronto, Ontario, Canada for her assistance with generating our search strategies.

We would like to thank Nicole Petrucci (content editor), Nathan Pace (statistical editor), Francis Leclerc, Paolo Pelosi and Michael Davies (peer reviewers) for their help and editorial advice during the preparation of the protocol and the final systematic review. We also would like to thank Nicholas Hart (peer reviewer) for commenting on the protocol for the systematic review. 


\section{R E F E R E N C E S}

\section{References to studies included in this review}

Agarwal 2013 \{published data only\}

Agarwal A, Srinivasan A, Aggarwal AN, Gupta D. Adaptive support ventilation for complete ventilatory support in acute respiratory distress syndrome: A pilot, randomized controlled trial. Respirology 2013;18:1108-15.

\section{Aghadavoudi 2012 \{published and unpublished data\}}

Aghadavoudi O, Kamran M, Masoudifar M. Comparison of two modes of ventilation after fast-track cardiac surgery: Adaptive support ventilation versus synchronized intermittent mandatory ventilation. Pakistan Journal of Medical Sciences 2012;28:303-8

\section{Burns 2013 \{published data only\}}

Burns KE, Meade MO, Lessard MR, Hand L, Zhou Q, Keenan SP, et al. Wean earlier and automatically with new technology (the WEAN study). A multicenter, pilot randomized controlled trial. American Journal of Respiratory and Critical Care Medicine 2013;187:1203-11.

\section{Davis 1989 \{published data only\}}

* Davis S, Potgieter PD, Linton DM. Mandatory minute volume weaning in patients with pulmonary pathology. Anaesthesia and Intensive Care 1989;17(2):170-4. [PUBMED: 2719237]

\section{Dongelmans 2009 \{published data only\}}

* Dongelsmans DA, Veelo DP, Paulus F, de Mol, BAJM, Korevaar JC, et al. Weaning automation with adaptive support ventilation: a randomized controlled trial in cardiothoracic surgery patients. Anesthesia and Analgesia 2009;108(2):565-71. [PUBMED: 19151288]

\section{Hendrix 2006 \{published data only\}}

* Hendrix $\mathrm{H}$, Kaiser ME, Yusen RD, Merk J. A randomized trial of automated versus conventional protocol-driven weaning from mechanical ventilation following coronary artery bypass surgery. European Journal of Cardio-Thoracic Surgery 2006;29(6):957-63. [PUBMED: 16520042]

\section{Jouvet 2013 \{published and unpublished data\}}

* Jouvet PA, Payen V, Gauvin F, Emeriaud G, Lacroix J. Weaning children from mechanical ventilation with a computer driven protocol: a pilot trial. Intensive Care Medicine 2013;39:919-25. [PUBMED: 22591622]

Kirakli 2011 \{published and unpublished data\}

* Kirakli C, Ozdemir I, Ucar ZZ, Cimen P, Kepil S, Ozkan SA. Adaptive support ventilation for faster weaning in COPD: a randomised controlled trial. European Respiratory Journal 2011;38(4):774-80. [PUBMED: 21406514]

\section{Lellouche 2006 \{published data only\}}

* Lellouche F, Mancebo J, Jolliet P, Roeseler J, Schortgen F, Dojat $\mathrm{M}$, et al. A multicenter randomized trial of computerdriven protocolized weaning from mechanical ventilation. American Journal of Respiratory and Critical Care Medicine 2006;174(8):894-900. [PUBMED: 16840741]
Liu 2013 \{published data only (unpublished sought but not used)\} Liu L, Xu X, Yang Y, Huang Y, Liu S, Qiu Hai-bo. Computer-driven automated weaning reduces weaning duration in difficultto-wean patients. Chinese Medical Journal 2013;126:1814-8. [PUBMED: 23673092]

\section{Petter 2003 \{published data only\}}

* Petter AH, Chiolero RL, Cassina T, Chassot P-G, Müller XM, Revelly J-P. Automatic "respirator/weaning" with adaptive support ventilation: the effect on duration of endotracheal intubation and patient management. Anesthesia and Analgesia 2003;97(6):1743-50. [PUBMED: 14633553]

Ramet 2002 \{published data only (unpublished sought but not used)\}

* Ramet J, Van Herreweghe I, Idrissi S, Huyghens L.

Computerized switch of ventilation mode during weaning. Intensive Care Medicine 2002;28:S123.

Rose 2008 \{published and unpublished data\}

* Rose L, Presneill JJ, Johnston L, Cade JF. A randomised, controlled trial of conventional versus automated weaning from mechanical ventilation using SmartCare ${ }^{\mathrm{TM}} / \mathrm{PS}$. Intensive Care Medicine 2008;34(10):1788-95. [PUBMED: 18575843]

Roth 2001 \{published data only\}

* Roth H, Luecke T, Lansche G, Bender HJ, Quintel M. Effects of patient-triggered automatic switching between mandatory and supported ventilation in the postoperative weaning period. Intensive Care Medicine 2001;27(1):47-51. [PUBMED: 11280672]

Schädler 2012 \{published and unpublished data\}

* Schädler D, Engel C, Elke G, Pulletz S, Haake N, Frerichs I, et al. Automatic control of pressure support for ventilator weaning in surgical intensive care patients. American Journal of Respiratory and Critical Care Medicine 2012;185:637-44. [PUBMED: 22268137]

Stahl 2009 \{published and unpublished data\}

* Stahl C, Dahmen G, Ziegler A, Muhl E. Protocolized automated versus non-protocolized physician-directed weaning from mechanical ventilation: a controlled clinical trial. Intensivemed Praxis 2009;46:441.

Strickland 1993 \{published data only\}

* Strickland JH, Hasson JH. A computer-controlled ventilator weaning system. A clinical trial. Chest 1993;103(4):1220-6. [PUBMED: 8131469]

\section{Sulzer 2001 \{published data only\}}

* Sulzer CF, Chiolero R, Chassot P-G, Mueller XM, Revelly J-P. Adaptive support ventilation for fast tracheal extubation after cardiac surgery. Anesthesiology 2001;95(6):1339-45. [PUBMED: 11748389]

Taniguchi 2009 \{published data only\}

* Taniguchi C, Eid RC, Saghabi C, Souza R, Silva E, Knobel, E, et al. Automatic versus manual pressure support reduction in the weaning of post-operative patients: a randomised controlled

Automated versus non-automated weaning for reducing the duration of mechanical ventilation for critically ill adults and children 
trial. Critical Care 2009;13(1):R6. [Trial registration number ISRCTN37456640; PUBMED: 19171056]

Walkey 2011 \{published and unpublished data\}

Walkey A, Reardon C. Clinical trial of a computer-driven weaning system for patients requiring mechanical ventilation. www.ClinicalTrials.gov 2011.

\section{Xirouchaki 2008 \{published and unpublished data\}}

* Xirouchaki N, Kondili E, Vaporidi K, Xirouchakis G, Klimathianaki M, Gavriilidis G, et al. Proportional assist ventilation with load-adjustable gain factors in critically ill patients: comparison with pressure support. Intensive Care Medicine 2008;34:2026-34. [PUBMED: 18607562]

\section{References to studies excluded from this review}

East 1999 \{published data only\}

* East TD, Heerman LK, Bradshaw RL, Lugo A, Sailors M, Ershler L, et al. Efficacy of a computerized decision support for mechanical ventilation: results of a prospective multicentre randomized controlled trial. Proceedings of the American Medical Informatics Association 1999:251-5. [PUBMED: 10566359]

\section{Jiang 2006 \{published data only\}}

Jiang H, Yu S-Y, Wang L-W. Comparison of Smartcare and spontaneous breathing trials for weaning old patients with chronic obstructive pulmonary diseases. Chinese Journal of Tuberculosis and Respiratory Disease 2006;29(8):545-8. [PUBMED: 17074269]

\section{Lellouche 2013 \{published and unpublished data\}}

Lellouche F, Bouchard PA, Simard S, L'Her E, Wysocki M. Evaluation of fully automated ventilation: a randomized controlled study in post-cardiac surgery patients. Intensive Care Medicine 2013;39:463-71.

\section{Ma 2010 \{published data only\}}

* Ma Y, Yang X, Cao X, Ma X. A comparison of computer-driven weaning and physician-directed weaning from mechanical ventilation: a randomized prospective study. Chinese Journal of Tuberculosis and Respiratory Disease 2010;33(3):174-8. [PUBMED: 20450634]

\section{Maloney 2007 \{published and unpublished data\}}

Maloney C, Steiner D, Rocha B. Randomized controlled trial of ventilator weaning: computerized protocol vs typical care. Critical Care Medicine 2007;35(12):A223.

\section{McKinley 2001 \{published data only\}}

* McKinley BA, Moore FA, Sailors RM, Cocanour CS, Marquez A, Wright RK, et al. Computerized decision support for mechanical ventilation of trauma induced ARDS: results form a randomized controlled trial. Journal of Trauma 2001;50(3):415-25. [PUBMED: 11265020]

\section{References to studies awaiting assessment}

Alander/Kontiokari 2010 \{published data only\}

Domingo 2010 \{published data only (unpublished sought but not used)\}

Fayed 2013 \{published data only\}

Fernandez 2013 \{published data only\}

Lim 2012 \{published data only\}

Vogelsang 2003 \{published data only (unpublished sought but not used)\}

\section{References to ongoing studies}

Arnal/Suppini 2013 \{published data only\}

S4: Trial Of Fully Closed-Loop Ventilation In ICU. Ongoing study November 2012

\section{Beale 2004 \{published and unpublished data\}}

Comparison of an automated weaning programme and a standard clinical weaning protocol for weaning critically ill patients: a randomized controlled trial. Ongoing study Dec 1 2004.

\section{Bosma 2012 \{published data only\}}

Comparison of weaning on pressure support vs. Proportional Assist Ventilation: a pilot study. Ongoing study March 2009.

Botha 2013 \{published data only\}

PAV+ VENTILATION TRIAL- A randomised controlled trial comparing Proportional Assist Ventilation $(\mathrm{PAV}+)$ ventilation and pressure support ventilation in patients eligible for spontaneous ventilation. Ongoing study Nov 2012.

Hadfield/Hart 2013 \{published data only\}

A randomised feasibility study examining Neurally-adjusted Ventilatory Assist (NAVA) in patients at high risk of prolonged ventilatory failure during recovery from critical illness. Ongoing study May 2013.

\section{Kacmarek 2013 \{published data only\}}

A comparative, multicenter, randomized, controlled study of neurally adjusted ventilatory assist (NAVA) vs. conventional lung protective ventilation in patients with acute respiratory failure. Ongoing study January 2013.

Kirakli 2012 \{published data only\}

Closed loop ventilation strategy in Intensive Care Unit (ICU) patients. Ongoing study April 2012. 
Liu/Qui 2010 \{unpublished data only\}

Effect of NAVA on duration of weaning in difficult to wean patients. Ongoing study December 2010.

\section{Navalesi 2012 \{published data only\}}

Effects of two different ventilatory modes i.e., neurally adjusted ventilatory assist and pressure support ventilation on duration of mechanical ventilation and intensive care unit length of stay in patients with acute respiratory failure. A multicenter randomized clinical trial. Ongoing study September 2012.

\section{Zhu 2011 \{published data only\}}

Prospective randomized controlled trial comparing adaptivesupport ventilation with routine weaning protocol after valve surgery. Ongoing study December 2011.

\section{Additional references}

\section{Arnal 2012}

Arnal J-M, Wysocki M, Novotni D, Demory D, Lopez R, Donati S, et al. Safety and efficacy of a fully closed loop control ventilation (Intellivent-ASV ${ }^{\circledR}$ ) in sedated ICU patients with acute respiratory failure: a prospective randomized crossover study. Intensive Care Medicine 2012;38:781-7. [MEDLINE: 22460854]

\section{Blackwood 2010a}

Blackwood B, Alderdice F, Burns KE, Cardwell CR, Lavery GG, O'Halloran P. Protocolized versus non-protocolized weaning for reducing the duration of mechanical ventilation in critically ill adult patients. Cochrane Database of Systematic Reviews 2010 Issue 5. [DOI: 10.1002/14651858.CD006904.pub2]

\section{Blackwood 2010b}

Blackwood B, Gregg L, McAuley DF, Rose L. United Kingdom (UK) survey of doctors views on mechanical ventilation and weaning role responsibilities. London: Intensive Care Society, 2010.

\section{Bland 1996}

Bland JM, Altman DG. The use of transformation when comparing two means. BMJ 1996;312:1153.

\section{Boles 2007}

Boles JM, Bion J, Connors A, Herridge M, Marsh B, Melot C, et al. Weaning from mechanical ventilation. European Respiratory Journal 2007;29:1033-56. [MEDLINE: 17470624]

\section{Branson 2004}

Branson R. Understanding and implementing advances in ventilator capabilities. Current Opinion in Critical Care 2004;10:23-32. [MEDLINE: 15166846]

\section{Burns 2009a}

Burns KEA, Lellouche F, Loisel F, Slutsky AS, Meret A, Smith O, et al. Weaning critically ill adults from invasive mechanical ventilation: a national survey. Canadian Journal of Anaesthesia 2009;56:567-76. [MEDLINE: 19582533]

\section{Burns 2010}

Burns KEA, Lellouche F, Nisenbaum R, Lessard M, Friedrich JO. SmartCare ${ }^{\mathrm{TM}}$ versus non-automated weaning strategies for weaning time in invasively ventilated critically ill adults. Cochrane Database of Systematic Reviews 2010, Issue 8. [DOI: 10.1002/14651858.CD008638]

\section{Burns 2014}

Burns KEA, Lellouche F, Lessard M, Friedrich JO. Automated weaning and spontaneous breathing trial systems versus non-automated weaning strategies for discontinuation time in invasively ventilated postoperative adults. Cochrane Database of Systematic Reviews 2014, Issue 2. [DOI: 10.1002/14651858.CD008639]

\section{Carson 2006}

Carson SS. Outcomes of prolonged mechanical ventilation. Current Opinion in Critical Care 2006;12:405-11. [MEDLINE: 16943717]

\section{Chatburn 2011}

Chatburn RL, Mireles-Cabodevila E. Closed-loop control of mechanical ventilation: description and classification of targeting schemes. Respiratory Care 2011;56:85-102. [MEDLINE: 21235841]

\section{Coplin 2000}

Coplin WM, Pierson DJ, Cooley KD, Newell DW, Rubenfeld GD. Implications of extubation delay in brain-injured patients meeting standard weaning criteria. American Journal of Respiratory and Critical Care Medicine 2000;161:1530-6. [MEDLINE: 10806150]

\section{Cuthbertson 2004}

Cuthbertson BH, Hull A, Strachan M, Scott J. Post-traumatic stress disorder after critical illness requiring general intensive care. Intensive Care Medicine 2004;30:450-5. [MEDLINE: 12961065]

\section{DeMets 1987}

DeMets DL. Methods for combining randomized clinical trials. Statistics in Medicine 1987;6:341-50. [MEDLINE: 3616287]

\section{Egger 1997}

Egger M, Davey Smith G, Schneider M, Minder C. Bias in meta-analysis detected by a simple, graphical test. $B M J$ 1997;315:629-34. [MEDLINE: 9310563]

\section{Ely 1996}

Ely EW, Baker A.M, Dunagan DP, Burke HL, Smith AC, Kelly PT, et al. Effect on the duration of mechanical ventilation of identifying patients capable of breathing spontaneously. New England Journal of Medicine 1996;335:1864-9. [MEDLINE: 8948561]

\section{Ely 2001a}

Ely EW, Gautam S, Margolin R, Francis J, May L, Speroff T, et al. The impact of delirium in the intensive care unit on hospital length of stay. Intensive Care Medicine 2001;27:1892-900. [MEDLINE: 11797025] 


\section{Esteban 2008}

Esteban A, Ferguson ND, Meade MO, Frutos-Vivar F, Apezteguia C, Brochard L, et al. Evolution of mechanical ventilation in response to clinical research. American Journal of Respiratory and Critical Care Medicine 2008;177:170-7. [MEDLINE: 11790214]

\section{Farias 2004}

Farias JA, Frutos F, Esteban A, Flores JC, Retta A, Baltodano A, et al. What is the daily practice of mechanical ventilation in pediatric intensive care units? A multicenter study. Intensive Care Medicine 2004;30:918-25.

\section{Fink 2006}

Fink MP, Suter PM. The future of our specialty: critical care medicine a decade from now. Critical Care Medicine 2006;34:1811-6. [MEDLINE: 16625123]

\section{Girard 2010}

Girard TD, Jackson JC, Pandharipande PP, Pun BT, Thompson JL, Shintani AK, et al. Delirium as a predictor of longterm cognitive impairment in survivors of critical illness. Critical Care Medicine 2010;38:1513-20. [MEDLINE: 20473145]

\section{Guyatt 2008}

Guyatt GH, Oxman AD, Kunz R, Falck-Ytter Y, Vist GE, Liberati $A$, et al. Rating quality of evidence and strength of recommendations: going from evidence to recommendations. BMJ 2008;336:1049-51. [MEDLINE: 18467413]

\section{Higgins 2011}

Higgins JPT, Green S, editors. Cochrane Handbook for Systematic Reviews of Interventions 5.1.0 [updated March 2011]. The Cochrane Collaboration, 2011. Available from www.cochrane-handbook.org.

\section{Hopkins 2005}

Hopkins RO, Weaver LK, Collingridge D, Parkinson RB, Chan KJ, Orme JF. Two-year cognitive, emotional, and qualityof-life outcomes in acute respiratory distress syndrome. American Journal of Respiratory and Critical Care Medicine 2005;171:340-7. [PUBMED: 15542793]

\section{Hozo 2005}

Hozo SP, Djulbegovic B, Hozo, I. Estimating the mean and variance from the median, range, and the size of a sample. $B M C$ Medical Research Methodology 2005;5:13. [MEDLINE: 15840177]

\section{Jackson 2011}

Jackson JC, Mitchell N, Hopkins RO. Cognitive functioning, mental health, and quality of life in ICU survivors: an overview. Anesthesiology Clinics 2011;29:751-64. [MEDLINE: 22078921]

\section{Jones 2001}

Jones C, Griffiths RD, Humphris G, Skirrow PM. Memory, delusions, and the development of acute posttraumatic stress disorder-related symptoms after intensive care. Critical Care Medicine 2001;29:573-80. [MEDLINE: 11373423]

\section{Jouvet, 2007}

Jouvet P, Farges C, Hatzakis G, Monir A, Lesage F, Dupic L, et al. Weaning children from mechanical ventilation with a computerdriven system (closed-loop protocol): a pilot study. Pediatric Critical Care Medicine 2007;8:425-32. [MEDLINE: 17693913]

\section{Jubran 2010a}

Jubran A, Lawm G, Duffner LA, Collins EG, Lanuza DM, Hoffman LA, et al. Post-traumatic stress disorder after weaning from prolonged mechanical ventilation. Intensive Care Medicine 2010;36:2030-7. [MEDLINE: 20661726]

\section{Jubran 2010b}

Jubran A, Lawm G, Kelly J, Duffner LA, Gungor G, Collins EG, et al. Depressive disorders during weaning from prolonged mechanical ventilation. Intensive Care Medicine 2010;36:828-35. [MEDLINE: 20232042]

\section{Kollef 1997}

Kollef MH, Shapiro SD, Silver P, St John RE, Prentice D, Sauer S, et al. A randomized, controlled trial of protocol-directed versus physician-directed weaning from mechanical ventilation. Critical Care Medicine 1997;25:567-74. [MEDLINE: 9142019]

\section{Kuipers 2011}

Kuipers MT, van der Poll T, Schultz MJ, Wieland CW. Benchto-bedside review: Damage-associated molecular patterns in the onset of ventilator-induced lung injury. Critical Care 2011;15:235. [MEDLINE: 22216838]

\section{Leclerc 2010}

Leclerc F, Noizet O, Botte A, Binoche A, Chaari W, Sadik A, Riou Y. Weaning from invasive mechanical ventilation in pediatric patients (excluding premature neonates). Archives of Pediatrics 2010;17:399-406.

\section{Lellouche 2009a}

Lellouche F, Brochard L. Advanced closed loops during mechanical ventilation (PAV, NAVA, ASV, SmartCare). Best Practice \& Research. Clinical Anaesthesiology 2009;23:81-93. [MEDLINE: 16840741]

\section{Luetz 2012}

Luetz A, Goldmann A, Weber-Carstens S, Spies C. Weaning from mechanical ventilation and sedation. Current Opinion in Anaesthesiology 2012;25:164-9. [MEDLINE: 22246460]

\section{MacIntyre 2001}

MacIntyre NR. Evidence-based guidelines for weaning and discontinuing ventilatory support. Chest 2001;120 Suppl:375-95. [MEDLINE: 11742959]

\section{Morris 2002}

Morris, AH. Decision support and safety of clinical environments. Quality \& Safety in Health Care 2002;11:69-75. [MEDLINE: 12078374]

\section{Murtagh 2007}

Murtagh D, Baum N. Protocols put more pennies in your practice pockets or protocols lead to practice improvement. http://www.neilbaum.com/articles/mkt_protocols.html 2007. 


\section{Needham 2006}

Needham DM, Bronskill SE, Rothwell DM, Sibbald WJ, Pronovoast PJ, Laupacis A, et al. Hospital volume and mortality for mechanical ventilation of medical surgical patients: a population-based analysis using administrative data. Critical Care Medicine 2006;34:2349-54. [MEDLINE: 16878036]

\section{Newth 2009}

Newth CJ, Venkataraman S, Willson DF, Meert KL, Harrison R, Dean JM, et al. Eunice Shriver Kennedy National Institute of Child Health and Human Development Collaborative Pediatric Critical Care Research Network. Weaning and extubation readiness in pediatric patients. Pediatric Critical Care Medicine. 2009;10:1-11. [MEDLINE: 19057432]

\section{Nguyen 2010}

Nguyen Y, Wunsch H, Angus D. Critical care: the impact of organization and management on outcomes. Current Opinion in Critical Care 2010;16:487-92. [MEDLINE: 20689418]

\section{Otis 1950}

Otis AB, Fehn WO, Rahn H. Mechanics of breathing in man. Journal of Applied Physiology 1950;251:877-83. [MEDLINE: 15411167]

\section{Payen 2012}

Payen V, Jouvet P, Lacroix J, Ducruet T, Gauvin F. Risk factors associated with increased length of mechanical ventilation in children. Pediatric Critical Care Medicine 2012;13:152-7.

\section{RevMan 5.2 [Computer program]}

The Nordic Cochrane Centre, The Cochrane Collaboration. Review Manager (RevMan). Version 5.2. Copenhagen: The Nordic Cochrane Centre, The Cochrane Collaboration, 2012.

\section{Rose 2009}

Rose L, Presneill JJ, Johnston L, Nelson S, Cade JF. Ventilation and weaning practices in Australia and New Zealand. Anaesthesia and Intensive Care 2009;37:99-107. [MEDLINE: 19157354]

\section{Sahn 1973}

Sahn SA, Lakshminarayan S. Bedside criteria for discontinuation of mechanical ventilation. Chest 1973;63:1002-5. [MEDLINE: 4514488]

\section{Santschi 2007}

Santschi M, Gauvin F, Hatzakis G, Lacroix J, Jouvet P. Acceptable respiratory physiological limits for children during the weaning phase of mechanical ventilation. Intensive Care Medicine 2007;33:319-25. [MEDLINE: 17063358]

\section{Schmidt 2010}

Schmidt M, Demoule A, Cracco C, Gharbi A, Fiamma M-N, Straus $C$, et al. Neurally adjusted ventilatory assist increases respiratory variability and complexity in acute respiratory failure. Anaesthesiology 2010;112:670-81. [MEDLINE: 20179505]

\section{Wanzuita 2012}

Wanzuita R, Poli-de-Figueiredo LF, Pfuetzenreiter F, Cavalcanti AB, Westphal GA. Replacement of fentanyl infusion by enteral methadone decreases the weaning time from mechanical ventilation: a randomized controlled trial. Critical Care 2012;16:R49. [MEDLINE: 22420584]

\section{Wunsch 2010}

Wunsch H, Linde-Zwirble WT, Angus DC, Hartman ME, Milbrandt EB, Kahn JM. The epidemiology of mechanical ventilation use in the United States. Critical Care Medicine 2010;38:1947-53. [MEDLINE: 20639743]

\section{Zilberberg 2012}

Zilberberg MD, de Wit M, Shorr AF. Accuracy of previous estimates for adult prolonged acute mechanical ventilation volume in 2020: update using 2000-2008 data. Critical Care Medicine 2012;40:18-20. [MEDLINE: 21926594]

\section{Zolnierek 2010}

Zolnierek CD, Steckel CM. Negotiating safety when staffing falls short. Critical Care Nursing Clinics of North America 2010;22:261-9. [MEDLINE: 20541075]

\section{References to other published versions of this review Rose 2013}

Rose L, Schultz MJ, Cardwell CR, Jouvet P, McAuley DF, Blackwood B. Automated versus non-automated weaning for reducing the duration of mechanical ventilation for critically ill adults and children. Cochrane Database of Systematic Reviews 2013, Issue 6. [DOI: 10.1002/14651858.CD009235.pub2]

* Indicates the major publication for the study

CHARACTERISTICS OF STUDIES

Characteristics of included studies [ordered by study ID]

Agarwal 2013

\begin{tabular}{ll}
\hline Methods & Randomized controlled trial in a single respiratory ICU \\
\hline Participants & Adults with acute respiratory distress syndrome \\
\hline Interventions & $\begin{array}{l}\text { Intervention: ASV. Patients were stabilized on volume control assist ventilation for } 1 \text { hour to determine } \\
\text { the adequate minute ventilation. Peak pressure alarm was set at } 45 \mathrm{~cm}_{2} \mathrm{O} \text { to avoid Pplat } \geq 35 \mathrm{~cm} \mathrm{H}_{2} \mathrm{O} .\end{array}$
\end{tabular}

Automated versus non-automated weaning for reducing the duration of mechanical ventilation for critically ill adults and children 
Agarwal 2013 (Continued)

Subsequent manipulation of \%MV was guided by interpretation of the following parameters: Pinsp, spontaneous respiratory frequency while on ASV (fspont) and target respiratory frequency (ftarget) calculated by the ASV algorithm. If the fspont was greater than ftarget by 10 breaths and/or associated was hypoxaemia $(\mathrm{PaO} 2<55 \mathrm{~mm} \mathrm{Hg}$ or $\mathrm{SpO} 2<88 \%$ ) or hypercapnic acidosis $(\mathrm{pH}<7.25)$, then the \%MV was escalated by $20 \%$. If the fspont was similar to ftarget without any hypercapnoea or hypoxaemia, then the $\% \mathrm{MV}$ was de-escalated by $10 \%$. The pressurization slope (percentage of the inspiratory time taken to reach the peak pressure) was maintained at $25 \%$ for all subjects.

Weaning comprised sequential decrease in \%MV every $2 \mathrm{~h}$ (or earlier). Spontaneous breathing trial was considered once $\% \mathrm{MV}$ was $\leq 70 \%$ and Pinsp was $\leq 8 \mathrm{cmH} 2 \mathrm{O}$. Patients were extubated if able to tolerate the spontaneous breathing trial for $60 \mathrm{~min}$.

Control: assist control mode ventilation using low tidal volume strategy of $6 \mathrm{ml} / \mathrm{kg}$ to maintain plateau pressures $<30 \mathrm{~cm} \mathrm{H} \mathrm{H}_{2} \mathrm{O}$ and $\mathrm{pH}>7.3$ with option to reduce tidal volume to $4 \mathrm{ml} / \mathrm{kg}$ and increase respiratory rate to $35 / \mathrm{min}$ to achieve the above said goals. PSV weaning commenced once PEEP and $\mathrm{FiO}_{2}$ requirements decreased to $8 \mathrm{~cm} \mathrm{H}_{2} \mathrm{O}$ and 0.4 respectively. The PS used was the Pplat recorded during VCV (PSmax). PS was decreased by $2 \mathrm{cmH}_{2} \mathrm{O}$ every $6 \mathrm{~h}$ (or earlier) until PS of $7 \mathrm{cmH}_{2} \mathrm{O}$. A 1 hour SBT viaT-piece off ventilator was then performed.

FIO2/PEEP was set according to ARDSnet protocol for both study arms to maintain $\mathrm{SpO}_{2}$ of $88-92 \%$ at minimum possible $\mathrm{FiO}_{2}$.

\begin{tabular}{|c|c|}
\hline \multirow[t]{6}{*}{ Outcomes } & Duration of mechanical ventilation \\
\hline & Duration of ICU stay \\
\hline & Duration of hospital stay \\
\hline & Mortality \\
\hline & Ease of use of ventilator mode \\
\hline & Frequency of blood gas analysis \\
\hline
\end{tabular}

Notes NCT01165528

\section{Risk of bias}

\begin{tabular}{|c|c|c|}
\hline Bias & Authors' judgement & Support for judgement \\
\hline $\begin{array}{l}\text { Random sequence genera- } \\
\text { tion (selection bias) }\end{array}$ & Low risk & Randomization sequence was computer generated \\
\hline $\begin{array}{l}\text { Allocation concealment } \\
\text { (selection bias) }\end{array}$ & Low risk & Assignments were placed in sealed opaque envelopes \\
\hline $\begin{array}{l}\text { Incomplete outcome data } \\
\text { (attrition bias) } \\
\text { All outcomes }\end{array}$ & Low risk & No attrition, no missing outcome data \\
\hline $\begin{array}{l}\text { Selective reporting (re- } \\
\text { porting bias) }\end{array}$ & Low risk & All pre-specified outcomes are reported \\
\hline Other bias & Low risk & No other sources of bias detected \\
\hline $\begin{array}{l}\text { Blinding of participants } \\
\text { and personnel (perfor- } \\
\text { mance bias) } \\
\text { All outcomes }\end{array}$ & High risk & Assumed as high risk due to the nature of the intervention \\
\hline
\end{tabular}

Automated versus non-automated weaning for reducing the duration of mechanical ventilation for critically ill adults and children 
Agarwal 2013 (Continued)

Blinding of outcome as- High risk Outcome assessors were also involved in treatment of patients sessment (detection bias)

All outcomes

Aghadavoudi 2012

\begin{tabular}{|c|c|}
\hline Methods & Single centre randomized controlled trial \\
\hline Participants & 81 surgical ICU population (adults) \\
\hline \multirow[t]{5}{*}{ Interventions } & $\begin{array}{l}\text { Intervention: ASV - initial ventilator parameters: } 100 \% \text { of the theoretical value based on predicted body } \\
\text { weight, } \mathrm{FIO}_{2} 60 \% \text {, PEEP } 3-5 \mathrm{cmH}_{2} \mathrm{O} \text {, maximum airway pressure } 35 \mathrm{~cm} \mathrm{H}_{2} \mathrm{O} \text {, flow sensitivity } 3 \mathrm{~L} / \mathrm{s} \text {. Ven- }\end{array}$ \\
\hline & $\begin{array}{l}\text { tilation was titrated according to } \mathrm{ABGs} 30 \text { minutes after connection to the ventilator or } 30 \text { minutes af- } \\
\text { ter any modification of the ventilator settings. If } \mathrm{PacO} 2 \mathrm{was}<35 \mathrm{mmHg} \text { or }>45 \mathrm{mmHg} \text {, minute ventila- } \\
\text { tion was decreased or increased, respectively, by } 10 \% \text {. } \mathrm{FIO}_{2} \text { was adjusted to maintain } \mathrm{SaO}_{2} \text { of }>95 \% \text {. Af- }\end{array}$ \\
\hline & $\begin{array}{l}\text { ter commencement of spontaneous breathing, ASV setting was reduced by } 50 \% \text { of minute ventilation. } \\
\text { When spontaneous breathing achieved an acceptable }(\mathrm{VT}>5 \mathrm{ml} / \mathrm{kg}) \text {, ventilator mode was changed to } \\
\text { CPAP and apnoea set at } 20 \mathrm{~s} \text {. After } 30 \text { minutes, if extubation criteria were met, tracheal extubation was } \\
\text { performed. }\end{array}$ \\
\hline & $\begin{array}{l}\text { Control. SIMV with a set tidal volume VT of } 10 \mathrm{ml} / \mathrm{kg} \text {, Flo } 260 \% \text {, RR } 10 \text { breath } / \mathrm{min} \text {, PS } 10 \mathrm{~cm} \mathrm{H} 2 \mathrm{O} \text {, and } \\
\text { PEEP } 3-5 \mathrm{~cm} \mathrm{H} \mathrm{H}_{2} \mathrm{O} \text {. After commencement of spontaneous breathing with an acceptable VT, RR was re- }\end{array}$ \\
\hline & $\begin{array}{l}\text { duced by two breaths/minutes every } 30 \text { minutes until it reached two breaths/min. Then, ventilation } \\
\text { mode was converted to CPAP and patients were extubated based on the criteria as the ASV group. }\end{array}$ \\
\hline
\end{tabular}

Duration of intubation
Duration of ICU stay
Total dose of sedation and analgesia
Haemodynamic and ventilatory characteristics (systolic, diastolic, and mean BP, HR, VT, RR, P peak, (A-
a) $\mathrm{O}_{2}$ difference, lung compliance, and $\mathrm{PaO}_{2} / \mathrm{FiO}_{2}, \mathrm{RSBI}, \mathrm{ABG}$ changes from baseline to 6 hours in the
$\mathrm{ICU}$

Notes

\section{Risk of bias}

Bias Authors' judgement Support for judgement

Random sequence genera- Low risk Computer-based random allocation on arrival in ICU

tion (selection bias)

\begin{tabular}{|c|c|c|}
\hline $\begin{array}{l}\text { Allocation concealment } \\
\text { (selection bias) }\end{array}$ & Low risk & $\begin{array}{l}\text { Assignments were placed in sealed opaque envelopes. (author communica- } \\
\text { tion) }\end{array}$ \\
\hline
\end{tabular}

\begin{tabular}{lll}
\hline $\begin{array}{l}\text { Incomplete outcome data } \\
\text { (attrition bias) } \\
\text { All outcomes }\end{array}$ & Low risk & No attrition, no missing outcome data \\
\hline $\begin{array}{l}\text { Selective reporting (re- } \\
\text { porting bias) }\end{array}$ & Low risk & All pre-specified outcomes are reported \\
\hline Other bias & Low risk & No other sources of bias detected \\
\hline
\end{tabular}


Aghadavoudi 2012 (Continued)
Blinding of participants
High risk
Assumed as high risk due to the nature of the intervention and personnel (performance bias)

All outcomes

\section{Blinding of outcome as- Low risk} sessment (detection bias)

All outcomes

Data collectors were extra nurses (one nurse in each shift) of the ICU who were trained for data collection in this study and were supervised by an anaesthesiologist. They were not involved in treatment of patients/care delivery (author communication)

Burns 2013

\begin{tabular}{ll}
\hline Methods & Multi-centre pilot randomized controlled trial \\
\hline Participants & 92 mixed ICU population (adults) \\
\hline Interventions & Intervention: Smartcare/PS \\
& Control: written protocol for weaning and sedation \\
\hline Outcomes & Protocol feasibility, acceptability and compliance \\
& Duration of weaning \\
& Duration of mechanical ventilation \\
& Length of ICU stay \\
& Length of hospital stay \\
& Mortality \\
\hline
\end{tabular}

Notes

\section{Risk of bias}

\begin{tabular}{|c|c|c|}
\hline Bias & Authors' judgement & Support for judgement \\
\hline $\begin{array}{l}\text { Random sequence genera- } \\
\text { tion (selection bias) }\end{array}$ & Low risk & Central randomization was concealed with use of an electronic mail system \\
\hline $\begin{array}{l}\text { Allocation concealment } \\
\text { (selection bias) }\end{array}$ & Low risk & $\begin{array}{l}\text { Central randomization was concealed with use of an electronic mail system } \\
\text { (Draeger) }\end{array}$ \\
\hline $\begin{array}{l}\text { Incomplete outcome data } \\
\text { (attrition bias) } \\
\text { All outcomes }\end{array}$ & Low risk & No attrition, no missing outcome data \\
\hline $\begin{array}{l}\text { Selective reporting (re- } \\
\text { porting bias) }\end{array}$ & Low risk & All pre-specified outcomes are reported \\
\hline Other bias & Low risk & No other sources of bias detected \\
\hline $\begin{array}{l}\text { Blinding of participants } \\
\text { and personnel (perfor- } \\
\text { mance bias) } \\
\text { All outcomes }\end{array}$ & High risk & Assumed as high risk due to the nature of the intervention \\
\hline
\end{tabular}

Automated versus non-automated weaning for reducing the duration of mechanical ventilation for critically ill adults and children 
Burns 2013 (Continued)

Blinding of outcome as- High risk Outcome assessors not blinded. Some outcome assessors (respiratory therasessment (detection bias)

pists) were involved in daily patient care (author communication)

All outcomes

Davis 1989

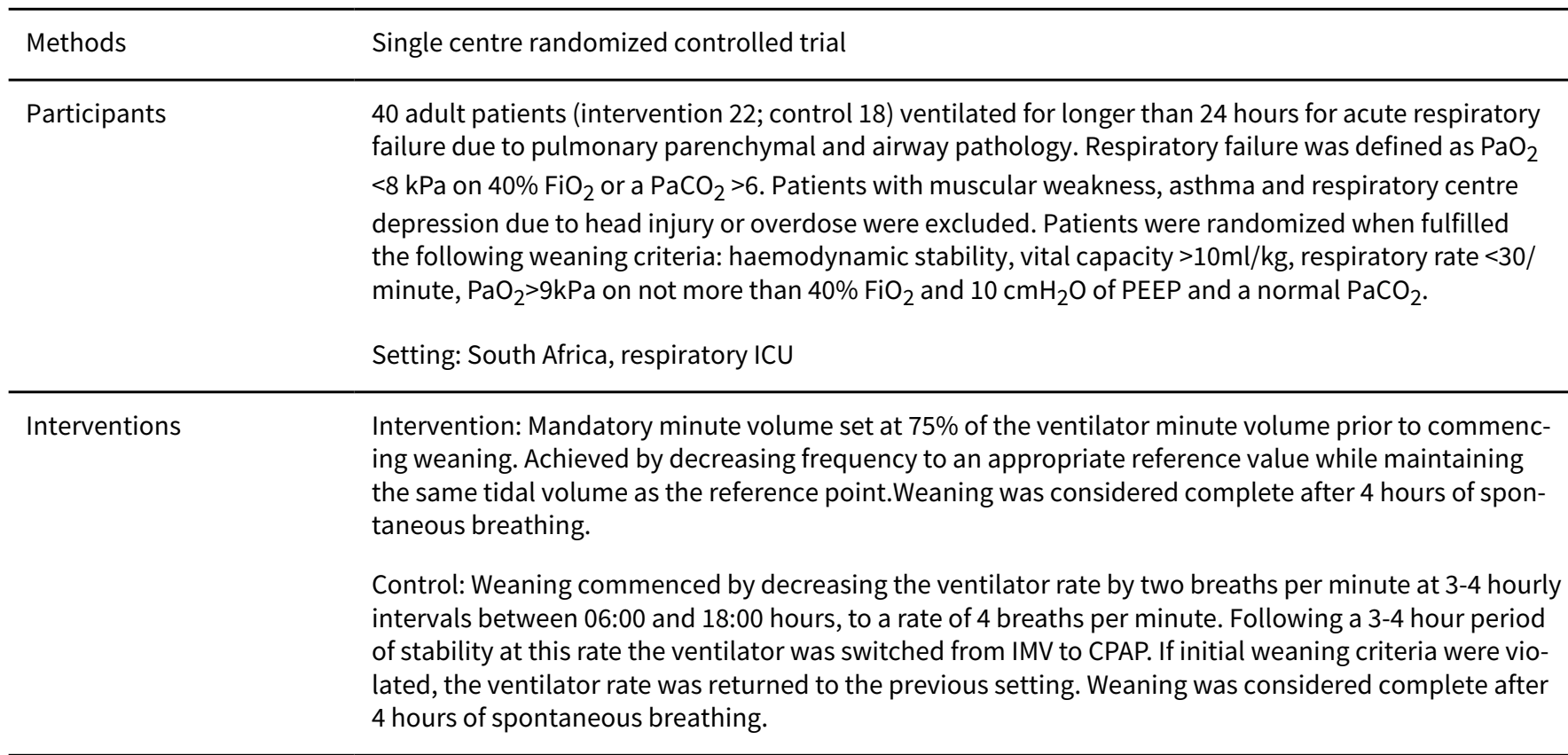

\begin{tabular}{ll}
\hline Outcomes & Weaning success \\
& Duration of successful wean \\
& Frequency of arterial blood gas sampling \\
& Number of ventilator adjustments \\
\hline Notes & $\begin{array}{l}\text { Duration of weaning success: time from randomization to } 4 \text { hours of independent spontaneous breath- } \\
\text { ing. }\end{array}$
\end{tabular}

\section{Risk of bias}

\begin{tabular}{lll}
\hline Bias & Authors' judgement & Support for judgement \\
\hline $\begin{array}{l}\text { Random sequence genera- } \\
\text { tion (selection bias) }\end{array}$ & Unclear risk & Not reported \\
\hline $\begin{array}{l}\text { Allocation concealment } \\
\text { (selection bias) }\end{array}$ & Unclear risk & Not reported \\
\hline $\begin{array}{l}\text { Incomplete outcome data } \\
\text { (attrition bias) } \\
\text { All outcomes }\end{array}$ & Low risk & No attrition, no missing outcome data \\
\hline $\begin{array}{l}\text { Selective reporting (re- } \\
\text { porting bias) }\end{array}$ & Low risk & All pre-specified outcomes are reported \\
\hline
\end{tabular}


Davis 1989 (Continued)

\begin{tabular}{lll} 
Other bias & Low risk & No other sources of bias detected \\
\hline $\begin{array}{l}\text { Blinding of participants } \\
\begin{array}{l}\text { and personnel (perfor- } \\
\text { mance bias) } \\
\text { All outcomes }\end{array}\end{array}$ & High risk & Assumed as high risk due to the nature of the intervention \\
\hline $\begin{array}{l}\text { Blinding of outcome as- } \\
\text { sessment (detection bias) } \\
\text { All outcomes }\end{array}$ & Unclear risk & $\begin{array}{l}\text { Unable to confirm whether clinicians or research staff not involved in patient } \\
\text { care recorded outcomes }\end{array}$ \\
\hline
\end{tabular}

Dongelmans 2009

\begin{tabular}{|c|c|}
\hline Methods & Single centre randomized controlled trial \\
\hline Participants & $\begin{array}{l}128 \text { adults (intervention } 64 \text { :control } 64 \text { ) } \geq 18 \text { years of age after uncomplicated coronary artery bypass } \\
\text { grafting without a history of pulmonary disease or haemodynamic instability. Excluded patients com- } \\
\text { prised those with pulmonary disease or history of pulmonary surgery, intraaortic balloon pump on ad- } \\
\text { mission to ICU, receiving inotropes and/pr vasopressors at a rate higher than usual (upper limits in mil- } \\
\text { ligrams per hour: dopamine } 20 \text {, norepinephrine } 0.5 \text {, dobutamine } 25 \text {, and epinephrine at any rate). }\end{array}$ \\
\hline
\end{tabular}

Setting: The Netherlands, 28 bed ICU of academic medical centre. Staffing comprised 140 nurses, 8 fulltime intensivists, 8 ICU fellows, and 10 residents of other specialties

Interventions

Intervention: Adaptive Support Ventilation with the minute ventilation was set at $100 \%$ of the theoretical value based on predicted body weight, $\mathrm{FiO}_{2}$ of $50 \%$, PEEP of $10 \mathrm{cmH}_{2} \mathrm{O}$ (maintained constant for 4 hours after which it was set to $5 \mathrm{cmH}_{2} \mathrm{O}$ until extubation), maximum airway pressure of $35 \mathrm{~cm} \mathrm{H}_{2} \mathrm{O}$ equivalent to an absolute Pinsp limit of $25 \mathrm{cmH}_{2} \mathrm{O}$, flow trigger $2 \mathrm{~L} / \mathrm{s}$. Arterial blood gas (ABG) analysis was performed 30 minutes after connection to the ventilator. If the $\mathrm{PaCO}_{2}$ was $<3.5 \mathrm{kPa}$ or $>5.5 \mathrm{kPa}$, minute ventilation was decreased or increased by $10 \%$. Any modification of ventilator settings was followed after 30 minutes by an ABG. Extubation criteria included: responsive and cooperative, urine output $>0.5 \mathrm{~mL} / \mathrm{kg} / \mathrm{hr}$, chest drainage $<100 \mathrm{~mL}$ last hour, no uncontrolled arrhythmia, rectal temperature $>36.0 \mathrm{C}$, respiratory frequency of $10-20$ breaths/min without machine-controlled breaths, $\mathrm{FiO}_{2} 40 \%$ and Pinsp 5-10 $\mathrm{cmH}_{2} \mathrm{O}$ for 30 minutes.

Control: Pressure Control Ventilation with VT of 6-8 mL/kg predicted body weight, respiratory rate of 12-15 breaths/min, $\mathrm{FiO}_{2}$, PEEP and flow trigger at same settings as ASV group. Respiratory rate was increased or decreased to satisfy ASV $\mathrm{PaCO}_{2}$ criteria on ABG taken 30 minutes after ventilation commenced. Any modification of ventilator settings was followed after 30 minutes by an ABG. When patients breathed spontaneously, the mode was switched to PSV set at $10 \mathrm{cmH}_{2} \mathrm{O}$, support was decreased to $5-10 \mathrm{cmH}_{2} \mathrm{O}$ depending on VT. Extubation criteria were the same as ASV group.

Outcomes Primary endpoint was time to tracheal extubation. Secondary endpoints were the duration of assisted ventilation as the proportion of the total duration of ventilation of MV and switches from controlled ventilation to assisted ventilation. Also studied ASV with respect to VT, airway pressures, respiratory rate, and $A B G$ results

Notes

\section{Risk of bias}

\begin{tabular}{lll}
\hline Bias & Authors' judgement & Support for judgement \\
\hline $\begin{array}{l}\text { Random sequence genera- } \\
\text { tion (selection bias) }\end{array}$ & Low risk & Allocation in random order (author communication) \\
\hline
\end{tabular}

Automated versus non-automated weaning for reducing the duration of mechanical ventilation for critically ill adults and children 
Dongelmans 2009 (Continued)

\begin{tabular}{lll}
$\begin{array}{l}\text { Allocation concealment } \\
\text { (selection bias) }\end{array}$ & Low risk & Opaque, sealed envelopes used \\
\hline $\begin{array}{l}\text { Incomplete outcome data } \\
\text { (attrition bias) }\end{array}$ & Low risk & No attrition, no missing outcome data \\
All outcomes & &
\end{tabular}

\begin{tabular}{lll}
\hline $\begin{array}{l}\text { Selective reporting (re- } \\
\text { porting bias) }\end{array}$ & Low risk & All pre-specified outcomes are reported \\
\hline Other bias & Low risk & No other sources of bias detected \\
\hline $\begin{array}{l}\text { Blinding of participants } \\
\begin{array}{l}\text { and personnel (perfor- } \\
\text { mance bias) }\end{array}\end{array}$ & High risk & Not possible due to nature of intervention \\
$\begin{array}{l}\text { All outcomes } \\
\begin{array}{l}\text { Blinding of outcome as- } \\
\text { sessment (detection bias) } \\
\text { All outcomes }\end{array}\end{array}$ & Low risk & $\begin{array}{l}\text { Outcome assessors were not involved in daily care of patients. Assumed as low } \\
\text { risk due to the objective nature of outcomes (weaning commencement/extu- } \\
\text { bation) }\end{array}$ \\
\hline
\end{tabular}

\section{Hendrix 2006}

\begin{tabular}{ll}
\hline Methods & Single centre randomized controlled trial \\
\hline Participants & $\begin{array}{l}20 \text { consecutive male adult patients undergoing coronary artery bypass grafting. Patients with a history } \\
\text { of respiratory disease or FEV } 1 \leq 70 \% \text { were excluded from the study } \\
\text { Setting: Germany, university hospital, cardiac surgery ICU }\end{array}$ \\
\hline
\end{tabular}

Interventions

Intervention: After surgery, patients were admitted to the ICU and ventilated with the Siemens 300A/ Automode ventilator set to pressure regulated volume control with VT of $10 \mathrm{~mL} / \mathrm{kg}$ body weight, I:E time of 1:1, upper pressure limit of $30 \mathrm{cmH}_{2} \mathrm{O}$ and Automode function on. Patients weaned and extubated according to standard criteria. After initial $\mathrm{FiO}_{2}$ weaning per protocol, all ventilator changes were automated (ventilator mode changes automatically from PRVC to VS when patient triggers the ventilator).

Control: Ventilated with conventional Siemens 300 ventilator using same ventilator settings as intervention group with the exception of Automode activation. Patients weaned and extubated according to same standard criteria as intervention group. When patients became fully alert, the ventilator mode was changed to CPAP with $10 \mathrm{cmH}_{2} \mathrm{O}$ pressure support by the ICU nurse or physician).
Outcomes
Time to extubation
Postoperative function of the cardiovascular system (cardiac index and mixed venous saturation)
Use of analgesic and sedative drugs
Adverse events including arrhythmias and blood loss
Pulmonary function testing five days postoperatively

\section{Notes}

\section{Risk of bias}


Hendrix 2006 (Continued)

\section{Bias Authors' judgement Support for judgement}

Random sequence genera- Unclear risk tion (selection bias)
Sequence generation described as "eligible patients were randomized in blocks of two prior to undergoing CABG. Only one single Automode ventilator was available for use. Thus, two patients undergoing surgery on the same day were randomized either to the Siemens $300 \mathrm{~A} /$ Automode ventilator (group A) or to the conventional Siemens 300 ventilator (group B) using slips of paper in a box technique which was our procedure to randomize patients. Once the Automode ventilator was again ready for use, two more patients could again be randomized".

It is unclear whether the 2 patients were randomly selected from the total number of CABG patients undergoing surgery that day (no response from author regarding clarification of this issue)

\begin{tabular}{|c|c|c|}
\hline $\begin{array}{l}\text { Allocation concealment } \\
\text { (selection bias) }\end{array}$ & Unclear risk & $\begin{array}{l}\text { It is unclear if the writing on the slips of paper were visible to the person se- } \\
\text { lecting them (no response from author regarding clarification of this issue) }\end{array}$ \\
\hline
\end{tabular}

Incomplete outcome data Low risk

(attrition bias)

All outcomes
No attrition, no missing outcome data

\begin{tabular}{lll}
\hline $\begin{array}{l}\text { Selective reporting (re- } \\
\text { porting bias) }\end{array}$ & Low risk & All pre-specified outcomes are reported \\
\hline Other bias & Low risk & No other sources of bias detected \\
\hline $\begin{array}{l}\text { Blinding of participants } \\
\begin{array}{l}\text { and personnel (perfor- } \\
\text { mance bias) }\end{array}\end{array}$ & High risk & Not possible to blind personnel \\
$\begin{array}{l}\text { All outcomes } \\
\text { Blinding of outcome as- } \\
\text { sessment (detection bias) } \\
\text { All outcomes }\end{array}$ & Unclear risk & $\begin{array}{l}\text { Unable to confirm if outcome assessors were also involved in the daily care of } \\
\text { patients }\end{array}$ \\
\hline
\end{tabular}

\section{Jouvet 2013}

\begin{tabular}{|c|c|}
\hline Methods & Single centre pilot randomized controlled trial \\
\hline Participants & $\begin{array}{l}30 \text { children (intervention } 15 \text {; control } 15 \text { ) between } 2 \text { years and } 18 \text { years with body weight } \geq 15 \mathrm{~kg} \text { ad- } \\
\text { mitted for any reason, except cardiac surgery and mechanically ventilated for at least } 12 \text { hours. Chil- } \\
\text { dren were included if the Evita } \mathrm{XL} \text { ventilator with SmartCare/PSTM was available and if they fulfilled } \\
\text { the following weaning criteria during the screening periods (Monday to Friday mornings): patient } \\
\text { able to breath spontaneously, no vasopressor or inotrope medication (other than digoxin or low dose } \\
\text { dopamine }\left(<5 \mathrm{\mu g} / \mathrm{kg} / \mathrm{min} \text { )), } \mathrm{FiO}_{2} \leq 60 \% \text { in order to obtain oxygen saturation by pulse oxymetry } \geq 95 \% \text {, }\right. \\
\text { positive end expiratory pressure (PEEP) } \leq 8 \mathrm{cmH}_{2} \mathrm{O} \text {, plateau pressure } \leq 25 \mathrm{cmH}_{2} \mathrm{O}, \mathrm{PaCO} \mathrm{Ca}_{2}<70 \mathrm{mmHg} \\
\text { on the most recent blood gas, endotracheal tube leak } \leq 20 \% \text {. Patients were excluded if: they had severe } \\
\text { chronic respiratory insufficiency due to neurological, neuromuscular or lung diseases prior to PICU ad- } \\
\text { mission, primary pulmonary hypertension or cyanotic congenital heart disease with unrepaired or pal- } \\
\text { liated right to left intracardiac shunt, children with extubation anticipated on the day of inclusion, not } \\
\text { expected to survive, with a decision to withdraw care or with no parental consent. }\end{array}$ \\
\hline
\end{tabular}

Setting: Canada, PICU 
Jouvet 2013 (Continued)

Interventions
Intervention: After passing a pressure support test, patients were weaned with SmartCare/PS ${ }^{\mathrm{TM}}$. PEEP was adjusted using a written protocol; if the child's clinical status deteriorated, ventilation mode was switched back to Assist Control. The decision to extubate was made by the attending clinician.

Control: Physicians weaned according to their discretion in the absence of formal guidelines, including modification of ventilator mode if required. The decision to extubate was made by the attending clinician.

\author{
Outcomes \\ Time from randomization to first extubation \\ Weaning failure defined as resumption of mechanical ventilation within 48 hours after extubation \\ Total duration of mechanical ventilation \\ Length of ICU stay \\ Length of hospital stay
}

Notes

Pilot study included 30 patients corresponding to $10 \%$ of the sample size needed for a multi-centre RCT

\title{
Risk of bias
}

\begin{tabular}{|c|c|c|}
\hline Bias & Authors' judgement & Support for judgement \\
\hline $\begin{array}{l}\text { Random sequence genera- } \\
\text { tion (selection bias) }\end{array}$ & Low risk & $\begin{array}{l}30 \text { sealed enveloped contained either control or Smartcare group sheet of pa- } \\
\text { per ( } 15 \text { each) in a random manner and numbered from } 1 \text { to } 30\end{array}$ \\
\hline $\begin{array}{l}\text { Allocation concealment } \\
\text { (selection bias) }\end{array}$ & Low risk & Opaque envelopes used \\
\hline $\begin{array}{l}\text { Incomplete outcome data } \\
\text { (attrition bias) } \\
\text { All outcomes }\end{array}$ & Low risk & No attrition, no missing outcome data \\
\hline $\begin{array}{l}\text { Selective reporting (re- } \\
\text { porting bias) }\end{array}$ & Low risk & All pre-specified outcomes are reported \\
\hline Other bias & Low risk & No other sources of bias detected \\
\hline $\begin{array}{l}\text { Blinding of participants } \\
\text { and personnel (perfor- } \\
\text { mance bias) } \\
\text { All outcomes }\end{array}$ & High risk & Blinding of personnel not possible \\
\hline $\begin{array}{l}\text { Blinding of outcome as- } \\
\text { sessment (detection bias) } \\
\text { All outcomes }\end{array}$ & Low risk & $\begin{array}{l}\text { Outcome assessors were not involved in daily care of patients. Assumed as low } \\
\text { risk due to the objective nature of outcomes (weaning commencement/extu- } \\
\text { bation) }\end{array}$ \\
\hline
\end{tabular}

Kirakli 2011

\begin{tabular}{ll}
\hline Methods & Single centre randomized controlled trial \\
\hline Participants & 97 COPD patients (intervention 49; control 48) with a confirmed diagnosis according to the Global Ini- \\
tiative for COPD criteria. Patients were excluded if they had severe cardiac or neurologic disease, sep- \\
sis, mechanical ventilation for $<24$ hours, and those with a tracheostomy. Patients receiving non-inva- \\
sive ventilation prior to intubation were not enrolled as care for these patients was managed by non-in- \\
tensivist pulmonary physicians.
\end{tabular}

Automated versus non-automated weaning for reducing the duration of mechanical ventilation for critically ill adults and children 
Kirakli 2011 (Continued)

Setting: Turkey, 30 bed respiratory ICU of an education and research hospital specializing in pulmonary diseases and thoracic surgery

Interventions

Intervention: Adaptive Support Ventilation with minute ventilation set at $100 \mathrm{~mL} / \mathrm{kg}$ ideal body weight (IBW). Minute ventilation was decreased to $50 \mathrm{~mL} / \mathrm{kg} \mathrm{IBW}$ after 1 hour and to $30 \mathrm{~mL} / \mathrm{kg}$ after 2 hours if patient was haemodynamically stable, had normal mental status and no signs of anxiety, somnolence or dyspnoea. Patients underwent a 2 hour trial of spontaneous breathing at $30 \mathrm{~mL} / \mathrm{kg}$ prior to extubation.

Control: Initial pressure support (above PEEP) was set at $15 \mathrm{cmH}_{2} \mathrm{O}$. Pressure support was evaluated at least every 30 minutes and titrated to keep the respiratory rate $\leq 35$ breaths/min and gradually decreased to $7 \mathrm{cmH}_{2} \mathrm{O}$ by $2 \mathrm{cmH}_{2} \mathrm{O}$ intervals. In patients achieving $7 \mathrm{cmH}_{2} \mathrm{O}$ pressure support, a 2-hour trial of spontaneous breathing was performed before extubation.

Outcomes Weaning duration defined as time from randomization to spontaneous breathing

Weaning success defined as independence from mechanical ventilation (invasive or non-invasive) for $\geq$ 48 hours after extubation

Respiratory parameters at the end of the weaning period

Duration of ventilation defined as the time from the initiation of ventilator support to the permanent cessation of any form of ventilatory support (invasive or non-invasive)

ICU length of stay

\section{Notes}

\section{Risk of bias}

\section{Bias} Authors' judgement Support for judgement

Random sequence genera- Low risk Used an online randomization website (author communication) tion (selection bias)

Allocation concealment $\quad$ Low risk
(selection bias)

\begin{tabular}{ll}
\hline $\begin{array}{l}\text { Incomplete outcome data } \\
\text { (attrition bias) }\end{array}$ & Low risk \\
All outcomes & $\begin{array}{l}\text { No attrition, no missing outcome data (though discrepancies of reported data } \\
\text { in sections of published manuscript resolved with author) }\end{array}$
\end{tabular}

\begin{tabular}{lll}
\hline $\begin{array}{l}\text { Selective reporting (re- } \\
\text { porting bias) }\end{array}$ & Low risk & All pre-specified outcomes are reported \\
\hline Other bias & Low risk & No other sources of bias detected \\
\hline $\begin{array}{l}\text { Blinding of participants } \\
\begin{array}{l}\text { and personnel (perfor- } \\
\text { mance bias) }\end{array}\end{array}$ & High risk & Not possible due to nature of intervention \\
All outcomes & & \\
\hline
\end{tabular}

\begin{tabular}{|c|c|c|}
\hline $\begin{array}{l}\text { Blinding of outcome as- } \\
\text { sessment (detection bias) }\end{array}$ & Low risk & $\begin{array}{l}\text { Assumed as low risk due to the objective nature of outcomes (weaning com- } \\
\text { mencement/extubation) }\end{array}$ \\
\hline utcomes & & $\begin{array}{l}\text { States "weaning and extubation performed by pulmonary and critical care } \\
\text { physicians who were not aware of the study". Clarification by the author as to } \\
\text { the meaning of this statement provided as "The physicians were aware of the } \\
\text { modes and which protocol they were going to use for that individual patient }\end{array}$ \\
\hline
\end{tabular}


Kirakli 2011 (Continued)

so that they could set the ventilator parameters but they were not aware of the hypothesis and the aim of the study"

Lellouche 2006

\begin{tabular}{ll}
\hline Methods & Multi-centre randomized controlled trial \\
\hline Participants & 147 adult patients (intervention 74 : control 70 ) ventilated for $\geq 24$ hours using an assisted mode \\
& screened for eligibility before usual criteria for weaning were present. Inclusion criteria were: pulse \\
& oximetry $>90 \%$ with $\mathrm{FiO}_{2} \leq 50 \%$ and $\mathrm{PEEP} \leq 8 \mathrm{cmH}_{2} \mathrm{O}$, no need for epinephrine or norepinephrine at a \\
& rate $>1 \mathrm{mg} / \mathrm{h}$, body temperature between 36 to $39{ }^{\circ} \mathrm{C}$, and a stable neurological status with little or no \\
& sedation. Eligibility criteria included absence of: a do-not-resuscitate order, expected poor short-term \\
& prognosis, tracheostomy, and cardiac arrest with poor neurological prognosis.
\end{tabular}

Setting: 5 teaching hospital medical-surgical ICUs in 4 countries in Europe (Belgium, Spain, France, Switzerland)

\begin{tabular}{|c|c|}
\hline Interventions & $\begin{array}{l}\text { Intervention: SmartCare/PS } \\
\text { Control: Weaning according to local practice (guideli } \\
\text { ICUs). Ventilator settings were chosen by the physici } \\
\text { once daily or more screening for criteria to decide for } \\
\text { formed as soon as criteria were present; after passin }\end{array}$ \\
\hline \multirow[t]{9}{*}{ Outcomes } & $\begin{array}{l}\text { Time to successful extubation defined as the time fro } \\
\text { by } 72 \text { hours without ventilator support) }\end{array}$ \\
\hline & Total duration of ventilation \\
\hline & Duration of ventilatory support until first extubation \\
\hline & Length of ICU stay \\
\hline & Length of hospital stay \\
\hline & Number of complications in the ICU \\
\hline & Number of cases of nosocomial pneumonia \\
\hline & ICU mortality \\
\hline & Hospital mortality \\
\hline
\end{tabular}

Notes

Proportion and time to satisfying extubation criteria not reported for usual care arm

\section{Risk of bias}

\begin{tabular}{lll}
\hline Bias & Authors' judgement & Support for judgement \\
\hline $\begin{array}{l}\text { Random sequence genera- } \\
\text { tion (selection bias) }\end{array}$ & Low risk & Computer generated by blocks of six \\
\hline $\begin{array}{l}\text { Allocation concealment } \\
\text { (selection bias) }\end{array}$ & Low risk & $\begin{array}{l}\text { Randomization was centralized, concealed and generated by electronic mail } \\
\text { system }\end{array}$ \\
\hline $\begin{array}{l}\text { Incomplete outcome data } \\
\text { (attrition bias) } \\
\text { All outcomes }\end{array}$ & Low risk & Attrition reported, analysis according to ITT, no missing outcome data \\
\hline
\end{tabular}

Automated versus non-automated weaning for reducing the duration of mechanical ventilation for critically ill adults and children 
Lellouche 2006 (Continued)

Selective reporting (re- Low risk $\quad$ All pre-specified outcomes are reported
porting bias)

\begin{tabular}{lll}
\hline Other bias & Low risk & No other sources of bias detected \\
\hline $\begin{array}{l}\text { Blinding of participants } \\
\text { and personnel (perfor- } \\
\text { mance bias) }\end{array}$ & High risk & Blinding of personnel not possible \\
All outcomes & \\
\hline
\end{tabular}

Blinding of outcome as- Unclear risk Unable to confirm if outcome assessors were involved in daily patient care sessment (detection bias)

All outcomes

Liu 2013

\begin{tabular}{|c|c|}
\hline Methods & Single centre randomized controlled trial \\
\hline \multirow[t]{3}{*}{ Participants } & $\begin{array}{l}\text { Difficult-to-wean defined as: failed SBT due to (1) impaired gas exchange }\left(\mathrm{SpO}_{2}<90 \% \text {; } \mathrm{PaO}_{2}<60 \mathrm{mmHg} \text {; }\right. \\
\text { increase in } \mathrm{PaCO} 2>10 \mathrm{mmHg} \text { ); (2) haemodynamic instability (heart rate changed }>20 \% \text {; systolic } \mathrm{BP} \\
>180 \text { or }<90 \mathrm{mmHg} \text {; } \mathrm{BP} \text { changed }>20 \% \text {; vasopressors required); (3) unstable ventilatory pattern ( }>35 \\
\text { breaths/minutes; } \mathrm{VT}<4 \mathrm{ml} / \mathrm{kg} \text { ); (4) change in mental status (somnolence, coma, agitation, anxiety), di- } \\
\text { aphoresis, and other onset or worsening of discomfort deemed by the clinical team. }\end{array}$ \\
\hline & $\begin{array}{l}\text { Control: Protocolized weaning based on local written weaning guidelines consisting of a daily weaning } \\
\text { readiness screen, followed by a } 30 \text {-minute SBT (CPAP } 5 \mathrm{~cm} \mathrm{H}_{2} \mathrm{O} \text { or added } 5-8 \mathrm{cmH}_{2} \mathrm{O} \text { pressure support) }\end{array}$ \\
\hline & $\begin{array}{l}\text { if screen criteria were fulfilled. If the criteria were not fulfilled, a new screen was performed the next } \\
\text { morning. Patients who did not reach the criteria for failed SBT were weaned. The SBT could be stopped } \\
\text { before } 30 \text { minutes with patients were returned to the previous ventilation mode until the next daily } \\
\text { screening. }\end{array}$ \\
\hline
\end{tabular}

Interventions Intervention: Patients were ventilated usingSmartCare/PS until recommendation of "consider separation" appeared or switched back to assist/control ventilation if weaning failed. Decision for extubation was made by attending physicians based on the acceptable blood gas levels and sufficient cough

Outcomes
Weaning duration (time from inclusion to first extubation)
ICU LOS
ICU mortality
Reintubation
Post-extubation NIV
ICU complications
VAP

\footnotetext{
Notes
}

\section{Risk of bias}

Bias Authors' judgement Support for judgement

Automated versus non-automated weaning for reducing the duration of mechanical ventilation for critically ill adults and children 
Liu 2013 (Continued)

Random sequence genera- Unclear risk Used a random digits table to randomly allocate eligible patients. Not stated tion (selection bias) who was responsible for this so bias is unclear

$\begin{array}{lll}\begin{array}{l}\text { Allocation concealment } \\ \text { (selection bias) }\end{array} & \text { Unclear risk described }\end{array}$

(selection bias)

$\begin{array}{ll}\begin{array}{l}\text { Incomplete outcome data } \\ \text { (attrition bias) }\end{array} & \text { Low risk }\end{array}$

All outcomes comes our reported

\begin{tabular}{|c|c|c|}
\hline $\begin{array}{l}\text { Selective reporting (re- } \\
\text { porting bias) }\end{array}$ & Low risk & All pre-specified outcomes are reported \\
\hline Other bias & Low risk & No other sources of bias detected \\
\hline $\begin{array}{l}\text { Blinding of participants } \\
\text { and personnel (perfor- } \\
\text { mance bias) } \\
\text { All outcomes }\end{array}$ & High risk & Not blinded \\
\hline $\begin{array}{l}\text { Blinding of outcome as- } \\
\text { sessment (detection bias) } \\
\text { All outcomes }\end{array}$ & Unclear risk & $\begin{array}{l}\text { Unable to confirm if outcome assessors were also involved in the daily care of } \\
\text { patients }\end{array}$ \\
\hline
\end{tabular}

\section{Petter 2003}

\begin{tabular}{|c|c|}
\hline Methods & Single centre randomized controlled trial \\
\hline Participants & $\begin{array}{l}34 \text { adult patients (18 intervention; } 16 \text { control) undergoing elective cardiac surgery under cardiopul- } \\
\text { monary bypass. Preoperative exclusion criteria were age }>80 \text { years, preoperative left ventricle ejection } \\
\text { fraction }<30 \% \text {, COPD requiring bronchodilator therapy, significant hepatic disease, renal failure, his- } \\
\text { tory of seizure and stroke. After enrolment, patients presenting with any condition hindering rapid ex- } \\
\text { tubation were excluded. Specific postoperative exclusion criteria were: severe postoperative haemor- } \\
\text { rhage, surgical complication requiring reoperation, postoperative cardiac failure requiring large dose } \\
\text { inotropes, refractory hypoxaemia, and neurological complication precluding patient collaboration. } \\
\text { Setting: Switzerland, surgical ICU }\end{array}$ \\
\hline Interventions & $\begin{array}{l}\text { Intervention: Adaptive support ventilation with initial settings at the default value and peak pressure } \\
\text { less than } 25 \mathrm{cmH}_{2} \mathrm{O} \text {. ABG analysis was performed } 10 \text { minutes after connection to the ventilator. If Pa- } \\
\mathrm{CO}_{2} \text { was } \leq 38 \mathrm{mmHg} \text { or } \geq 50 \mathrm{mmHg} \text {, the } \% \text { minute volume was decreased or increased by } 20 \% \text { (phase } \\
\text { 1). All subsequent changes to ventilator settings were assessed after } 10 \text { minutes via ABG analysis. } \\
\text { Phase } 1 \text { ended with recovery of spontaneous breathing (no controlled breaths for } 20 \text { minutes). Phase } 2 \\
\text { ended when PS had decreased to } 10 \mathrm{cmH}_{2} \mathrm{O} \text { (within } 2 \mathrm{cmH}_{2} \mathrm{O} \text { for } 20 \text { minutes). ABGs and clinical criteria } \\
\text { for weaning failure were assessed. Phase } 3 \text { comprised manual setting of PS to } 5 \mathrm{cmH}_{2} \mathrm{O} \text { for } 10 \text { minutes, } \\
\text { if no contraindications were present, the patient was extubated. } \\
\text { Control: reflected current standard of care. Initial settings were SIMV, VT of } 8 \mathrm{~mL} / \mathrm{kg} \text { IBW, respiratory } \\
\text { rate of } 12 \text { breaths/min. ABG management was identical to ASV group. When patients breathed sponta- } \\
\text { neously for } \geq 6 \text { breaths/min, PS } 10 \mathrm{cmH} 2 \mathrm{O} \text { was set manually. After } 20 \text { minutes, ABG and clinical criteria } \\
\text { were assessed. If weaning was stopped if not tolerated, and patient reassessed after } 20 \text { minutes for fur- } \\
\text { ther reduction of PS. Phase } 3 \text { performed same as ASV group. }\end{array}$ \\
\hline
\end{tabular}

Outcomes Duration of tracheal intubation

Mechanical ventilation transitions from controlled to assisted ventilation 
Petter 2003 (Continued)

Number of ventilator setting changes performed by healthcare workers

Number of alarms

Amount of sedative and analgesic administered

Notes Underpowered study as identified by authors

\title{
Risk of bias
}

\begin{tabular}{|c|c|c|}
\hline Bias & Authors' judgement & Support for judgement \\
\hline $\begin{array}{l}\text { Random sequence genera- } \\
\text { tion (selection bias) }\end{array}$ & Low risk & $\begin{array}{l}\text { A study nurse not involved in the study wrote the assignment (ASV versus con- } \\
\text { trol equal number of each) on cards. She shuffled the cards, put them in sealed } \\
\text { envelopes, and numbered the envelopes. Hence the sequence of allocation } \\
\text { was defined by the shuffling of the cards, but unknown to the investigators } \\
\text { (author communication) }\end{array}$ \\
\hline $\begin{array}{l}\text { Allocation concealment } \\
\text { (selection bias) }\end{array}$ & Low risk & Opaque envelopes used (author communication) \\
\hline $\begin{array}{l}\text { Incomplete outcome data } \\
\text { (attrition bias) } \\
\text { All outcomes }\end{array}$ & Low risk & Attrition reported, analysis according to ITT, no missing outcome data \\
\hline $\begin{array}{l}\text { Selective reporting (re- } \\
\text { porting bias) }\end{array}$ & Low risk & All pre-specified outcomes are reported \\
\hline Other bias & Low risk & No other sources of bias detected \\
\hline $\begin{array}{l}\text { Blinding of participants } \\
\text { and personnel (perfor- } \\
\text { mance bias) } \\
\text { All outcomes }\end{array}$ & High risk & Personnel not blinded \\
\hline $\begin{array}{l}\text { Blinding of outcome as- } \\
\text { sessment (detection bias) } \\
\text { All outcomes }\end{array}$ & High risk & $\begin{array}{l}\text { Outcome assessors were not blinded and were also involved in the daily care } \\
\text { of patients }\end{array}$ \\
\hline
\end{tabular}

Ramet 2002

\begin{tabular}{ll}
\hline Methods & Single centre pilot randomized controlled trial \\
\hline Participants & $\begin{array}{l}18 \text { infants (aged }>4 \text { weeks confirmed through author communication) receiving mechanical ventilation } \\
\text { with pressure regulated volume control (PRVC) }\end{array}$ \\
\hline Interventions & $\begin{array}{l}\text { Intervention: Automode (Siemens Servo 300) with automated switching from PRVC to volume support } \\
\text { ventilation (VSV) }\end{array}$ \\
Control: manual (clinician) switching from PRVC to VSV
\end{tabular}

Outcomes

\author{
Days of ventilation \\ Randomization to extubation in hours \\ Randomization to switching to VSV in hours
}


Ramet 2002 (Continued)

Comfort score on extubation

Notes Available in abstract form only

\section{Risk of bias}

\begin{tabular}{|c|c|c|}
\hline Bias & Authors' judgement & Support for judgement \\
\hline $\begin{array}{l}\text { Random sequence genera- } \\
\text { tion (selection bias) }\end{array}$ & Unclear risk & Not reported and unable to obtain additional information \\
\hline $\begin{array}{l}\text { Allocation concealment } \\
\text { (selection bias) }\end{array}$ & Unclear risk & Not reported and unable to obtain additional information \\
\hline $\begin{array}{l}\text { Incomplete outcome data } \\
\text { (attrition bias) } \\
\text { All outcomes }\end{array}$ & Unclear risk & Unable to obtain additional information \\
\hline $\begin{array}{l}\text { Selective reporting (re- } \\
\text { porting bias) }\end{array}$ & Unclear risk & $\begin{array}{l}\text { Unable to obtain information to make an assessment - cannot find trial regis- } \\
\text { tration }\end{array}$ \\
\hline Other bias & Unclear risk & Study only available in abstract form \\
\hline $\begin{array}{l}\text { Blinding of participants } \\
\text { and personnel (perfor- } \\
\text { mance bias) } \\
\text { All outcomes }\end{array}$ & High risk & Due to intervention type assumed personnel not blinded \\
\hline $\begin{array}{l}\text { Blinding of outcome as- } \\
\text { sessment (detection bias) } \\
\text { All outcomes }\end{array}$ & Unclear risk & Unable to obtain information to make an assessment \\
\hline
\end{tabular}

\section{Rose 2008}

\begin{tabular}{|c|c|}
\hline Methods & Single centre randomized controlled trial \\
\hline \multirow[t]{3}{*}{ Participants } & $\begin{array}{l}102 \text { adult patients ( } 51 \text { intervention: } 51 \text { control) requiring }>24 \text { hours of mechanical ventilation on a } \\
\text { mandatory ventilator mode. Patients tolerating PSV within } 24 \text { hours of ventilation were excluded. Oth- } \\
\text { er eligibility criteria included: } \mathrm{PEEP} \leq 8 \mathrm{~cm} \mathrm{H}_{2} \mathrm{O}, \mathrm{PaO}_{2} / \mathrm{FiO}_{2} \text { ratio }>150 \text { or } \mathrm{SaO}_{2} \geq 90 \% \text { with } \mathrm{FiO}_{2} \leq 0.5 \text {, } \\
\text { plateau pressure } \leq 30 \mathrm{cmH} \mathrm{CH}_{2} \mathrm{O} \text {, haemodynamic stability, peripheral body temperature } 36-39 \mathrm{C} \text {, stable } \\
\text { neurological status with } \mathrm{GCS}>4 \text {, and no anticipated (within } 2 \text { hours) for transport or surgery). Final } \\
\text { study inclusion criterion was completion of } 30 \text { minute } \mathrm{SBT} \text { to determine tolerance of pressure support. }\end{array}$ \\
\hline & $\begin{array}{l}\text { Exclusion criteria: no SmartCare/PS }{ }^{\mathrm{TM}} \text { enabled ventilator available, CNS disorder with anticipated poor } \\
\text { outcome. }\end{array}$ \\
\hline & $\begin{array}{l}\text { Setting: Australia, } 390 \text { bed acute tertiary referral hospital with } 100,000 \text { admissions/annum, } 24 \text { bed } \\
\text { mixed medical/surgical/trauma ICU. Nurse:patient ratio 1:1, } 9 \text { intensivists providing twice daily struc- } \\
\text { tured rounds supported by } 26 \text { hospital medical officers (registrars and residents) }\end{array}$ \\
\hline \multirow[t]{2}{*}{ Interventions } & Intervention: SmartCare/PS ${ }^{\mathrm{TM}}$. Extubation remained at the discretion of the attending clinician \\
\hline & $\begin{array}{l}\text { Control: clinicians instructed to wean PS and PEEP according to usual local practice in the absence of } \\
\text { formal guidelines. Clinicians were instructed to wean PS as able with no constraints as to the frequen- } \\
\text { cy or size of PS adjustment while maintaining patients in the same zone of comfort as described for } \\
\text { SmartCare/PS }\end{array}$ \\
\hline
\end{tabular}

Automated versus non-automated weaning for reducing the duration of mechanical ventilation for critically ill adults and children 
Rose 2008 (Continued)

Outcomes
Time to separation defined as time in hours from randomization to separation potential

Total duration of weaning defined as time from randomization to successful extubation

Time from intubation to first extubation

Time from intubation to successful extubation

ICU length of stay

Hospital length of stay

ICU mortality

Reintubation

Post-extubation NIV

\section{Notes}

\section{Risk of bias}

\begin{tabular}{|c|c|c|}
\hline Bias & Authors' judgement & Support for judgement \\
\hline $\begin{array}{l}\text { Random sequence genera- } \\
\text { tion (selection bias) }\end{array}$ & Low risk & Computer generated block randomization \\
\hline $\begin{array}{l}\text { Allocation concealment } \\
\text { (selection bias) }\end{array}$ & Low risk & Sequential opaque envelopes \\
\hline $\begin{array}{l}\text { Incomplete outcome data } \\
\text { (attrition bias) } \\
\text { All outcomes }\end{array}$ & Low risk & Attrition reported, analysis according to ITT, no missing outcome data \\
\hline $\begin{array}{l}\text { Selective reporting (re- } \\
\text { porting bias) }\end{array}$ & Low risk & All pre-specified outcomes are reported \\
\hline Other bias & Low risk & No other sources of bias detected \\
\hline $\begin{array}{l}\text { Blinding of participants } \\
\text { and personnel (perfor- } \\
\text { mance bias) } \\
\text { All outcomes }\end{array}$ & High risk & Personnel not blinded \\
\hline $\begin{array}{l}\text { Blinding of outcome as- } \\
\text { sessment (detection bias) } \\
\text { All outcomes }\end{array}$ & Low risk & $\begin{array}{l}\text { Assumed as low risk due to the objective nature of outcomes (weaning com- } \\
\text { mencement/extubation). Outcome assessor was independent from those } \\
\text { managing care }\end{array}$ \\
\hline
\end{tabular}

Roth 2001

\begin{tabular}{ll}
\hline Methods & Single centre randomized controlled trial \\
\hline Participants & $\begin{array}{l}40 \text { consecutive adult patients (intervention 20: control 20) with healthy lungs who underwent brain } \\
\text { surgery. Included patients were those who required controlled ventilation and who were expected to } \\
\text { show spontaneous breathing efforts during the } 1 \text { st } 24 \text { hours after ICU admission. Patients with central } \\
\text { depression of breathing drive expected to last }>24 \text { hours as well as patients with mechanical or neural } \\
\text { damage making spontaneous breathing efforts impossible were excluded. }\end{array}$
\end{tabular}


Roth 2001 (Continued)

Setting: Germany, university hospital, 18 bed ICU

Interventions

Intervention: Automode on Siemens Servo ventilator 300. Initial stabilisation period on PCV for 20 minutes after ICU admission. Automode was activated by automatically switching from PCV to PSV in cases of repeated triggering of the ventilator and back in cases of apnoea of more than 12 seconds. Patients were considered ready for extubation when there was stable spontaneous breathing without switching back to controlled ventilation.

Control: SIMV with an initial stabilisation period on PCV for 20 minutes after ICU admission. Mandatory frequency was initially reduced by 2 breaths/min if the ventilator indicated triggering by the patient. Mandatory frequency was further decreased in cases of stability and/or an increase in minute ventilation over the pre-set alarms. If MV dropped below the pre-set alarms, the mandatory rate was increased again. Adjustments were made by the nurses, supervised by the physicians. Manual switching to PSV was done in cases of stable spontaneous breathing. Alarm levels for MV were set to $8-\%$ and $120 \%$ of values measured in the stabilisation phase.

In both groups, pressure levels were adjusted within a range of $10-15 \mathrm{cmH}_{2} \mathrm{O}$ to reach a VT of $10 \mathrm{~mL}$ / $\mathrm{kg}$ body weight. Respiratory rate adjusted to reach normoventilation. I: $\mathrm{E}$ ratio set to $1: 2, \mathrm{FiO}_{2} \mathbf{0 . 3 5}-40$ $\left(\mathrm{PaO}_{2} 90 \mathrm{mmHg}\right)$, PEEP $5 \mathrm{cmH}_{2} \mathrm{O}$. PSV was adjusted to the same inspiratory pressure used during PCV. $\mathrm{PS}, \mathrm{PEEP}$ and $\mathrm{FiO}_{2}$ were kept constant until extubation. Patients were considered ready for extubation when there was stable spontaneous breathing without the need for mandatory background frequency.

Outcomes

Total weaning time

Number of manipulations

Respiratory and circulatory parameters measured at randomization (T0), 20 minutes after the 1st spontaneous breathing activity (T20), 2 hours after T20 (T140), before extubation (Tex), and 1 hour after extubation (Tpost)

Variability of ventilation (range of $\mathrm{PaCO}_{2}$ levels)

Notes

\section{Risk of bias}

\begin{tabular}{|c|c|c|}
\hline Bias & Authors' judgement & Support for judgement \\
\hline $\begin{array}{l}\text { Random sequence genera- } \\
\text { tion (selection bias) }\end{array}$ & Unclear risk & Not reported \\
\hline $\begin{array}{l}\text { Allocation concealment } \\
\text { (selection bias) }\end{array}$ & Unclear risk & Not reported \\
\hline $\begin{array}{l}\text { Incomplete outcome data } \\
\text { (attrition bias) } \\
\text { All outcomes }\end{array}$ & Low risk & No attrition, no missing outcome data \\
\hline $\begin{array}{l}\text { Selective reporting (re- } \\
\text { porting bias) }\end{array}$ & Low risk & All pre-specified outcomes are reported \\
\hline Other bias & Low risk & No other sources of bias detected \\
\hline $\begin{array}{l}\text { Blinding of participants } \\
\text { and personnel (perfor- } \\
\text { mance bias) } \\
\text { All outcomes }\end{array}$ & High risk & Not possible to blind personnel \\
\hline
\end{tabular}


Roth 2001 (Continued)

Blinding of outcome as- Unclear risk Unable to confirm if outcome assessors were also involved in the daily care of sessment (detection bias) patients

All outcomes

Schädler 2012

\begin{tabular}{ll}
\hline Methods & Single centre (multiple ICU) randomized controlled trial \\
\hline Participants & 300 surgical adult patients (Intervention 150; Control 150) who at 09:00 AM, were ventilated for longer \\
& $\begin{array}{l}\text { than } 9 \text { hours since ICU admission. Exclusion criteria comprised: cerebral surgery/trauma, age }<18 \text { years, } \\
\text { do-not-resuscitate order, duration of ventilation }>24 \text { hours, patients already enrolled in the study. }\end{array}$
\end{tabular}

Setting: Germany, academic tertiary hospital, 3 ICUs serving all surgical disciplines (10 bed cardiovascular ICU, 10 bed interdisciplinary ICU and 8 bed surgical ICU). ICUs staffed with a 1:2 nurse:patient ratio. During daytime a board certified physician was responsible for medical care +1 resident for 3 shifts per day and 1 consultant on-call. Daily ward round carried out by 2-3 experienced intensivists, one resident, one consultant microbiologist and 1-2 nurses.

Interventions In both study arms, haemodynamically stable patients (maximal continuous infusion of epinephrine or norepinephrine of $0.01 \mathrm{mg} / \mathrm{kg} / \mathrm{h}$ ) were assessed with a 30 minute pressure support test initiated by the responsible physician or during study visits if clinically indicated. Patients were switched from PCV to PSV with PS between 15 to $30 \mathrm{cmH}_{2} \mathrm{O}$ and identical settings of $\mathrm{FiO}_{2}$ and PEEP. Patients passed the PS test if remained clinically stable, spontaneous breaths were $<35$ per minute, $V T \geq 6 \mathrm{~mL} / \mathrm{kg}$ predicted body weight with allowed PS, $\mathrm{SpO}_{2} \geq 90 \%$. Patients successfully passing the PS test were then weaned according to the allocated group.

Intervention: SmartCare/PS ${ }^{\mathrm{TM}}$ via Evita XL ventilators with night rest and automatic tube compensation turned off and using a heat and moisture exchange filter. Readiness for extubation was identified by SmartCare/PS ${ }^{\text {TM }}$. Extubation or end of ventilator therapy for tracheostomized patients occurred when the following criteria were satisfied: $\mathrm{PaO}_{2} / \mathrm{FiO}_{2}>200$, patient awake and cooperative, sufficient airway protection or GCS $>8$, effective cough, and no surgical indication.

Control: Standardized weaning protocol. Adjustment of PS at least 3 times per day by 2 or $3 \mathrm{~cm} \mathrm{H}_{2} \mathrm{O}$ with the aim of maintaining the spontaneous breath rate $\leq 35$ and good clinical adaptation. PS was increased if the spontaneous breath rate was $>35$ for longer than 3 minutes. A daily SBT lasting 30 minutes was commenced when PS $\leq 12 \mathrm{cmH}_{2} \mathrm{O}, \mathrm{PEEP} \leq 5 \mathrm{cmH}_{2} \mathrm{O}$ and $\mathrm{FiO}_{2} \leq 0.5$. Patients were deemed to have passed the SBT if the spontaneous breath rate remained below $35, \mathrm{SpO}_{2} \geq 90 \%$, patient remained clinically stable (no diaphoresis, agitation or decreased level of consciousness). If a patient failed the SBT the test was reinitiated at least once during the next 24 hours. The same criteria were used for extubation/discontinuation of ventilation as used in the intervention arm.

Analgesia was maintained by a continuous infusion of sufentanil (range 0.1 to $0.4 \mu \mathrm{g} / \mathrm{kg} / \mathrm{h}$ ). Sedation was achieved via continuous infusion of propofol $(\max 4 \mathrm{mg} / \mathrm{kg} / \mathrm{h}$ ) for 24 hours after inclusion. Thereafter bolus doses of midazolam were used to maintain a Ramsay score of 2 .

Outcomes Overall ventilation time during ICU stay considering any time the patient required invasive or noninvasive ventilation during the 28 day study period

Time in zone of respiratory comfort

Number of ventilator manipulations

Length of ICU stay

Length of hospital stay

28-day mortality 
Schädler 2012 (Continued)

90-day mortality

Notes Study sponsored by Dräger Medical via a restricted research grant. Sponsor had no role in the study

\section{Risk of bias}

\begin{tabular}{|c|c|c|}
\hline Bias & Authors' judgement & Support for judgement \\
\hline $\begin{array}{l}\text { Random sequence genera- } \\
\text { tion (selection bias) }\end{array}$ & Low risk & Electronically generated and locally maintained randomization schedule \\
\hline $\begin{array}{l}\text { Allocation concealment } \\
\text { (selection bias) }\end{array}$ & Low risk & Allocation was concealed \\
\hline $\begin{array}{l}\text { Incomplete outcome data } \\
\text { (attrition bias) } \\
\text { All outcomes }\end{array}$ & Low risk & Attrition reported, analysis according to ITT, no missing outcome data \\
\hline $\begin{array}{l}\text { Selective reporting (re- } \\
\text { porting bias) }\end{array}$ & Low risk & All pre-specified outcomes are reported \\
\hline Other bias & Low risk & No other sources of bias detected \\
\hline $\begin{array}{l}\text { Blinding of participants } \\
\text { and personnel (perfor- } \\
\text { mance bias) } \\
\text { All outcomes }\end{array}$ & High risk & Not possible to blind personnel \\
\hline $\begin{array}{l}\text { Blinding of outcome as- } \\
\text { sessment (detection bias) } \\
\text { All outcomes }\end{array}$ & High risk & $\begin{array}{l}\text { Blinding of outcome assessors not possible. Outcome assessors were also in- } \\
\text { volved in the daily care of patients }\end{array}$ \\
\hline
\end{tabular}

\section{Stahl 2009}

\begin{tabular}{ll}
\hline Methods & Randomized controlled trial \\
\hline Participants & 60 adult patients (Intervention 30; Control 30) who were mechanically ventilated via an endotracheal \\
& tube or tracheostomy for at least 24 hours, breathing spontaneously, Ramsay sedation $\mathrm{score} \leq 3, \mathrm{PaO}_{2}$ \\
& $>75 \mathrm{mmHg}$ or $\mathrm{SaO}_{2}>90 \%$ with $\mathrm{FiO}$ \\
2 & $\leq 0.5,18-80$ years of age, body weight $35-200 \mathrm{~kg}$. Exclusion criteria \\
& comprised: $\mathrm{PEEP}>10 \mathrm{cmH}_{2} \mathrm{O}$, haemodynamic instability with a need for catecholamines, rectal tem- \\
perature $>39^{\circ} \mathrm{C}$, haemoglobin $<7 \mathrm{~g} / \mathrm{dL}$, and $\mathrm{pH}<7.2$.
\end{tabular}

Interventions Intervention: SmartCare/PS ${ }^{\mathrm{TM}}$

Control: physician-directed weaning using no strict protocol but recommending PS should be gradually reduced in single steps of no more than $15 \mathrm{cmH}_{2} \mathrm{O}$

Extubation criteria: respiratory rate $<30$ breaths $/ \mathrm{min}, \mathrm{PaO}_{2}>75 \mathrm{mmHg}$ or $\mathrm{SaO}_{2}>90 \%$, sufficient airway protection, haemodynamic stability

Duration of ventilator weaning (time from switching controlled to assisted breathing (CPAP/ASB mode)
until extubation or disconnection (if tracheostomy)
Total duration of mechanical ventilation (intubation to successful extubation)
Length of ICU stay


Stahl 2009 (Continued)

Reintubation within 48 hours

Physician workload (frequency of $\mathrm{PS}, \mathrm{FiO}_{2}$ and PEEP setting changes/hour)

Nursing workload (frequency of alarms indicating clean $\mathrm{CO}_{2}$ cuvette/hour)

ICU and hospital mortality

\begin{tabular}{|c|c|c|}
\hline Notes & & \\
\hline \multicolumn{3}{|l|}{ Risk of bias } \\
\hline Bias & Authors' judgement & Support for judgement \\
\hline $\begin{array}{l}\text { Random sequence genera- } \\
\text { tion (selection bias) }\end{array}$ & Low risk & $\begin{array}{l}\text { Randomization list generated using RITA version 1.13a. Stratified randomiza- } \\
\text { tion with age and duration of mechanical ventilation prior to weaning }\end{array}$ \\
\hline $\begin{array}{l}\text { Allocation concealment } \\
\text { (selection bias) }\end{array}$ & Low risk & Opaque sealed envelopes \\
\hline $\begin{array}{l}\text { Incomplete outcome data } \\
\text { (attrition bias) } \\
\text { All outcomes }\end{array}$ & Low risk & All a priori outcomes reported. Analysis according to ITT \\
\hline $\begin{array}{l}\text { Selective reporting (re- } \\
\text { porting bias) }\end{array}$ & Low risk & All pre-specified outcomes are reported \\
\hline Other bias & Unclear risk & $\begin{array}{l}\text { Sample size calculation states: based on } 80 \% \text { power to detect a } 2 \text { days differ- } \\
\text { ence in weaning time, a } 0.05 \text { requires } 54 \text { patients in each group. Unplanned in- } \\
\text { terim analysis was undertaken because of low recruitment after } 1 \text { year: sample } \\
\text { size and significance levels were recalculated as } N=60 \text {. After the } 60 \text { th patient } \\
\text { the trial was stopped for futility }\end{array}$ \\
\hline
\end{tabular}

\begin{tabular}{lll}
\hline $\begin{array}{l}\text { Blinding of participants } \\
\text { and personnel (perfor- } \\
\text { mance bias) }\end{array}$ & High risk & Participants, staff and research personnel were unblinded \\
All outcomes & \\
\hline $\begin{array}{l}\text { Blinding of outcome as- } \\
\text { sessment (detection bias) } \\
\text { All outcomes }\end{array}$ & Low risk & $\begin{array}{l}\text { Assumed as low risk due to the objective nature of outcomes (weaning com- } \\
\text { mencement/extubation). Communication with authors: outcome assessors } \\
\text { were independent from those managing patient care }\end{array}$ \\
\hline
\end{tabular}

\section{Strickland 1993}

\begin{tabular}{|c|c|}
\hline Methods & Single centre pilot randomized controlled trial \\
\hline \multirow[t]{5}{*}{ Participants } & $\begin{array}{l}17 \text { patients ( } 9 \text { computer; } 7 \text { physician weaning group) judged ready to wean by his/her attending physi- } \\
\text { cian and meeting the following criteria: } \mathrm{pH} \geq 7.30 \text { and } \leq 7.50, \mathrm{PaCO}_{2} \geq 30 \text { and } \leq 50 \mathrm{mmHg}, \mathrm{SaO}_{2} \geq 90 \%\end{array}$ \\
\hline & while on SIMV with a rate of $6-10$, VT of $10-15 \mathrm{~mL} / \mathrm{kg}, \mathrm{PS} 20 \mathrm{cmH}_{2} \mathrm{O}$ and $\mathrm{FiO}_{2} \leq 0.4$, negative inspirato- \\
\hline & ry force $\leq-20 \mathrm{cmH}_{2} \mathrm{O}$, forced vital capacity $\geq 10 \mathrm{~mL} / \mathrm{kg}$, stable haemodynamics and renal function, par- \\
\hline & $\begin{array}{l}\text { enteral or enteral feeding, no ileus, normal electrolytes, infection controlled with antibiotics with oral } \\
\text { temperature } \leq 37.7 \text { C. Post operative patients were excluded unless had been on ventilator for } \geq 3 \text { days. } \\
\text { Patients requiring PEEP had to be weaned of (PEEP) prior to entering the studv. }\end{array}$ \\
\hline & $\begin{array}{l}\text { Setting: United States, } 3 \text { pulmonary physicians were involved in patient care either in a consultative or } \\
\text { attending role }\end{array}$ \\
\hline
\end{tabular}

Automated versus non-automated weaning for reducing the duration of mechanical ventilation for critically ill adults and children 
Strickland 1993 (Continued)

Interventions
Intervention: modification of Puritan Bennett 7200 to allow direct control of the ventilator settings by an external PC-compatible computer that monitored the patient and ventilator data through the serial digital outputs of the pulse oximeter and ventilator. Weaning started at SIMV rate 6, PS $20 \mathrm{~cm} \mathrm{H}_{2} \mathrm{O}$, $\mathrm{FiO}_{2} \leq 0.4$, and $\mathrm{VT} 10-15 \mathrm{~mL} / \mathrm{kg}$. The computer sampled respiratory rate and $\mathrm{SpO}_{2}$ every 5 minutes, and calculated a moving average of $\mathrm{VT}$ using the average of the last 5 time 1 minute $\mathrm{V}_{\mathrm{T}}$ samples. To proceed with weaning the respiratory rate had to be $\geq 8$ and $\leq 30$ and $V_{T} \geq 5 \mathrm{~mL} / \mathrm{kg}$ (ideal body weight based on height). The system alarmed if $\mathrm{SpO}_{2}$ was $<90 \%$ but no weaning changes were made by the computer based on SpO2. The computer decreased the SIMV rate by 2 every hour until a rate of 2 was reached. The computer then decreased the PS by $2 \mathrm{cmH}_{2} \mathrm{O}$ every hour as long as the VT and respiratory rate limits were met. The weaning process was complete when the SIMV rate was 2 and the PS $5 \mathrm{cmH}_{2} \mathrm{O}$. If the 5-minute samples of respiratory rate or $\mathrm{V}_{\mathrm{T}}$ were not within acceptable limits, the computer increased the level of ventilator support.

Control: weaning progressed through SIMV rate and PS reduction as judged appropriate by the patient's physician

Wutcomes
Time to wean
Number of ABG samples
Number of minutes per hour respiratory rate and VT were outside acceptable limits

Notes

\section{Risk of bias}

\begin{tabular}{|c|c|c|}
\hline Bias & Authors' judgement & Support for judgement \\
\hline $\begin{array}{l}\text { Random sequence genera- } \\
\text { tion (selection bias) }\end{array}$ & Low risk & Random number table \\
\hline $\begin{array}{l}\text { Allocation concealment } \\
\text { (selection bias) }\end{array}$ & Low risk & Sealed envelopes \\
\hline $\begin{array}{l}\text { Incomplete outcome data } \\
\text { (attrition bias) } \\
\text { All outcomes }\end{array}$ & Low risk & Attrition reported, no missing outcome data \\
\hline $\begin{array}{l}\text { Selective reporting (re- } \\
\text { porting bias) }\end{array}$ & Low risk & All pre-specified outcomes are reported \\
\hline Other bias & Low risk & No other sources of bias detected \\
\hline $\begin{array}{l}\text { Blinding of participants } \\
\text { and personnel (perfor- } \\
\text { mance bias) } \\
\text { All outcomes }\end{array}$ & High risk & Impossible to blind personnel \\
\hline $\begin{array}{l}\text { Blinding of outcome as- } \\
\text { sessment (detection bias) } \\
\text { All outcomes }\end{array}$ & Unclear risk & $\begin{array}{l}\text { Unable to confirm if outcome assessors were also involved in daily patient } \\
\text { care }\end{array}$ \\
\hline
\end{tabular}


Sulzer 2001

Methods Single centre randomized controlled trial

Participants

36 adults undergoing elective coronary artery bypass grafting under cardiopulmonary bypass. preoperative exclusion criteria comprised: age $>75$ years, poor myocardial function (preoperative ejection fraction $<30 \%$ ), COPD requiring bronchodilator therapy, significant hepatic disease, renal failure, history of seizure or stroke. Postoperative exclusion criteria comprised: severe postoperative haemorrhage, repeat operation, postoperative myocardial ischaemia, refractory hypoxaemia, neurologic complication.

Setting: Switzerland, university hospital, surgical ICU

Interventions

Intervention: Adaptive support ventilation with initial settings at minute ventilation set at $100 \%, \mathrm{FiO}_{2}$ $100 \%$, PEEP $4 \mathrm{cmH}_{2} \mathrm{O}$ and peak pressure less than $25 \mathrm{~cm} \mathrm{H}_{2} \mathrm{O}$. ABG analysis was performed 10 minutes after connection to the ventilator. If $\mathrm{PaCO}_{2}$ was $\leq 38 \mathrm{mmHg}$ or $\geq 50 \mathrm{mmHg}$, the $\%$ minute volume was decreased or increased by $20 \%$ (phase 1). All subsequent changes to ventilator settings were assessed after 10 minutes via ABG analysis. Phase 1 lasted until patients breathed spontaneous at $\geq 6$ breaths per minute for 20 minutes. Weaning progressed after ABG was checked and clinical criteria of poor tolerance were ruled out. Continuation of weaning composed of 2 phases lasting at least 20 minutes each. In Phase 2 minute ventilation was lowered by $50 \%$. If ABGs and clinical criteria indicated poor tolerance, phase 1 was reinstated. If ABGs and clinical criteria were satisfactory, weaning progressed to Phase 3. In Phase 3 minute ventilation was lowered by another 50\%. At the end of Phase 3, if the patient achieved extubation criteria, pulmonary physiotherapy was performed, followed by extubation.

Control: reflected current standard of care. Initial settings (Phase 1) were SIMV, VT of $7 \mathrm{~mL} / \mathrm{kg}$, respiratory rate of 12 breaths/min. ABG performed after 10 minutes, respiratory rate was lowered or increased to satisfy same criteria as ASV group. When patients breathed spontaneously for $\geq 6$ breaths/min for 20 minutes, weaning could progress to Phase 2, according to the criteria defined for the ASV group. The ventilator was set to PSV of $10 \mathrm{cmH}_{2} \mathrm{O}$. ABG and clinical criteria were assessed. If indicating poor tolerance, phase 1 was reinstated, if $A B G$ and clinical criteria were complied with, weaning progressed to Phase 3 in which PS was reduced to $5 \mathrm{cmH}_{2} \mathrm{O}$. At the end of Phase 3 patients were assessed for extubation according to the same criteria as the ASV group.

Outcomes Duration of mechanical ventilation (Phases 1, 2 and 3)

Amount of sedative and analgesic drugs administered

\section{Notes}

\section{Risk of bias}

Bias Authors' judgement Support for judgement

Random sequence genera- Low risk tion (selection bias)

A study nurse not involved in the study wrote the assignment (ASV versus control equal number of each) on cards. She shuffled the cards, put them in sealed envelopes, and numbered the envelopes. Hence the sequence of allocation was defined by the shuffling of the cards, but unknown to the investigators (author communication)

\begin{tabular}{|c|c|c|}
\hline $\begin{array}{l}\text { Allocation concealment } \\
\text { (selection bias) }\end{array}$ & Low risk & Sealed opaque envelopes \\
\hline $\begin{array}{l}\text { Selective reporting (re- } \\
\text { porting bias) }\end{array}$ & Low risk & All pre-specified outcomes are reported \\
\hline Other bias & Low risk & No other sources of bias detected \\
\hline
\end{tabular}

Automated versus non-automated weaning for reducing the duration of mechanical ventilation for critically ill adults and children (Review)

Copyright (c) 2018 The Cochrane Collaboration. Published by John Wiley \& Sons, Ltd. 
Sulzer 2001 (Continued)
Blinding of participants
High risk
Blinding of personnel not possible and personnel (performance bias)

All outcomes

Blinding of outcome as-
sessment (detection bias)

All outcomes

Blinding of outcome assessors not possible. Outcome assessors were also involved in the daily care of patients

Taniguchi 2009

\begin{tabular}{ll}
\hline Methods & Single centre randomized controlled trial \\
\hline Participants & $\begin{array}{l}106 \text { (53 in each group) postoperative adults (over } 18 \text { years), receiving mechanical ventilation after car- } \\
\text { diac, thoracic, abdominal or orthopaedic surgery. Excluded patients included neurological surgery and } \\
\text { patients with previous pulmonary disease or haemodynamic instability during weaning. }\end{array}$
\end{tabular}

Setting: Brazil, adult ICU

Interventions

Intervention: mandatory rate ventilation (MRV) automatic, computerised weaning, ventilated with Taema-Horus Ventilator. Initial ventilation was the same as the control group except that to obtain a RR of 15 breaths per minute, the target RR was set at 15 and the minimum RR as 15 . When the patient commenced breathing spontaneously the ventilator mode was switched to PSV to achieve a $V_{T} \geq 8 \mathrm{~mL} / \mathrm{kg}$ with PS maximum of $25 \mathrm{cmH}_{2} \mathrm{O}$, target RR of 15 with minimum RR of $8, \mathrm{FiO}_{2}$ to achieve an $\mathrm{SpO}_{2}$ of $95 \%$, PEEP $5 \mathrm{cmH}_{2} \mathrm{O}$. The MRV mode then commenced automatic reduction of PS.

Control: manual weaning guided by ICU staff comprising PCV targeting a $\mathrm{V}_{\mathrm{T}}$ of $8 \mathrm{~mL} / \mathrm{kg}$, with a RR of 15 breaths per minute, $\mathrm{FiO}_{2}$ to achieve an $\mathrm{SpO}_{2}$ of $95 \%$, PEEP of $5 \mathrm{cmH}_{2} \mathrm{O}$. When the patient started breathing spontaneously the ventilator mode was switched to PSV set to achieve $V_{T}$ of $8 \mathrm{~mL} / \mathrm{kg}, \mathrm{RR} /$ $\mathrm{VT}$ less than $80 \mathrm{~L}, \mathrm{FiO}_{2}$ to achieve an $\mathrm{SpO}_{2}$ of $95 \%$, PEEP $5 \mathrm{cmH}_{2} \mathrm{O}$. PSV was reduced every 30 minutes keeping RR/ $\mathrm{V}_{\mathrm{T}}<80$ and $\mathrm{VT} \geq 8 \mathrm{~mL} / \mathrm{kg}$. PSV could be reassessed and possibly decreased every $30 \mathrm{~min}-$ utes aiming to make the manual weaning as close as possible to the automatic algorithm.

Patients in both arms were extubated if meeting the following criteria: PSV from $5-7 \mathrm{cmH} 2 \mathrm{O}$, PEEP 5 $\mathrm{cmH}_{2} \mathrm{O}, \mathrm{FiO}_{2} 40 \%, \mathrm{SpO}_{2}>95 \%$, haemodynamically stable, adequate mental status, capable of protecting airway, $\mathrm{RR} / \mathrm{V}_{\mathrm{T}}<80 \mathrm{~L}$.

Outcomes Duration of the weaning process from the moment the patient started to breathe spontaneously until successful extubation

Levels of $\mathrm{PS}, \mathrm{VT}, \mathrm{RR}, \mathrm{FiO}_{2}, \mathrm{SpO}_{2}, \mathrm{PEEP}$ and $\mathrm{RR} / \mathrm{V}_{\mathrm{T}}$ required during the weaning process

Need for reintubation

Need for NIV

Notes

Risk of bias

\begin{tabular}{lll}
\hline Bias & Authors' judgement & Support for judgement \\
\hline $\begin{array}{l}\text { Random sequence genera- } \\
\text { tion (selection bias) }\end{array}$ & Low risk & Randomly drew folded slips of paper from large envelope \\
\hline
\end{tabular}

Automated versus non-automated weaning for reducing the duration of mechanical ventilation for critically ill adults and children 
Taniguchi 2009 (Continued)

\begin{tabular}{|c|c|c|}
\hline $\begin{array}{l}\text { Allocation concealment } \\
\text { (selection bias) }\end{array}$ & Low risk & Slips of paper drawn from opaque envelope \\
\hline $\begin{array}{l}\text { Incomplete outcome data } \\
\text { (attrition bias) } \\
\text { All outcomes }\end{array}$ & Low risk & Attrition reported, analysis according to ITT, no missing outcome data \\
\hline $\begin{array}{l}\text { Selective reporting (re- } \\
\text { porting bias) }\end{array}$ & Low risk & All pre-specified outcomes are reported. \\
\hline Other bias & Low risk & No other sources of bias detected \\
\hline $\begin{array}{l}\text { Blinding of participants } \\
\text { and personnel (perfor- } \\
\text { mance bias) } \\
\text { All outcomes }\end{array}$ & High risk & Unable to blind personnel \\
\hline
\end{tabular}

Blinding of outcome as- High risk Blinding of outcome assessors not possible. Outcome assessors were also insessment (detection bias) volved in the daily care of patients

All outcomes

Walkey 2011

\begin{tabular}{|c|c|}
\hline Methods & Single centre randomized controlled trial \\
\hline \multirow[t]{2}{*}{ Participants } & $\begin{array}{l}33 \text { adult patients ( } 15 \text { intervention; } 18 \text { control) receiving mechanical ventilation via an endotracheal } \\
\text { tube for }>48 \text { hours }\end{array}$ \\
\hline & Setting: USA, medical ICU \\
\hline \multirow[t]{2}{*}{ Interventions } & Intervention: SmartCare/PS ${ }^{\mathrm{TM}}$ \\
\hline & Control: weaning according to usual care \\
\hline \multirow[t]{3}{*}{ Outcomes } & $\begin{array}{l}\text { Duration of weaning assessed as the time from the initiation of weaning (randomization) to the time of } \\
\text { successful extubation (defined as } 48 \text { hours free of mechanical ventilation) }\end{array}$ \\
\hline & Hospital mortality \\
\hline & $\begin{array}{l}\text { Complications (death during wean, ventilator-associated pneumonia during wean, self extubation, } \\
\text { reintubation) }\end{array}$ \\
\hline Notes & This trial was terminated early due to slow recruitment \\
\hline
\end{tabular}

\section{Risk of bias}

\begin{tabular}{lll}
\hline Bias & Authors' judgement & Support for judgement \\
\hline $\begin{array}{l}\text { Random sequence genera- } \\
\text { tion (selection bias) }\end{array}$ & Low risk & Online random number generator \\
\hline $\begin{array}{l}\text { Allocation concealment } \\
\text { (selection bias) }\end{array}$ & Low risk & Opaque envelopes used \\
\hline $\begin{array}{l}\text { Incomplete outcome data } \\
\text { (attrition bias) }\end{array}$ & High risk & $\begin{array}{l}\text { Study terminated early due to slow recruitment. Limited reporting of outcome } \\
\text { data }\end{array}$ \\
\hline
\end{tabular}

Automated versus non-automated weaning for reducing the duration of mechanical ventilation for critically ill adults and children 
Walkey 2011 (Continued)

All outcomes

\begin{tabular}{lll}
\hline $\begin{array}{l}\text { Selective reporting (re- } \\
\text { porting bias) }\end{array}$ & Unclear risk & $\begin{array}{l}\text { Study terminated early due to slow recruitment. Limited reporting of outcome } \\
\text { data }\end{array}$ \\
\hline Other bias & Unclear risk & Study terminated early due to slow recruitment \\
\hline $\begin{array}{l}\text { Blinding of participants } \\
\begin{array}{l}\text { and personnel (perfor- } \\
\text { mance bias) }\end{array}\end{array}$ & High risk & Not possible due to nature of intervention \\
All outcomes & & \\
\hline
\end{tabular}

\begin{tabular}{|c|c|c|}
\hline $\begin{array}{l}\text { Blinding of outcome as- } \\
\text { sessment (detection bias) }\end{array}$ & Unclear risk & $\begin{array}{l}\text { Unable to confirm if outcome assessors were also involved in the daily care of } \\
\text { patients }\end{array}$ \\
\hline
\end{tabular}
sessment (detection bias) patients

Xirouchaki 2008

\begin{tabular}{ll}
\hline Methods & Single centre randomized controlled trial \\
\hline Participants & $\begin{array}{l}208(108 \text { intervention; } 100 \text { control }) \text { adults ventilated for }>36 \text { hours on a controlled mode. Exclusion cri- } \\
\text { teria comprised: severe acidaemia }(\mathrm{pH}>7.30) ; \text { severe haemodynamic instability defined as a need for } \\
\text { norepinephrine infusion at a rate greater than } 0.5 \mu \mathrm{g} / \mathrm{kg} / \mathrm{h} \text {, and severe bronchospasm }\end{array}$ \\
\hline
\end{tabular}

Interventions Intervention: Proportional Assist Ventilation + using a Puritan-Bennett 840 ventilator and a specific pre-defined written algorithm was used to set and adjust the ventilator. The initial percentage of assist was set to $60-80 \%$.

$\mathrm{PAV}+$ was continued for 48 hours unless the patients met pre-defined criteria either for switching to CMV (failure criteria) or for breathing without ventilator assistance.

Control: PSV with pre-defined written algorithms were used to adjust the ventilator settings

\begin{tabular}{ll}
\hline Outcomes & Proportion of patients meeting failure criteria in each mode during the 48 hour study period \\
& $\begin{array}{l}\text { Proportion of patients meeting criteria for unassisted breathing } \\
\text { Proportion of patients exhibiting major patient- ventilator dys-synchronies } \\
\text { Total amount of sedative, analgesic and vasoactive drugs during the } 48 \text { hour of observation }\end{array}$ \\
\hline Notes & Duration of ventilation and ICU stay provided in electronic supplement
\end{tabular}

\section{Risk of bias}

\begin{tabular}{lll}
\hline Bias & Authors' judgement & Support for judgement \\
\hline $\begin{array}{l}\text { Random sequence genera- } \\
\text { tion (selection bias) }\end{array}$ & Low risk & Randomization schedule previously generated by a statistician \\
\hline $\begin{array}{l}\text { Allocation concealment } \\
\text { (selection bias) }\end{array}$ & Low risk & Opaque and sealed envelopes used \\
\hline $\begin{array}{l}\text { Incomplete outcome data } \\
\text { (attrition bias) } \\
\text { All outcomes }\end{array}$ & Low risk & Attrition reported, no missing outcome data \\
\hline
\end{tabular}


Xirouchaki 2008 (Continued)

\begin{tabular}{lll}
$\begin{array}{l}\text { Selective reporting (re- } \\
\text { porting bias) }\end{array}$ & Low risk & All pre-specified outcomes are reported \\
\hline Other bias & Low risk & No other sources of bias detected \\
\hline $\begin{array}{l}\text { Blinding of participants } \\
\begin{array}{l}\text { and personnel (perfor- } \\
\text { mance bias) }\end{array}\end{array}$ & High risk & Not possible due to nature of intervention \\
$\begin{array}{l}\text { All outcomes } \\
\begin{array}{l}\text { Blinding of outcome as- } \\
\text { sessment (detection bias) } \\
\text { All outcomes }\end{array}\end{array}$ & High risk & $\begin{array}{l}\text { Individuals collecting the results and outcome data were also involved in clini- } \\
\text { cal management of patients }\end{array}$
\end{tabular}

\section{Characteristics of excluded studies [ordered by study ID]}

\begin{tabular}{ll}
\hline Study & Reason for exclusion \\
\hline East 1999 & Not evaluating a closed loop automated system \\
\hline Jiang 2006 & $\begin{array}{l}\text { Quasi-randomized trial. Allocation sequence generated according to case record number (odd and } \\
\text { even) }\end{array}$ \\
\hline Lellouche 2013 & $\begin{array}{l}\text { Automated system only used for four hours of study duration not until extubation therefore unable } \\
\text { to determine effect on weaning and ventilation }\end{array}$ \\
\hline Ma 2010 & $\begin{array}{l}\text { Quasi-randomized trial. Study subjects separated into two clinical trial groups according to their } \\
\text { sequence of ICU admittance }\end{array}$ \\
\hline Maloney 2007 & $\begin{array}{l}\text { Not evaluating a closed loop automated system } \\
\text { McKinley } 2001\end{array}$ \\
\hline $\begin{array}{l}\text { Reporting data on a subset of trauma patients from the East } 1999 \text { study. Not evaluating a closed } \\
\text { loop automated system }\end{array}$ \\
\hline
\end{tabular}

\section{Characteristics of studies awaiting assessment [ordered by study ID]}

\section{Alander/Kontiokari 2010}

\begin{tabular}{ll}
\hline Methods & Randomized controlled trial \\
\hline Participants & $\begin{array}{l}\text { All children from term newborn ( } 37+0 \text { gestational week) to } 16 \text { years old needing ventilatory care at } \\
\text { least } 30 \text { minutes. Exclusion criteria are: any condition that prevents feeding tube positioning. Criti- } \\
\text { cal ventilatory or perfusion problems }\end{array}$ \\
\hline Interventions & Intervention: NAVA \\
& $\begin{array}{l}\text { Control: pressure controlled ventilation for newborns; older children will be treated with pressure } \\
\text { regulated volume controlled (PRVC) ventilation }\end{array}$ \\
\hline Outcomes & Duration of mechanical ventilation \\
& Amount of sedative medication needed
\end{tabular}


Alander/Kontiokari 2010 (Continued)

Notes

NCT01056939

Domingo 2010

\begin{tabular}{ll}
\hline Methods & Single centre parallel group allocation \\
\hline Participants & Post cardiac surgery patients \\
\hline Interventions & Intervention: adaptive support ventilation \\
& Control: standard protocol using T-piece weaning \\
\hline Outcomes & Duration of weaning \\
& Duration of tracheal intubation \\
& Length of ICU stay \\
& Length of hospital stay \\
& Reintubation \\
Rates of ventilator associated pneumonia and pneumothorax
\end{tabular}

\section{Fayed 2013}

\begin{tabular}{ll}
\hline Methods & Randomized controlled trial \\
\hline Participants & Adults admitted to ICU for acute exacerbation of COPD \\
\hline Interventions & Intervention: ASV \\
& Control: pressure support weaning \\
\hline Outcomes & Weaning success \\
& Duration of ventilation \\
& Length of ICU stay \\
Length of hospital stay \\
\hline Notes & Presented at 2013 ESICM annual meeting; available in abstract form \\
\hline
\end{tabular}

\section{Fernandez 2013}

\begin{tabular}{ll}
\hline Methods & Multi-centre randomized controlled trial \\
\hline Participants & Adults 18 years of age or older with an anticipated duration of mechanical ventilation $>24$ hours \\
\hline
\end{tabular}


Fernandez 2013 (Continued)

Interventions
Intervention: ventilatory support performed by PAV at $80 \%$ assistance (PB 840-plus) $\mathrm{FiO}_{2}$ and PEEP according to routine practice

Control: assist-control ventilation, tidal volume, $\mathrm{FiO}_{2}$ and $\mathrm{PEEP}$ set according to routine practice

Notes NCT01204281

$\operatorname{Lim} 2012$

\begin{tabular}{ll}
\hline Methods & Single centre randomized controlled trial \\
\hline Participants & Adults 21 years of age or older, assisted-mode mechanical ventilation $>24$ hrs, stable neurology \\
\hline Interventions & Intervention: SmartCare/PS \\
& Control: usual care \\
\hline Outcomes & Total weaning time (time from inclusion to extubation without reintubation for 72 hrs) \\
\hline Notes & Available in abstract form only \\
\hline
\end{tabular}

\section{Vogelsang 2003}

\begin{tabular}{ll}
\hline Methods & Single centre randomized controlled trial \\
\hline Participants & Children over 4 weeks old \\
\hline Interventions & Intervention: Automode \\
& Control: PRVC with manual switch to volume support \\
\hline Outcomes & Study randomization to successful extubation \\
& Duration of ventilation \\
& Time from randomization to switch to volume support \\
\hline Notes & Available in abstract only. Awaiting contact with study authors to clarify participant numbers \\
\hline
\end{tabular}

Automated versus non-automated weaning for reducing the duration of mechanical ventilation for critically ill adults and children 
Characteristics of ongoing studies [ordered by study ID]

Arnal/Suppini 2013

\begin{tabular}{|c|c|}
\hline Trial name or title & S4: Trial Of Fully Closed-Loop Ventilation In ICU \\
\hline Methods & Randomized controlled trial \\
\hline Participants & $\begin{array}{l}\text { Unselected ICU patients invasively ventilated for less than } 24 \text { hours, with an expected duration of } \\
\text { MV longer than } 48 \text { hour }\end{array}$ \\
\hline Interventions & Intellivent-ASV \\
\hline \multirow[t]{7}{*}{ Outcomes } & Numbers of manual adjustments until mechanical ventilation no longer needed \\
\hline & Sedation duration \\
\hline & Ventilation parameters \\
\hline & Sedation doses \\
\hline & Duration of invasive ventilation \\
\hline & ICU mortality \\
\hline & 28 days mortality \\
\hline Starting date & November 2012 \\
\hline Contact information & jean-michel.arnal@ch-toulon.fr; jean-philippe.suppini@ch-toulon.fr \\
\hline Notes & NCT01781091 \\
\hline
\end{tabular}

\section{Beale 2004}

Trial name or title

Comparison of an automated weaning programme and a standard clinical weaning protocol for weaning critically ill patients: a randomized controlled trial

\begin{tabular}{ll}
\hline Methods & Randomized controlled trial \\
\hline Participants & $\begin{array}{l}\text { Adults } \geq 18 \text { years with suspected or proven infection, presence of a systemic response to the infec- } \\
\text { tion within the } 48 \text {-hour period immediately preceding enrolment into the study, have or have had } \\
\text { one or more sepsis-induced organ failures within the } 48 \text {-hour period immediately preceding enrol- } \\
\text { ment into the study with an expected length of stay in the ICU }>3 \text { days }\end{array}$ \\
\hline Interventions & Intervention: Smartcare/PS \\
Control: weaning from mechanical ventilation using the standard protocol \\
\hline Outcomes & Time from the initiation of weaning to successful separation of the patient from the ventilator, de- \\
fined as no longer needing mechanical ventilation for a minimum period of 48 hours \\
Mortality (28-day, ICU and hospital, six months) \\
Infectious complications (e.g. pneumonia, wound infection, abscesses) \\
APACHE II \\
Organ failure-free days
\end{tabular}

Automated versus non-automated weaning for reducing the duration of mechanical ventilation for critically ill adults and children 
Beale 2004 (Continued)
LOS in ICU
LOS in hospital (intervention until discharge)
Duration of antibiotic treatment (antibiotics days)
Duration of ventilation (ventilator days)
Duration of renal support

\begin{tabular}{ll}
\hline Starting date & Dec 12004 \\
\hline Contact information & $\begin{array}{l}\text { Richard Beale, Adult ICU East Wing St Thomas' Hospital Lambeth Palace Rd, London, United King- } \\
\text { dom, +44 (0)20 7188 3038, Richard.Beale@gstt.nhs.uk }\end{array}$ \\
\hline Notes & ISRCTN82559457 \\
\hline
\end{tabular}

Bosma 2012

\begin{tabular}{|c|c|}
\hline Trial name or title & Comparison of weaning on pressure support vs. Proportional Assist Ventilation: a pilot study \\
\hline Methods & Randomized controlled trial \\
\hline Participants & $\begin{array}{l}\text { Mechanically ventilated patients } \geq 18 \text { years who are ready to begin weaning according to prespeci- } \\
\text { fied eligibility criteria, and tolerate } 30 \text { minutes of pressure support ventilation, but are not ready for } \\
\text { extubation, defined as an } \mathrm{f} / \mathrm{Vt}>105 \text { after } 2 \text { minutes of CPAP or failing a spontaneous breathing trial } \\
\text { on PSV } 5 \mathrm{cmH}_{2} \mathrm{O}\end{array}$ \\
\hline \multirow[t]{2}{*}{ Interventions } & Intervention: weaning with $\mathrm{PAV}^{+}$ \\
\hline & Control: weaning using pressure support \\
\hline \multirow[t]{5}{*}{ Outcomes } & $\begin{array}{l}\text { Duration of weaning: (1) randomization to successfully passing a spontaneous breathing trial; and } \\
\text { (2) randomization to successful extubation }\end{array}$ \\
\hline & $\begin{array}{l}\text { Number of ventilator free days (alive and free of mechanical ventilation } 28 \text { days post-randomiza- } \\
\text { tion }\end{array}$ \\
\hline & Change in asynchrony index from baseline \\
\hline & Change in sedative drug administration from baseline \\
\hline & Delirium \\
\hline Starting date & March 2009 \\
\hline \multirow[t]{2}{*}{ Contact information } & KarenJ.Bosma@lhsc.on.ca \\
\hline & TraceyC.Bentall@lhsc.on.ca \\
\hline Notes & \\
\hline
\end{tabular}

\section{Botha 2013}

Trial name or title

PAV+ VENTILATION TRIAL- A randomised controlled trial comparing Proportional Assist Ventilation

$(\mathrm{PAV}+)$ ventilation and pressure support ventilation in patients eligible for spontaneous ventilation

Automated versus non-automated weaning for reducing the duration of mechanical ventilation for critically ill adults and children 
Botha 2013 (Continued)

Methods Randomized controlled trial

Participants Adults ventilated for at least 48 hours on a mode other than PAV+ or PS, and deemed ready for
spontaneous ventilation

Interventions Intervention: Proportional Assist Ventilation $\left(\mathrm{PAV}^{+}\right)$

Control: weaning using pressure support

\begin{tabular}{ll}
\hline Outcomes & Duration of ventilation \\
& Length of ICU stay \\
& Length of hospital stay \\
& ICU mortality \\
& Hospital mortality \\
& Reintubation rate \\
\hline Starting date & Nov 2012 \\
\hline Contact information & John Botha jbotha@phcn.vic.gov.au \\
\hline Notes & ACTRN12612001097831 \\
\hline
\end{tabular}

\section{Hadfield/Hart 2013}

\begin{tabular}{ll}
\hline Trial name or title & $\begin{array}{l}\text { A randomised feasibility study examining Neurally-adjusted Ventilatory Assist (NAVA) in patients at } \\
\text { high risk of prolonged ventilatory failure during recovery from critical illness }\end{array}$ \\
\hline Methods & Randomized controlled trial \\
\hline Participants & $\begin{array}{l}\text { Adaults admitted to ICU who are likely to remain intubated and ventilated for greater than 48 hours } \\
\text { with a diagnosis of one or a combination of COPD and left and/or right ventricular heart failure }\end{array}$ \\
\hline Interventions & Intervention: NAVA \\
Control: usual weaning practice \\
\hline Outcomes & Ventilator free days \\
\hline Starting date & May 2013 \\
\hline Contact information & daniel.hadfield@nhs.net; p.hopkins@nhs.net \\
\hline Notes & NCT01826890 \\
\hline
\end{tabular}

\section{Kacmarek 2013}

Trial name or title

A comparative, multicenter, randomized, controlled study of neurally adjusted ventilatory assist (NAVA) vs. conventional lung protective ventilation in patients with acute respiratory failure 
Kacmarek 2013 (Continued)

Methods Multicenter, randomized, controlled trial

Participants

Adults with hypoxaemic or hypercapnic acute respiratory failure requiring intubation and mechanical ventilation anticipated for longer than $72 \mathrm{hrs}$

Interventions Intervention: NAVA

Control: Conventional lung protective ventilation

\begin{tabular}{ll}
\hline Outcomes & Number of invasive ventilator free days \\
& Total length of mechanical ventilation (invasive plus non-invasive) \\
& Length of ICU stay \\
& Length of hospital stay \\
& 90 day mortality \\
& Ventilator associated pneumonia \\
& Incidence of barotrauma \\
& Development of acute respiratory distress syndrome \\
\hline Starting date & January 2013 \\
\hline Contact information & Robert Kacmarek rkacmarek@partners.org; dsulemanji@partners.org \\
\hline Notes & NCT01730794 \\
\hline
\end{tabular}

Kirakli 2012

\begin{tabular}{ll}
\hline Trial name or title & Closed loop ventilation strategy in Intensive Care Unit (ICU) patients \\
\hline Methods & Randomized controlled trial \\
\hline Participants & $\begin{array}{l}\text { Adults intubated and mechanically ventilated ICU patients for more than 24 hours. Patients receiv- } \\
\text { ing ventilation via tracheostomy will be excluded }\end{array}$ \\
\hline Interventions & Intervention: Adaptive Support Ventilation according to the patients ideal body weight \\
\hline Cutcomes & Duntrol: Pressure Controlled Ventilation (6-8 ml/kg tidal volume) according to our ICU protocol \\
\hline Starting date & April 2012 \\
\hline Contact information & $\begin{array}{l}\text { Cenk Kirakli, +905052352024, ckirakli@hotmail.com, Izmir Chest Diseases and Surgery Education } \\
\text { and Research Hospital, Intensive Care Unit, Izmir, Yenisehir, Turkey }\end{array}$ \\
\hline Notes & NCT01472302 \\
\hline
\end{tabular}


Liu/Qui 2010

\begin{tabular}{|c|c|}
\hline Trial name or title & Effect of NAVA on duration of weaning in difficult to wean patients \\
\hline Methods & Randomized controlled trial \\
\hline Participants & $\begin{array}{l}\text { Intubated patients deemed ready for extubation by the clinical team but who fail the first sponta- } \\
\text { neous breathing trials (SBT) or weaning attempt. }\end{array}$ \\
\hline \multirow[t]{2}{*}{ Interventions } & Intervention: Neurally adjusted ventilatory assist (NAVA) \\
\hline & Control: Pressure Support Ventilation weaning \\
\hline \multirow[t]{4}{*}{ Outcomes } & Duration of weaning was defined as time from study enrolment to extubation \\
\hline & Extubation rate defined as the percentage of patients with successful weaning \\
\hline & $\begin{array}{l}\text { Diaphragmatic function was measured by neuro-ventilatory efficiency (NVE), a ratio of tidal volume } \\
\text { to diaphragm electrical activity (Vt/EAdi), and neuro-mechanical efficiency (NME), a ratio of airway } \\
\text { pressure to EAdi(Paw/EAdi) during airway occlusion }\end{array}$ \\
\hline & $\begin{array}{l}\text { Patient ventilator asynchrony (time delay between neuro-inspiration and ventilator delivery. Time } \\
\text { delay between neuro expiration and ventilator cycle-off) }\end{array}$ \\
\hline Starting date & December 2010 \\
\hline Contact information & $\begin{array}{l}\text { Ling Liu+86-25-83272201 liuling6600@yahoo.com.cn; Haibo Qiu +86-25-83272200 haiboq2000@ya- } \\
\text { hoo.com.cn, Nanjing Zhong-Da Hospital, Nanjing, Jiangsu, China }\end{array}$ \\
\hline Notes & NCT01280773 \\
\hline
\end{tabular}

\section{Navalesi 2012}

Trial name or title

Effects of two different ventilatory modes i.e., neurally adjusted ventilatory assist and pressure support ventilation on duration of mechanical ventilation and intensive care unit length of stay in patients with acute respiratory failure. A multicenter randomized clinical trial

\begin{tabular}{ll}
\hline Methods & Randomized controlled trial \\
\hline Participants & Adults intubated for $>24$ hours \\
\hline Interventions & Intervention: NAVA \\
& Control: not stated in trial registration \\
\hline
\end{tabular}

Duration of mechanical ventilation: intubation to successful extubation(expressed in days)
ICU length of stay
Hospital length of stay
Hospital charges
Tracheostomy
Reintubation
Weaning time


Navalesi 2012 (Continued)

Paolo Navalesi:

Notes ACTRN12612000815864

\section{Zhu 2011}

\begin{tabular}{|c|c|}
\hline Trial name or title & $\begin{array}{l}\text { Prospective randomized controlled trial comparing adaptive-support ventilation with routine } \\
\text { weaning protocol after valve surgery }\end{array}$ \\
\hline Participants & Adults following cardiac valve surgery (isolated valve surgery or combined with CABG) \\
\hline Interventions & $\begin{array}{l}\text { Intervention: ASV } \\
\text { Control: routine weaning }\end{array}$ \\
\hline Outcomes & $\begin{array}{l}\text { Duration of intubation } \\
\text { Postoperative hospital mortality } \\
\text { Complications including major bleeding, sepsis } \\
\text { Reintubation rate }\end{array}$ \\
\hline Starting date & December 2011 \\
\hline Contact information & Zhu Fang +852 26321912 carolchan@cuhk.edu.hk; alicewywong@cuhk.edu.hk \\
\hline Notes & ChiCTR-TRC-11001794 \\
\hline
\end{tabular}

\section{DATA AND ANALYSES}

Comparison 1. Primary analysis: automated closed loop system versus non-automated system

\begin{tabular}{llllll}
\hline Outcome or subgroup title & No. of studies & $\begin{array}{l}\text { No. of partici- } \\
\text { pants }\end{array}$ & Statistical method & Effect size \\
\hline $\begin{array}{l}\text { 1 Total weaning duration by } \\
\text { study population }\end{array}$ & 16 & 1246 & $\begin{array}{l}\text { Mean Difference (IV, Random, 95\% } \\
\text { Cl) }\end{array}$ & $-0.36[-0.59,-0.14]$ \\
\hline $\begin{array}{l}\text { 1.1 Mixed and medical ICU } \\
\text { population }\end{array}$ & 9 & 542 & $\begin{array}{l}\text { Mean Difference (IV, Random, 95\% } \\
\text { Cl) }\end{array}$ & $-0.55[1.00,-0.10]$ \\
\hline $\begin{array}{l}\text { 1.2 Surgical ICU population } \\
\text { n Total weaning duration by }\end{array}$ & 7 & & Mean Difference (IV, Random, 95\% & $-0.07[-0.18,0.04]$ \\
\hline \begin{tabular}{l} 
automated system \\
\hline
\end{tabular} & 704 & 1246 & $\begin{array}{l}\text { Mean Difference (IV, Random, 95\% } \\
\text { Cl) }\end{array}$ & $-0.36[-0.59,-0.14]$ \\
\hline
\end{tabular}




\begin{tabular}{|c|c|c|c|c|}
\hline Outcome or subgroup title & No. of studies & $\begin{array}{l}\text { No. of partici- } \\
\text { pants }\end{array}$ & Statistical method & Effect size \\
\hline 2.1 Smartcare/PS & 7 & 744 & $\begin{array}{l}\text { Mean Difference (IV, Random, 95\% } \\
\mathrm{CI})\end{array}$ & $-0.33[-0.58,-0.09]$ \\
\hline 2.2 ASV & 4 & 295 & $\begin{array}{l}\text { Mean Difference (IV, Random, 95\% } \\
\mathrm{Cl} \text { ) }\end{array}$ & $-0.03[-0.11,0.05]$ \\
\hline 2.3 Other & 5 & 207 & $\begin{array}{l}\text { Mean Difference (IV, Random, 95\% } \\
\mathrm{CI})\end{array}$ & $-0.54[-1.17,0.08]$ \\
\hline $\begin{array}{l}3 \text { Total weaning duration } \\
\text { by non-automated strategy } \\
\text { (control arm) }\end{array}$ & 16 & 1246 & $\begin{array}{l}\text { Mean Difference (IV, Random, 95\% } \\
\mathrm{CI})\end{array}$ & $-0.36[-0.59,-0.14]$ \\
\hline 3.1 usual care & 5 & 238 & $\begin{array}{l}\text { Mean Difference (IV, Random, 95\% } \\
\mathrm{Cl} \text { ) }\end{array}$ & $-0.46[-0.83,-0.10]$ \\
\hline $\begin{array}{l}3.2 \text { protocolized weaning } \\
\text { (non-automated) }\end{array}$ & 11 & 1008 & $\begin{array}{l}\text { Mean Difference (IV, Random, 95\% } \\
\mathrm{CI})\end{array}$ & $-0.32[-0.59,-0.06]$ \\
\hline $\begin{array}{l}4 \text { Randomization to first extu- } \\
\text { bation }\end{array}$ & 11 & 1039 & $\begin{array}{l}\text { Mean Difference (IV, Random, 95\% } \\
\mathrm{Cl} \text { ) }\end{array}$ & $-0.20[-0.34,-0.05]$ \\
\hline $\begin{array}{l}5 \text { Ventilation duration by } \\
\text { study population }\end{array}$ & 14 & 1248 & $\begin{array}{l}\text { Mean Difference (IV, Random, 95\% } \\
\mathrm{Cl} \text { ) }\end{array}$ & $-0.11[-0.18,-0.03]$ \\
\hline $\begin{array}{l}5.1 \text { Mixed and medical ICU } \\
\text { population }\end{array}$ & 9 & 777 & $\begin{array}{l}\text { Mean Difference (IV, Random, 95\% } \\
\mathrm{CI})\end{array}$ & $-0.14[-0.25,-0.02]$ \\
\hline 5.2 Surgical ICU population & 5 & 471 & $\begin{array}{l}\text { Mean Difference (IV, Random, 95\% } \\
\mathrm{CI})\end{array}$ & $-0.12[-0.26,0.01]$ \\
\hline $\begin{array}{l}6 \text { Ventilation duration of by } \\
\text { automated system }\end{array}$ & 11 & 1002 & $\begin{array}{l}\text { Mean Difference (IV, Random, 95\% } \\
\mathrm{Cl} \text { ) }\end{array}$ & $-0.09[-0.18,-0.00]$ \\
\hline 6.1 Smartcare/PS & 6 & 706 & $\begin{array}{l}\text { Mean Difference (IV, Random, 95\% } \\
\mathrm{Cl} \text { ) }\end{array}$ & $-0.17[-0.31,-0.03]$ \\
\hline $6.2 \mathrm{ASV}$ & 5 & 296 & $\begin{array}{l}\text { Mean Difference (IV, Random, 95\% } \\
\mathrm{Cl} \text { ) }\end{array}$ & $-0.04[-0.15,0.07]$ \\
\hline $\begin{array}{l}7 \text { Ventilation duration of by } \\
\text { non-automated strategy } \\
\text { (control arm) }\end{array}$ & 14 & 1248 & $\begin{array}{l}\text { Mean Difference (IV, Random, 95\% } \\
\mathrm{Cl} \text { ) }\end{array}$ & $-0.11[-0.18,-0.03]$ \\
\hline 7.1 Usual care & 2 & 132 & $\begin{array}{l}\text { Mean Difference (IV, Random, 95\% } \\
\mathrm{Cl} \text { ) }\end{array}$ & $-0.11[-0.39,0.17]$ \\
\hline $\begin{array}{l}7.2 \text { Protocolized weaning } \\
\text { (non-automated) }\end{array}$ & 12 & 1116 & $\begin{array}{l}\text { Mean Difference (IV, Random, 95\% } \\
\mathrm{Cl} \text { ) }\end{array}$ & $-0.11[-0.19,-0.03]$ \\
\hline $\begin{array}{l}8 \text { Intubation to randomiza- } \\
\text { tion }\end{array}$ & 10 & 631 & $\begin{array}{l}\text { Mean Difference (IV, Random, 95\% } \\
\mathrm{Cl} \text { ) }\end{array}$ & $-0.04[-0.14,0.05]$ \\
\hline $\begin{array}{l}9 \text { Secondary outcome } 5.1 \text { : } \\
\text { mortality }\end{array}$ & 12 & 1128 & Risk Ratio (M-H, Random, 95\% Cl) & $1.04[0.83,1.31]$ \\
\hline
\end{tabular}




\begin{tabular}{|c|c|c|c|c|}
\hline Outcome or subgroup title & No. of studies & $\begin{array}{l}\text { No. of partici- } \\
\text { pants }\end{array}$ & Statistical method & Effect size \\
\hline 9.1 ICU mortality & 6 & 254 & Risk Ratio (M-H, Random, 95\% Cl) & $1.23[0.58,2.60]$ \\
\hline 9.230 day mortality & 2 & 397 & Risk Ratio (M-H, Random, 95\% Cl) & $1.14[0.75,1.75]$ \\
\hline 9.3 Hospital & 4 & 477 & Risk Ratio (M-H, Random, 95\% Cl) & $0.95[0.62,1.45]$ \\
\hline 10 Hospital length of stay & 7 & 749 & $\begin{array}{l}\text { Mean Difference (IV, Random, 95\% } \\
\mathrm{Cl} \text { ) }\end{array}$ & $-0.10[-0.21,0.02]$ \\
\hline $\begin{array}{l}11 \text { ICU length of stay by ICU } \\
\text { population }\end{array}$ & 13 & 1339 & $\begin{array}{l}\text { Mean Difference (IV, Random, 95\% } \\
\mathrm{Cl} \text { ) }\end{array}$ & $-0.08[-0.16,0.00]$ \\
\hline $\begin{array}{l}\text { 11.1 Mixed or medical ICU } \\
\text { population }\end{array}$ & 8 & 760 & $\begin{array}{l}\text { Mean Difference (IV, Random, 95\% } \\
\mathrm{CI})\end{array}$ & $-0.18[-0.32,-0.04]$ \\
\hline 11.2 Surgical ICU population & 5 & 579 & $\begin{array}{l}\text { Mean Difference (IV, Random, 95\% } \\
\mathrm{CI})\end{array}$ & $0.02[-0.02,0.06]$ \\
\hline $\begin{array}{l}12 \text { ICU length of stay by auto- } \\
\text { mated system }\end{array}$ & 12 & 1131 & $\begin{array}{l}\text { Mean Difference (IV, Random, 95\% } \\
\mathrm{CI})\end{array}$ & $-0.10[-0.19,-0.01]$ \\
\hline 12.1 Smartcare/PS & 6 & 707 & $\begin{array}{l}\text { Mean Difference (IV, Random, 95\% } \\
\mathrm{CI})\end{array}$ & $-0.26[-0.43,-0.09]$ \\
\hline 12.2 ASV & 6 & 424 & $\begin{array}{l}\text { Mean Difference (IV, Random, 95\% } \\
\mathrm{CI})\end{array}$ & $0.02[-0.02,0.06]$ \\
\hline 13 Reintubation & 13 & 1081 & Risk Ratio $(\mathrm{M}-\mathrm{H}$, Random, 95\% Cl) & $0.80[0.61,1.05]$ \\
\hline 13.1 Usual care & 4 & 182 & Risk Ratio (M-H, Random, 95\% Cl) & $0.71[0.27,1.88]$ \\
\hline $\begin{array}{l}\text { 13.2 Protocolized weaning } \\
\text { (non-automated) }\end{array}$ & 9 & 899 & Risk Ratio (M-H, Random, 95\% Cl) & $0.81[0.61,1.07]$ \\
\hline 14 Self-extubation & 9 & 813 & Risk Ratio (M-H, Random, 95\% Cl) & $1.24[0.58,2.67]$ \\
\hline 15 Non invasive ventilation & 12 & 1314 & Risk Ratio (M-H, Random, 95\% Cl) & $0.73[0.53,1.02]$ \\
\hline $\begin{array}{l}16 \text { Prolonged mechanical } \\
\text { ventilation }\end{array}$ & 7 & 753 & Risk Ratio (M-H, Random, 95\% Cl) & $0.51[0.27,0.95]$ \\
\hline 17 Tracheostomy & 9 & 962 & Risk Ratio (M-H, Random, 95\% Cl) & $0.67[0.50,0.90]$ \\
\hline
\end{tabular}

Analysis 1.1. Comparison 1 Primary analysis: automated closed loop system versus non-automated system, Outcome 1 Total weaning duration by study population.

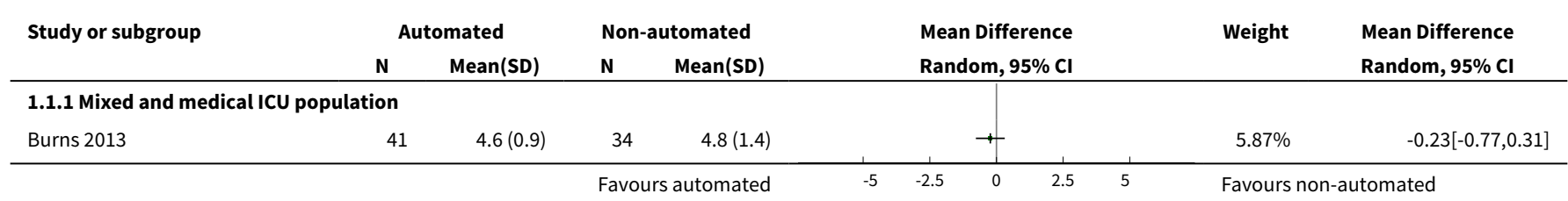




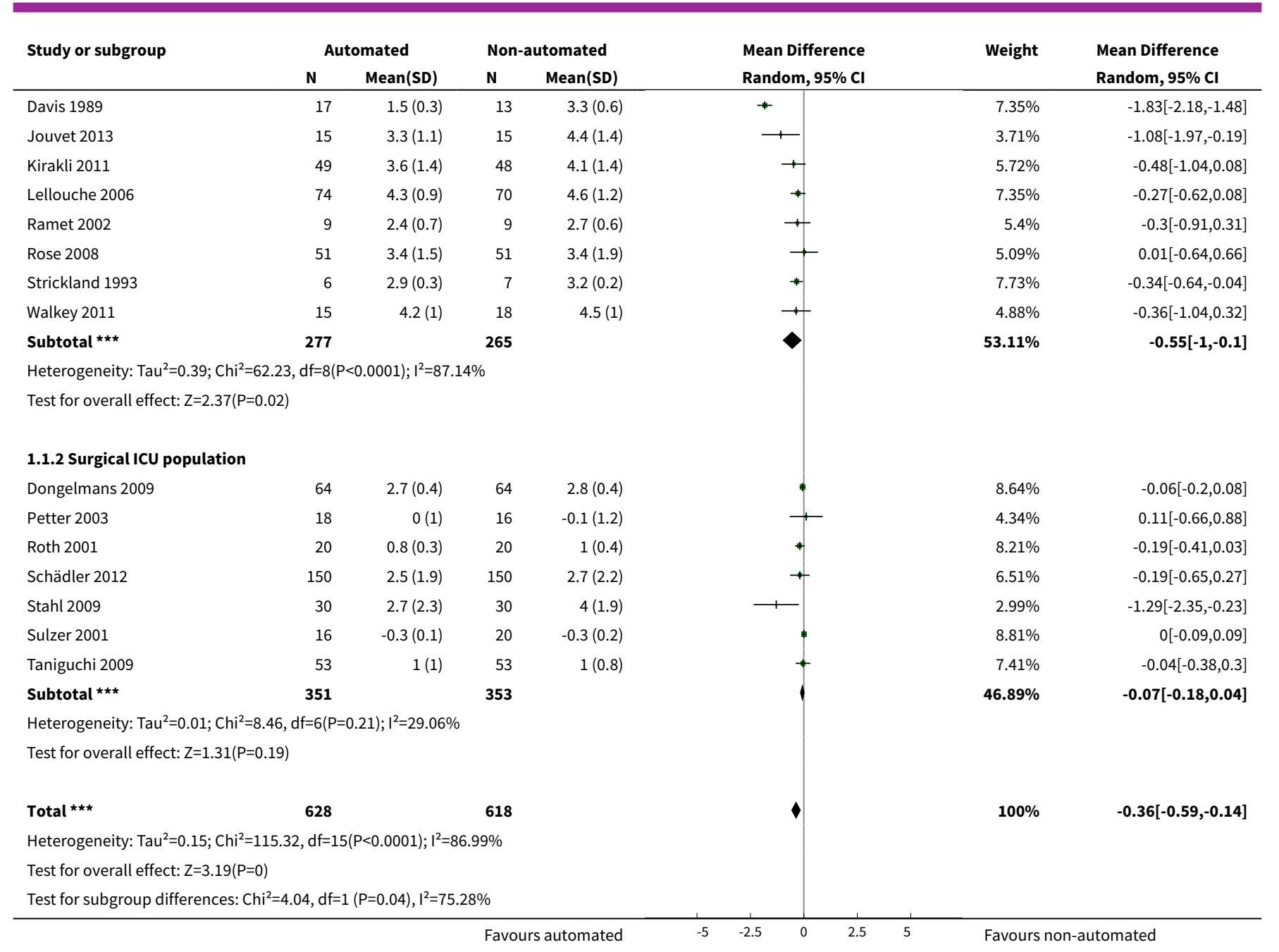

\section{Analysis 1.2. Comparison 1 Primary analysis: automated closed loop system versus non-automated system, Outcome 2 Total weaning duration by automated system.}

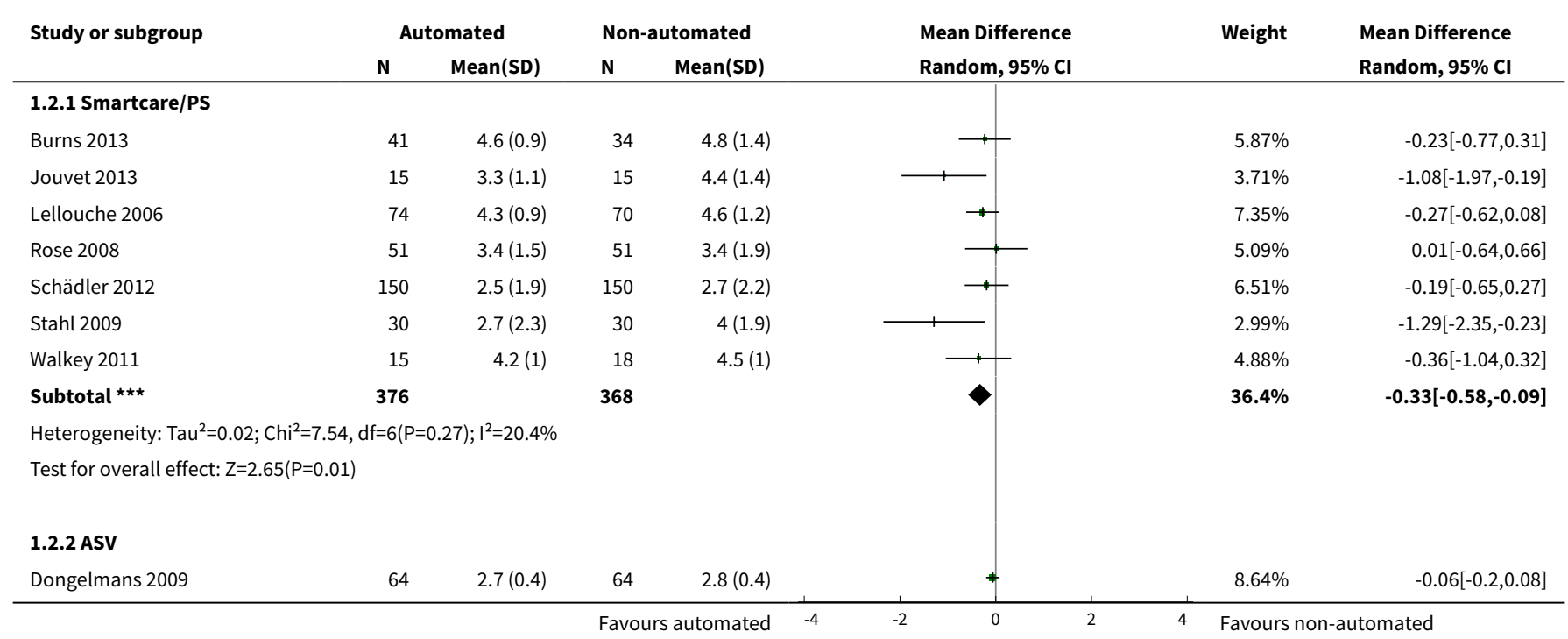




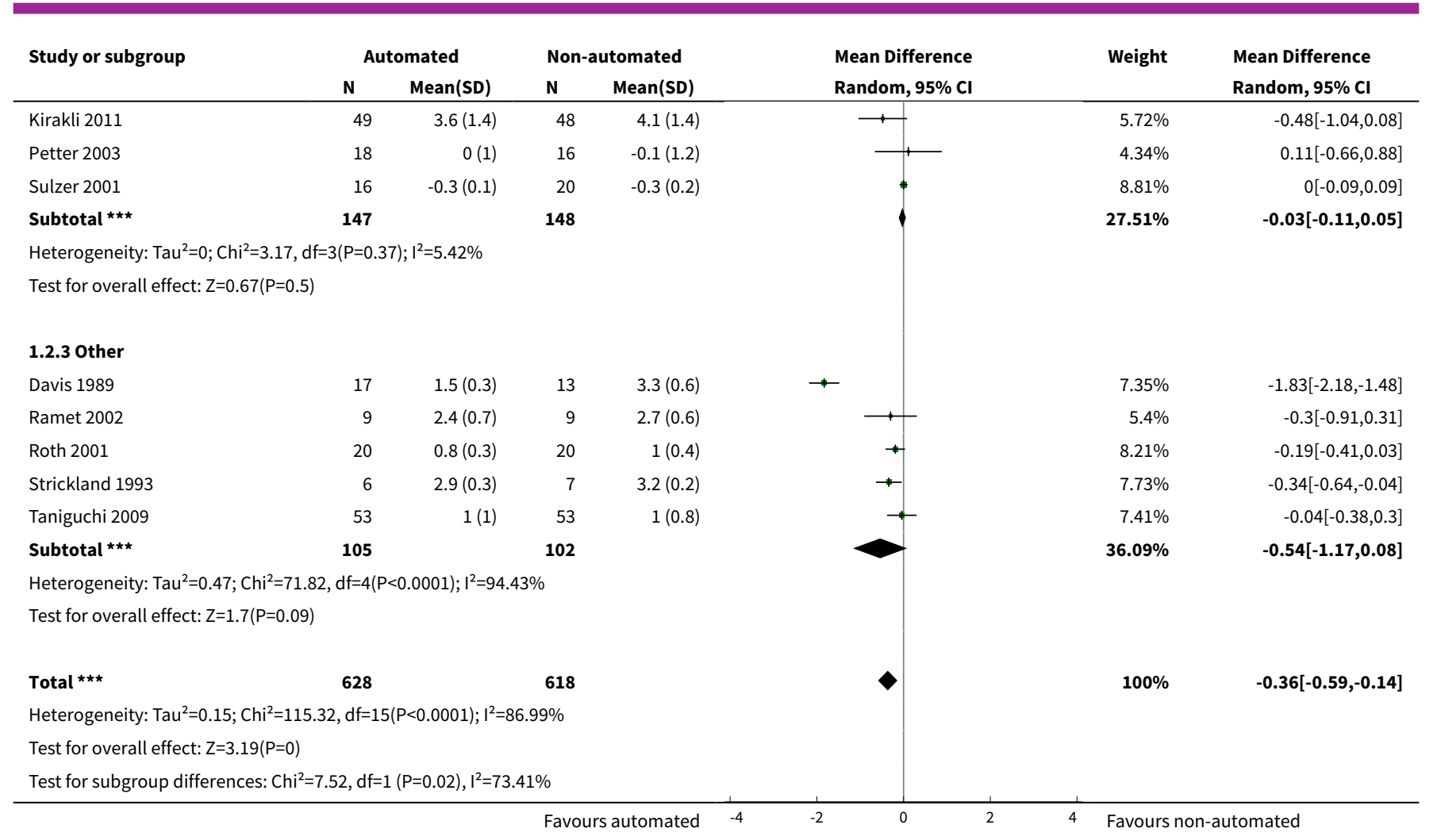

Analysis 1.3. Comparison 1 Primary analysis: automated closed loop system versus nonautomated system, Outcome 3 Total weaning duration by non-automated strategy (control arm).

\begin{tabular}{|c|c|c|c|c|c|c|c|c|}
\hline \multirow{3}{*}{$\begin{array}{l}\text { Study or subgroup } \\
\text { 1.3.1 usual care }\end{array}$} & \multicolumn{2}{|c|}{ Automated } & \multicolumn{2}{|c|}{ Non-automated } & \multirow{2}{*}{\multicolumn{2}{|c|}{$\begin{array}{l}\text { Mean Difference } \\
\text { Random, } 95 \% \mathrm{Cl}\end{array}$}} & \multirow[t]{2}{*}{ Weight } & \multirow{2}{*}{$\begin{array}{l}\text { Mean Difference } \\
\text { Random, } 95 \% \mathrm{Cl}\end{array}$} \\
\hline & \multirow[t]{2}{*}{$\mathbf{N}$} & \multirow[t]{2}{*}{ Mean(SD) } & \multirow[t]{2}{*}{$\mathbf{N}$} & \multirow{2}{*}{ Mean(SD) } & & & & \\
\hline & & & & & & & & \\
\hline Jouvet 2013 & 15 & $3.3(1.1)$ & 15 & $4.4(1.4)$ & $\longrightarrow$ & - & $3.71 \%$ & $-1.08[-1.97,-0.19]$ \\
\hline Rose 2008 & 51 & $3.4(1.5)$ & 51 & $3.4(1.9)$ & & & $5.09 \%$ & $0.01[-0.64,0.66]$ \\
\hline Stahl 2009 & 30 & $2.7(2.3)$ & 30 & $4(1.9)$ & & & $2.99 \%$ & $-1.29[-2.35,-0.23]$ \\
\hline Strickland 1993 & 6 & $2.9(0.3)$ & 7 & $3.2(0.2)$ & & $\rightarrow$ & $7.73 \%$ & $-0.34[-0.64,-0.04]$ \\
\hline 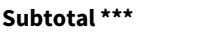 & 117 & & 121 & & & & $24.4 \%$ & $-0.46[-0.83,-0.1]$ \\
\hline \multicolumn{9}{|c|}{ Heterogeneity: $\mathrm{Tau}^{2}=0.07 ; \mathrm{Chi}^{2}=6.67, \mathrm{df}=4(\mathrm{P}=0.15) ; \mathrm{I}^{2}=40.02 \%$} \\
\hline \multicolumn{9}{|c|}{ Test for overall effect: $Z=2.46(P=0.01)$} \\
\hline \multicolumn{9}{|c|}{ 1.3.2 protocolized weaning (non-automated) } \\
\hline Burns 2013 & 41 & $4.6(0.9)$ & 34 & $4.8(1.4)$ & & $\rightarrow$ & $5.87 \%$ & $-0.23[-0.77,0.31]$ \\
\hline Dongelmans 2009 & 64 & $2.7(0.4)$ & 64 & $2.8(0.4)$ & & + & $8.64 \%$ & $-0.06[-0.2,0.08]$ \\
\hline Kirakli 2011 & 49 & $3.6(1.4)$ & 48 & $4.1(1.4)$ & & & $5.72 \%$ & $-0.48[-1.04,0.08]$ \\
\hline Lellouche 2006 & 74 & $4.3(0.9)$ & 70 & $4.6(1.2)$ & & 7 & $7.35 \%$ & $-0.27[-0.62,0.08]$ \\
\hline Petter 2003 & 18 & $0(1)$ & 16 & $-0.1(1.2)$ & & & $4.34 \%$ & $0.11[-0.66,0.88]$ \\
\hline Ramet 2002 & 9 & $2.4(0.7)$ & 9 & $2.7(0.6)$ & & - & $5.4 \%$ & $-0.3[-0.91,0.31]$ \\
\hline Roth 2001 & 20 & $0.8(0.3)$ & 20 & $1(0.4)$ & & $*$ & $8.21 \%$ & $-0.19[-0.41,0.03]$ \\
\hline Schädler 2012 & 150 & $2.5(1.9)$ & 150 & $2.7(2.2)$ & & 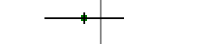 & $6.51 \%$ & $-0.19[-0.65,0.27]$ \\
\hline Sulzer 2001 & 16 & $-0.3(0.1)$ & 20 & $-0.3(0.2)$ & & + & $8.81 \%$ & $0[-0.09,0.09]$ \\
\hline
\end{tabular}




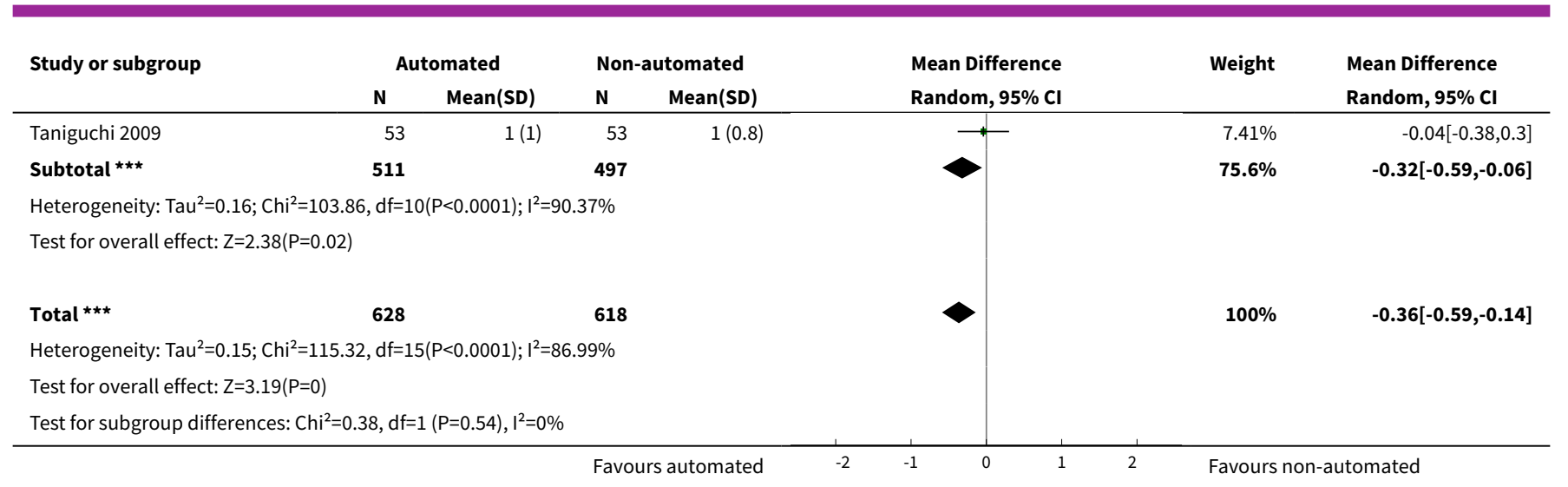

Analysis 1.4. Comparison 1 Primary analysis: automated closed loop system versus non-automated system, Outcome 4 Randomization to first extubation.

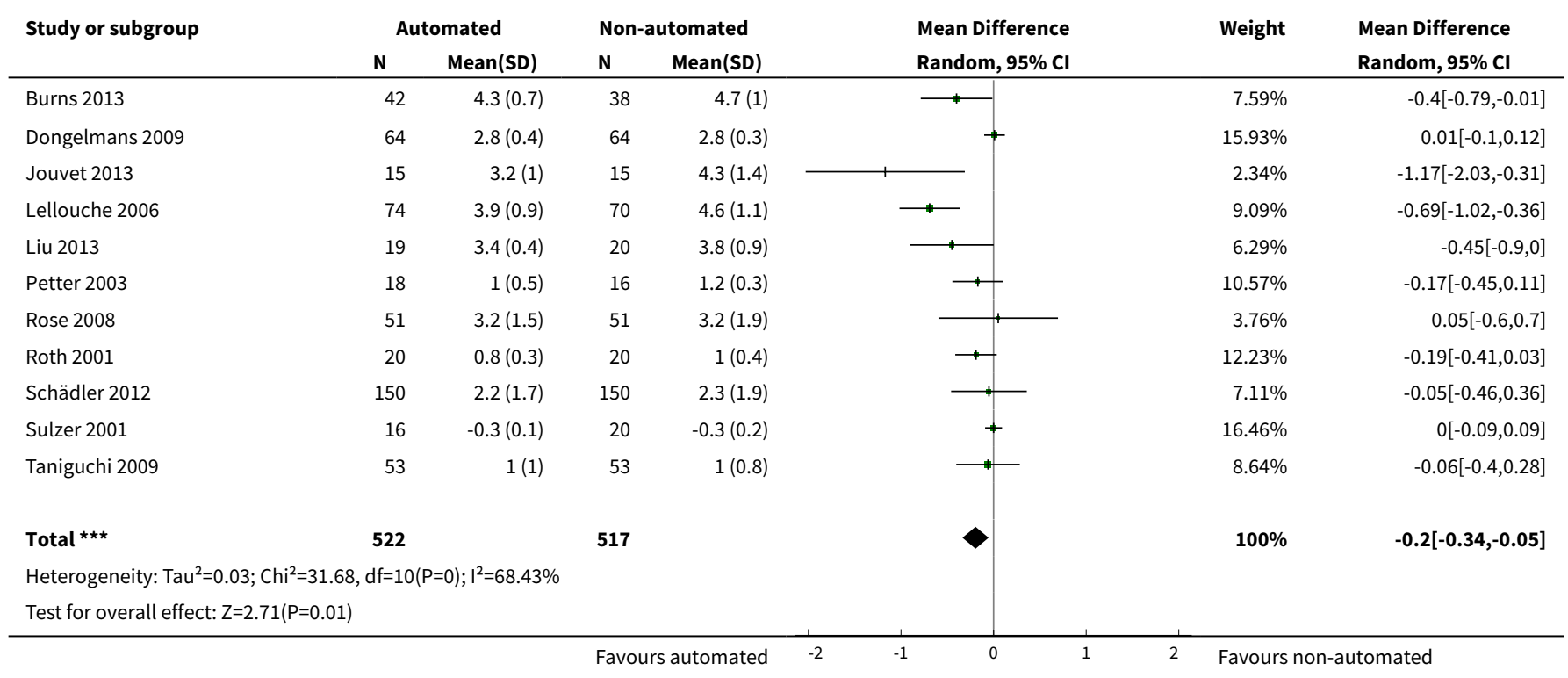

\section{Analysis 1.5. Comparison 1 Primary analysis: automated closed loop system versus non-automated system, Outcome 5 Ventilation duration by study population.}

\begin{tabular}{|c|c|c|c|c|c|c|c|}
\hline \multirow[t]{2}{*}{ Study or subgroup } & \multicolumn{2}{|c|}{ Automated } & \multicolumn{2}{|c|}{ Non-automated } & \multirow{2}{*}{$\begin{array}{l}\text { Mean Difference } \\
\text { Random, } 95 \% \mathrm{Cl}\end{array}$} & \multirow[t]{2}{*}{ Weight } & \multirow{2}{*}{$\begin{array}{l}\text { Mean Difference } \\
\text { Random, } 95 \% \mathrm{CI}\end{array}$} \\
\hline & $\mathbf{N}$ & Mean(SD) & $\mathbf{N}$ & Mean(SD) & & & \\
\hline \multicolumn{8}{|c|}{ 1.5.1 Mixed and medical ICU population } \\
\hline Agarwal 2013 & 23 & $4.8(1)$ & 25 & $5(0.9)$ & & $2.08 \%$ & $-0.18[-0.71,0.35]$ \\
\hline Burns 2013 & 48 & $5.5(0.6)$ & 43 & $5.6(1.1)$ & $\square$ & $4.43 \%$ & $-0.05[-0.41,0.31]$ \\
\hline Jouvet 2013 & 15 & $5(0.7)$ & 15 & $5.4(0.9)$ & $\leftarrow$ & $1.68 \%$ & $-0.32[-0.9,0.26]$ \\
\hline Kirakli 2011 & 49 & $5(0.9)$ & 48 & $5.1(0.9)$ & $\longrightarrow$ & $4.77 \%$ & $-0.12[-0.47,0.23]$ \\
\hline Lellouche 2006 & 74 & $5.1(0.8)$ & 70 & $5.3(1)$ & & $6.63 \%$ & $-0.24[-0.53,0.05]$ \\
\hline Liu 2013 & 19 & $4.9(0.5)$ & 20 & $5.3(0.9)$ & & $2.91 \%$ & $-0.34[-0.78,0.1]$ \\
\hline Ramet 2002 & 9 & $4.6(0.4)$ & 9 & $4.4(0.7)$ & $\longrightarrow$ & $2 \%$ & $0.24[-0.3,0.78]$ \\
\hline Rose 2008 & 51 & $4.8(0.8)$ & 51 & $4.8(0.9)$ & 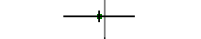 & $5.7 \%$ & $-0.05[-0.37,0.27]$ \\
\hline
\end{tabular}




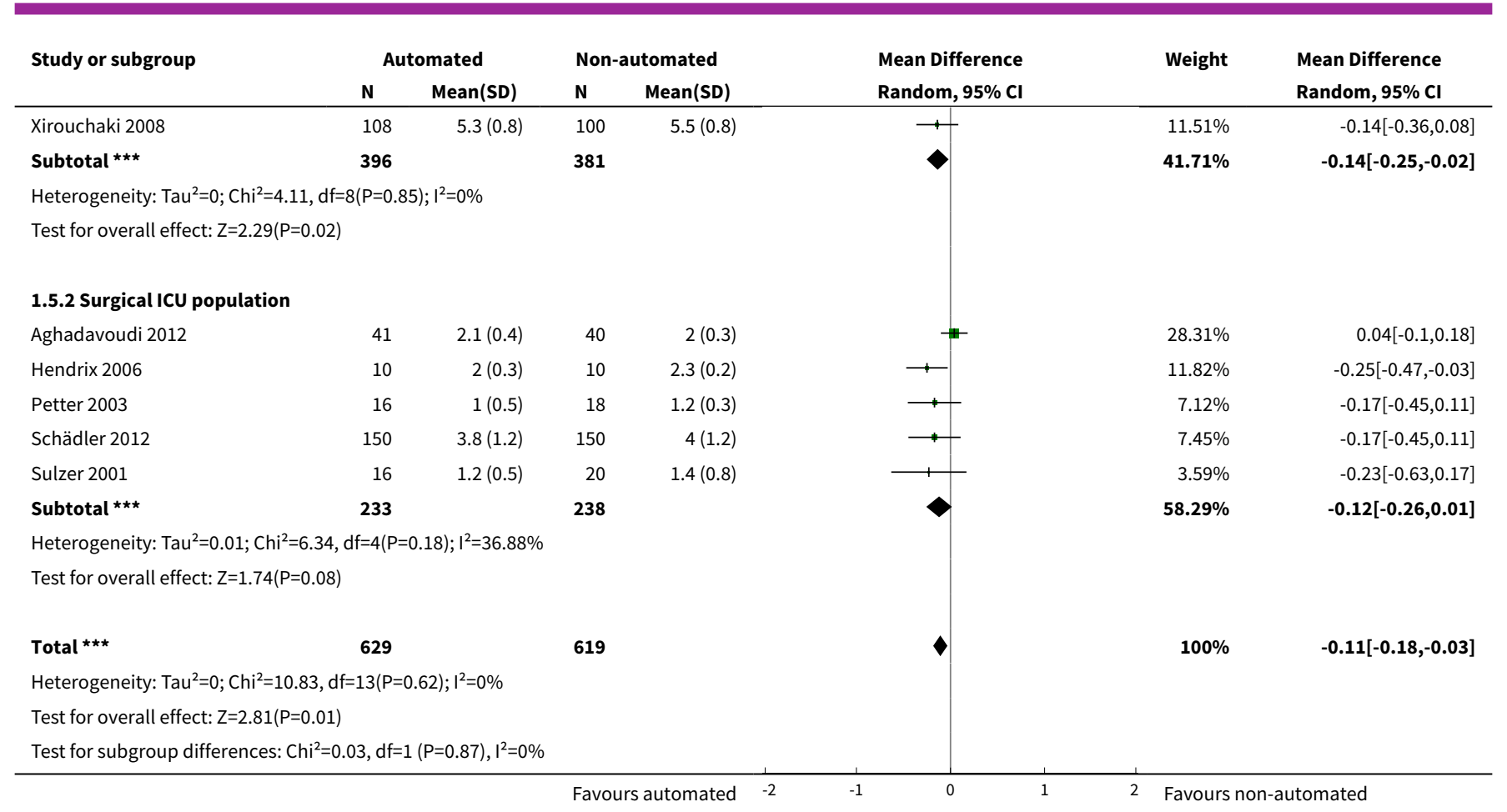

Analysis 1.6. Comparison 1 Primary analysis: automated closed loop system versus non-automated system, Outcome 6 Ventilation duration of by automated system.

\begin{tabular}{|c|c|c|c|c|c|c|c|}
\hline \multirow{3}{*}{$\begin{array}{l}\text { Study or subgroup } \\
\text { 1.6.1 Smartcare/PS }\end{array}$} & \multicolumn{2}{|c|}{ Automated } & \multicolumn{2}{|c|}{ Non-automated } & \multirow{2}{*}{$\begin{array}{l}\text { Mean Difference } \\
\text { Random, 95\% Cl }\end{array}$} & \multirow[t]{2}{*}{ Weight } & \multirow{2}{*}{$\begin{array}{l}\text { Mean Difference } \\
\text { Random, } 95 \% \mathrm{CI}\end{array}$} \\
\hline & \multirow[t]{2}{*}{$\mathbf{N}$} & \multirow[t]{2}{*}{$\operatorname{Mean}(S D)$} & \multirow[t]{2}{*}{$\mathbf{N}$} & \multirow[t]{2}{*}{$\operatorname{Mean}(\mathrm{SD})$} & & & \\
\hline & & & & & & & \\
\hline Burns 2013 & 48 & $5.5(0.6)$ & 43 & $5.6(1.1)$ & - & $5.93 \%$ & $-0.05[-0.41,0.31]$ \\
\hline Jouvet 2013 & 15 & $5(0.7)$ & 15 & $5.4(0.9)$ & - & $2.25 \%$ & $-0.32[-0.9,0.26]$ \\
\hline Lellouche 2006 & 74 & $5.1(0.8)$ & 70 & $5.3(1)$ & $\longrightarrow$ & $8.88 \%$ & $-0.24[-0.53,0.05]$ \\
\hline Liu 2013 & 19 & $4.9(0.5)$ & 20 & $5.3(0.9)$ & - & $3.9 \%$ & $-0.34[-0.78,0.1]$ \\
\hline Schädler 2012 & 150 & $3.8(1.2)$ & 150 & $4(1.2)$ & $\longrightarrow$ & $9.97 \%$ & $-0.17[-0.45,0.11]$ \\
\hline Subtotal $\star \star \star$ & 357 & & 349 & & & $38.58 \%$ & $-0.17[-0.31,-0.03]$ \\
\hline \multicolumn{8}{|c|}{ Heterogeneity: $\operatorname{Tau}^{2}=0 ; \mathrm{Chi}^{2}=2.02, \mathrm{df}=5(\mathrm{P}=0.85) ; \mathrm{I}^{2}=0 \%$} \\
\hline \multicolumn{8}{|c|}{ Test for overall effect: $Z=2.36(P=0.02)$} \\
\hline \multicolumn{8}{|l|}{ 1.6.2 ASV } \\
\hline Aghadavoudi 2012 & 41 & $2.1(0.4)$ & 40 & $2(0.3)$ & \# & $37.91 \%$ & $0.04[-0.1,0.18]$ \\
\hline Kirakli 2011 & 49 & $5(0.9)$ & 48 & $5.1(0.9)$ & $\longrightarrow$ & $6.39 \%$ & $-0.12[-0.47,0.23]$ \\
\hline Petter 2003 & 16 & $1(0.5)$ & 18 & $1.2(0.3)$ & $\rightarrow$ & $9.53 \%$ & $-0.17[-0.45,0.11]$ \\
\hline Sulzer 2001 & 16 & $1.2(0.5)$ & 20 & $1.4(0.8)$ & 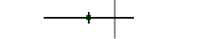 & $4.8 \%$ & $-0.23[-0.63,0.17]$ \\
\hline Subtotal $\star \star \star$ & 145 & & 151 & & & $61.42 \%$ & $-0.04[-0.15,0.07]$ \\
\hline \multicolumn{8}{|c|}{ Heterogeneity: Tau $^{2}=0 ; \mathrm{Chi}^{2}=3.37, \mathrm{df}=4(\mathrm{P}=0.5) ; \mathrm{I}^{2}=0 \%$} \\
\hline \multicolumn{8}{|c|}{ Test for overall effect: $\mathrm{Z}=0.71(\mathrm{P}=0.48)$} \\
\hline 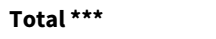 & 502 & & 500 & & 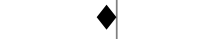 & $100 \%$ & $-0.09[-0.18,-0]$ \\
\hline \multicolumn{8}{|c|}{ Heterogeneity: $\mathrm{Tau}^{2}=0 ; \mathrm{Chi}^{2}=7.38, \mathrm{df}=10(\mathrm{P}=0.69) ; \mathrm{I}^{2}=0 \%$} \\
\hline & & & Favo & automated & 0 & Favours r & tomated \\
\hline
\end{tabular}

Automated versus non-automated weaning for reducing the duration of mechanical ventilation for critically ill adults and children 


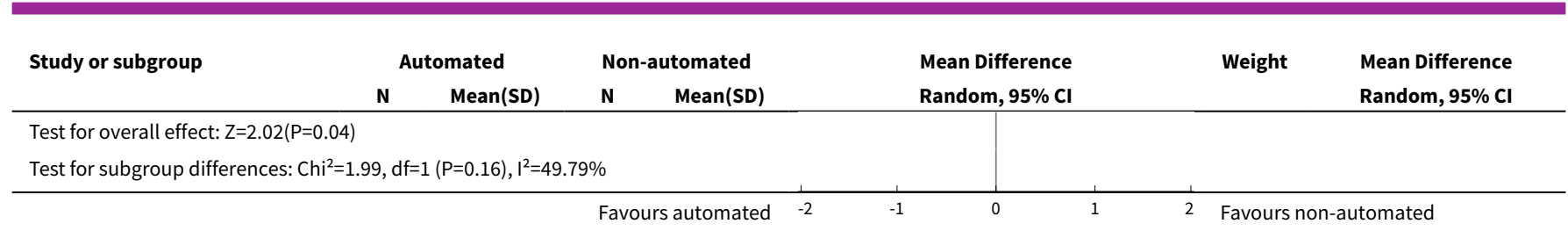

Analysis 1.7. Comparison 1 Primary analysis: automated closed loop system versus nonautomated system, Outcome 7 Ventilation duration of by non-automated strategy (control arm).

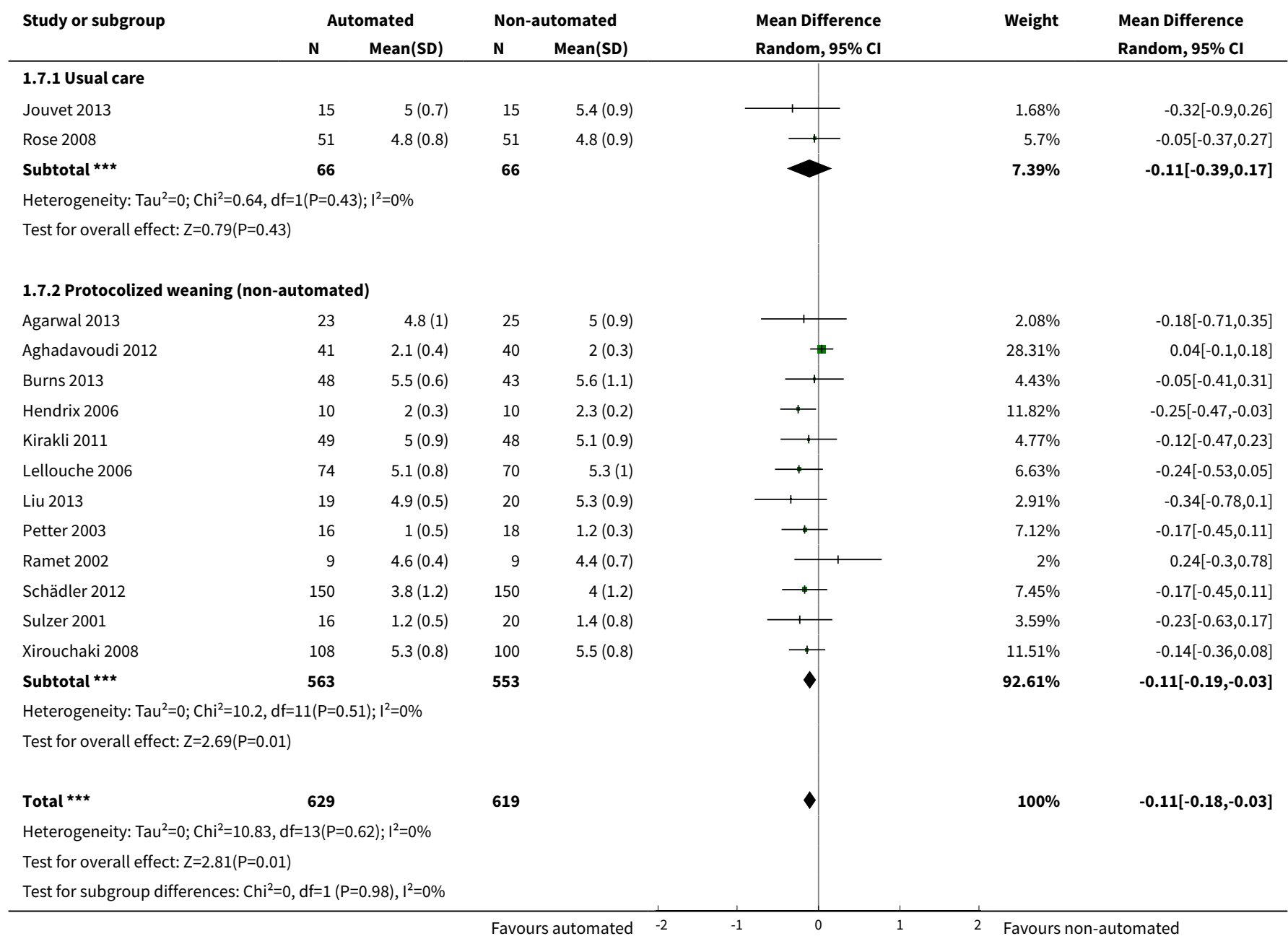

Analysis 1.8. Comparison 1 Primary analysis: automated closed loop system versus non-automated system, Outcome 8 Intubation to randomization.

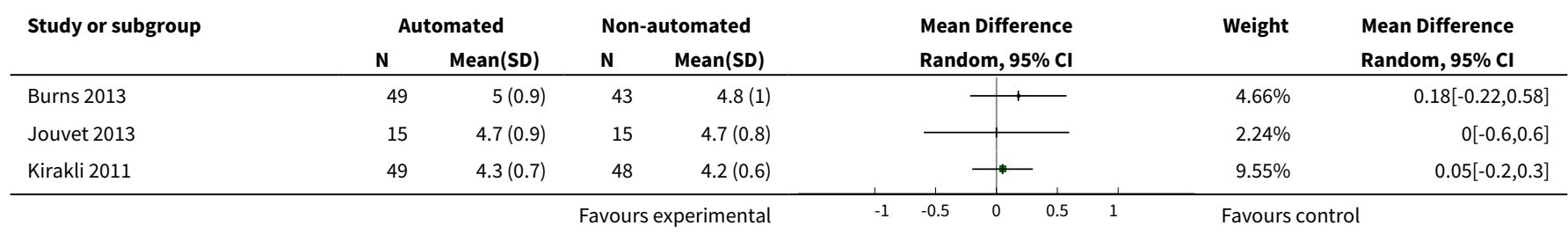

Automated versus non-automated weaning for reducing the duration of mechanical ventilation for critically ill adults and children 65 (Review)

Copyright (c) 2018 The Cochrane Collaboration. Published by John Wiley \& Sons, Ltd. 


\begin{tabular}{|c|c|c|c|c|c|c|c|}
\hline \multirow[t]{2}{*}{ Study or subgroup } & \multicolumn{2}{|c|}{ Automated } & \multicolumn{2}{|c|}{ Non-automated } & \multirow{2}{*}{$\begin{array}{l}\text { Mean Difference } \\
\text { Random, } 95 \% \mathrm{Cl}\end{array}$} & \multirow[t]{2}{*}{ Weight } & \multirow{2}{*}{$\begin{array}{l}\text { Mean Difference } \\
\text { Random, 95\% Cl }\end{array}$} \\
\hline & $\mathbf{N}$ & Mean(SD) & $\mathbf{N}$ & Mean(SD) & & & \\
\hline Lellouche 2006 & 74 & $4.4(0.8)$ & 70 & $4.6(0.6)$ & 1 & $10.24 \%$ & $-0.13[-0.37,0.11]$ \\
\hline Liu 2013 & 19 & $4.5(0.7)$ & 20 & $4.8(1.2)$ & + & $2.16 \%$ & $-0.35[-0.96,0.26]$ \\
\hline Petter 2003 & 16 & $1.6(0.1)$ & 18 & $1.5(0.1)$ & \# & $25.81 \%$ & $0.08[0.01,0.15]$ \\
\hline Rose 2008 & 51 & $4.2(0.7)$ & 51 & $4.4(0.7)$ & 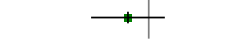 & $8.69 \%$ & $-0.15[-0.42,0.12]$ \\
\hline Roth 2001 & 20 & $0.8(0.3)$ & 20 & $1(0.4)$ & $\longrightarrow$ & $11.02 \%$ & $-0.18[-0.4,0.04]$ \\
\hline Strickland 1993 & 10 & $5.6(0.5)$ & 7 & $5.6(0.7)$ & & $2.19 \%$ & $0.01[-0.59,0.61]$ \\
\hline Sulzer 2001 & 16 & $1.5(0.1)$ & 20 & $1.6(0.2)$ & - & $23.43 \%$ & $-0.1[-0.19,-0.01]$ \\
\hline 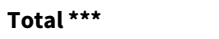 & 319 & & 312 & & 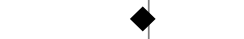 & $100 \%$ & $-0.04[-0.14,0.05]$ \\
\hline \multicolumn{8}{|c|}{ Heterogeneity: $\mathrm{Tau}^{2}=0.01 ; \mathrm{Chi}^{2}=16.53, \mathrm{df}=9(\mathrm{P}=0.06) ; \mathrm{I}^{2}=45.55 \%$} \\
\hline \multicolumn{8}{|c|}{ Test for overall effect: $Z=0.91(P=0.36)$} \\
\hline
\end{tabular}

Analysis 1.9. Comparison 1 Primary analysis: automated closed loop system versus non-automated system, Outcome 9 Secondary outcome 5.1: mortality.

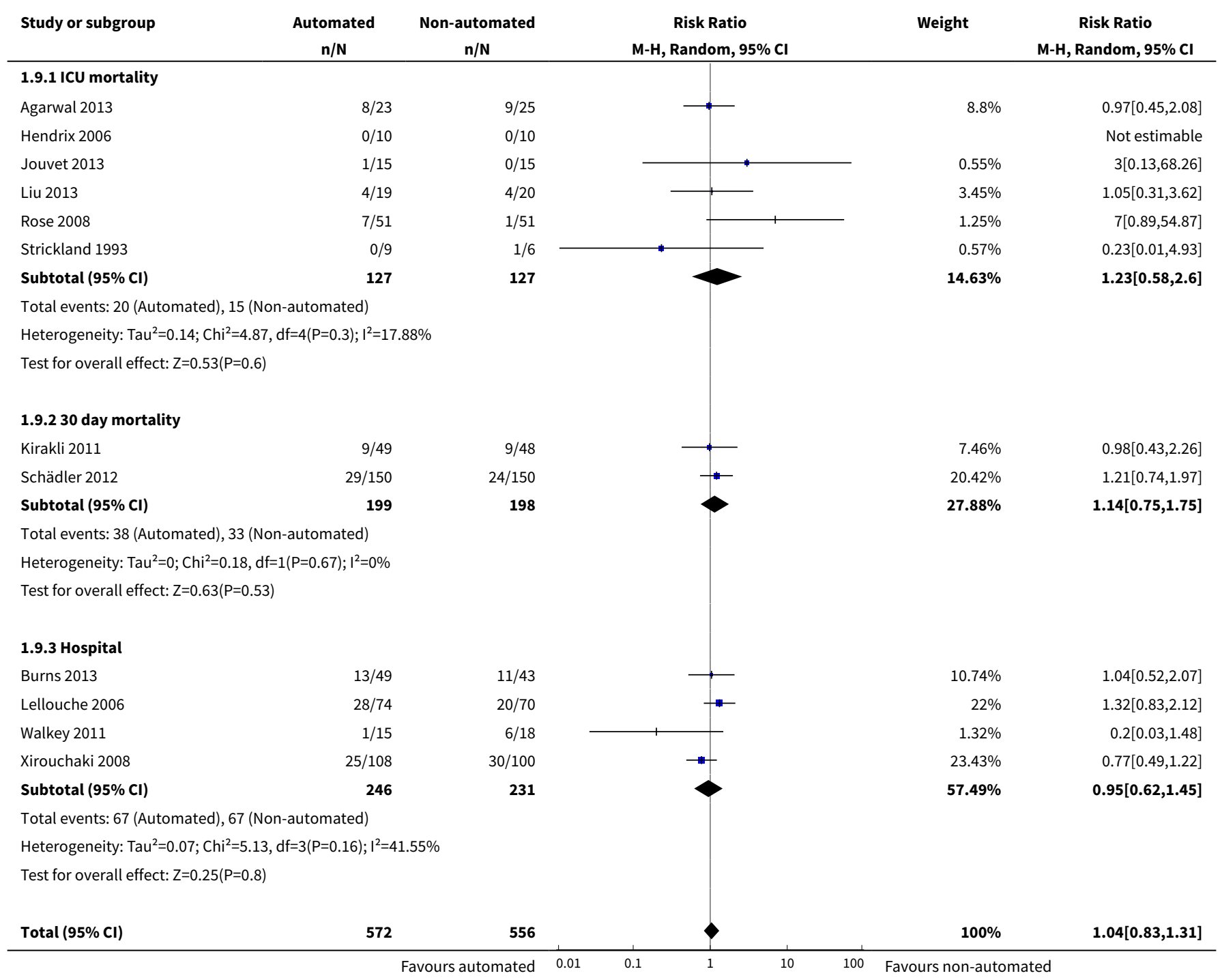




\begin{tabular}{|c|c|c|c|c|c|c|c|}
\hline Study or subgroup & $\begin{array}{c}\text { Automated } \\
\mathrm{n} / \mathrm{N}\end{array}$ & $\begin{array}{c}\text { Non-automated } \\
\mathrm{n} / \mathrm{N} \\
\end{array}$ & \multicolumn{3}{|c|}{$\begin{array}{c}\text { Risk Ratio } \\
\text { M-H, Random, } 95 \% \mathrm{CI}\end{array}$} & \multirow[t]{2}{*}{ Weight } & \multirow[t]{2}{*}{$\begin{array}{c}\text { Risk Ratio } \\
\text { M-H, Random, } 95 \% \text { C } \\
\end{array}$} \\
\hline \multicolumn{6}{|c|}{ Total events: 125 (Automated), 115 (Non-automated) } & & \\
\hline \multicolumn{8}{|c|}{ Heterogeneity: $\mathrm{Tau}^{2}=0.01 ; \mathrm{Chi}^{2}=10.33, \mathrm{df}=10(\mathrm{P}=0.41) ; \mathrm{I}^{2}=3.24 \%$} \\
\hline \multicolumn{8}{|c|}{ Test for overall effect: $\mathrm{Z}=0.35(\mathrm{P}=0.72)$} \\
\hline \multicolumn{8}{|c|}{ Test for subgroup differences: $\mathrm{Chi}^{2}=0.54, \mathrm{df}=1(\mathrm{P}=0.76), \mathrm{I}^{2}=0 \%$} \\
\hline
\end{tabular}

Analysis 1.10. Comparison 1 Primary analysis: automated closed loop system versus non-automated system, Outcome 10 Hospital length of stay.

\begin{tabular}{|c|c|c|c|c|c|c|c|}
\hline \multirow{3}{*}{$\begin{array}{l}\text { Study or subgroup } \\
\text { Agarwal } 2013\end{array}$} & \multicolumn{2}{|c|}{ Automated } & \multicolumn{2}{|c|}{ Non-automated } & \multirow{2}{*}{$\begin{array}{l}\text { Mean Difference } \\
\text { Random, } 95 \% \mathrm{Cl}\end{array}$} & \multirow[t]{2}{*}{ Weight } & \multirow{2}{*}{$\begin{array}{l}\text { Mean Difference } \\
\text { Random, } 95 \% \mathrm{Cl}\end{array}$} \\
\hline & $\mathbf{N}$ & $\operatorname{Mean}(S D)$ & $\mathbf{N}$ & $\operatorname{Mean}(S D)$ & & & \\
\hline & 23 & $2.4(0.5)$ & 25 & $2.4(0.8)$ & 1 & $10.07 \%$ & $0[-0.37,0.37]$ \\
\hline Burns 2013 & 49 & $3.3(0.6)$ & 43 & $3.6(0.8)$ & $\longrightarrow$ & $15.77 \%$ & $-0.34[-0.63,-0.05]$ \\
\hline Jouvet 2013 & 15 & $3(0.8)$ & 15 & $3.1(0.7)$ & - & $4.96 \%$ & $-0.18[-0.7,0.34]$ \\
\hline Lellouche 2006 & 74 & $3.4(0.9)$ & 70 & $3.6(0.8)$ & $\rightarrow$ & $18.64 \%$ & $-0.16[-0.43,0.11]$ \\
\hline Rose 2008 & 51 & $2.9(0.7)$ & 51 & $3(0.7)$ & - & $19.17 \%$ & $-0.09[-0.36,0.18]$ \\
\hline Walkey 2011 & 15 & $2.9(0.6)$ & 18 & $3(0.7)$ & + & $6.78 \%$ & $-0.07[-0.52,0.38]$ \\
\hline 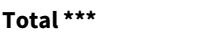 & 377 & & 372 & & & $100 \%$ & $-0.1[-0.21,0.02]$ \\
\hline \multicolumn{8}{|c|}{ Heterogeneity: $\mathrm{Tau}^{2}=0 ; \mathrm{Chi}^{2}=5.18, \mathrm{df}=6(\mathrm{P}=0.52) ; \mathrm{I}^{2}=0 \%$} \\
\hline \multicolumn{3}{|c|}{ Test for overall effect: $Z=1.64(P=0.1)$} & & & & & \\
\hline
\end{tabular}

Analysis 1.11. Comparison 1 Primary analysis: automated closed loop system versus non-automated system, Outcome 11 ICU length of stay by ICU population.

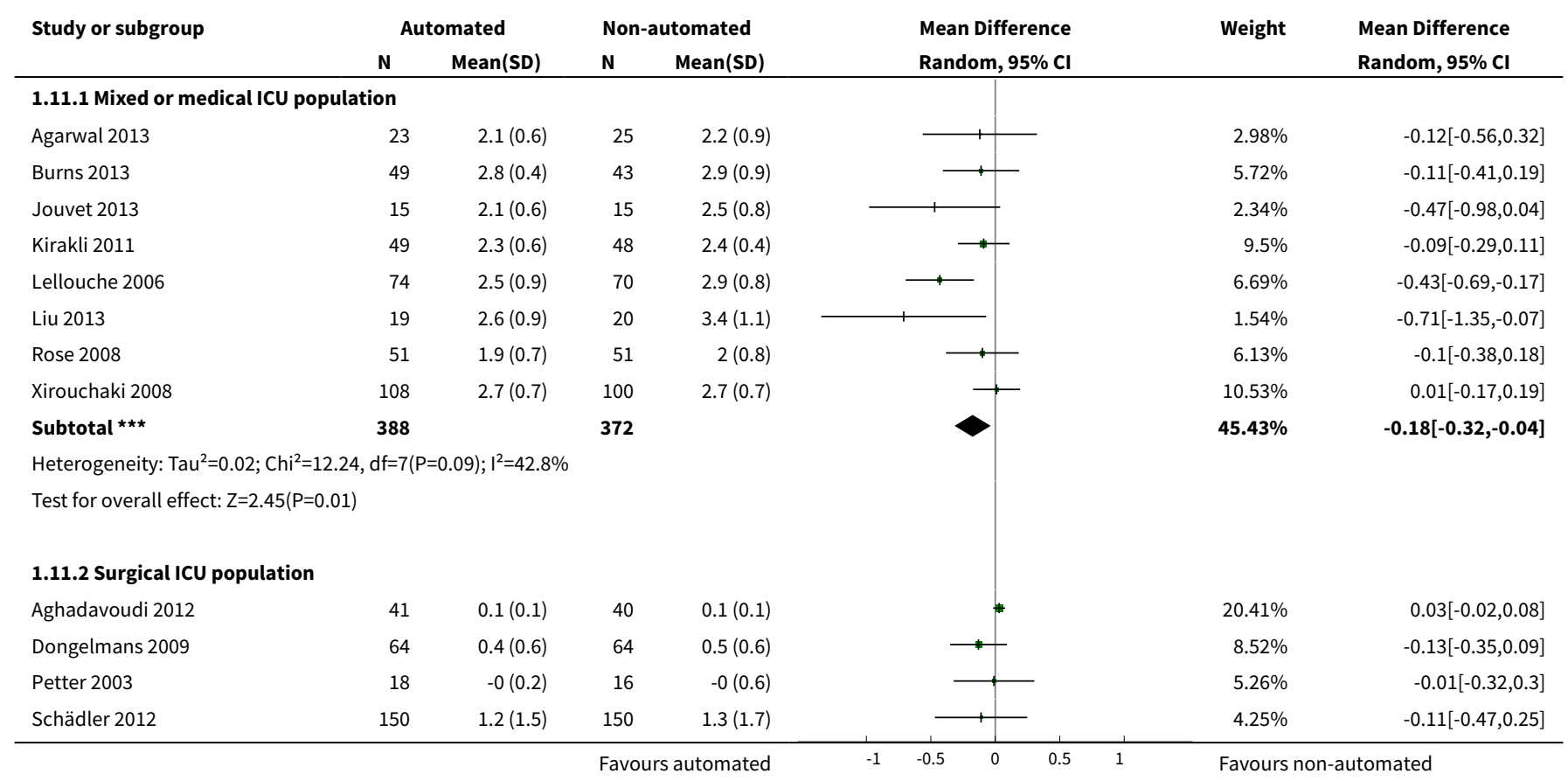




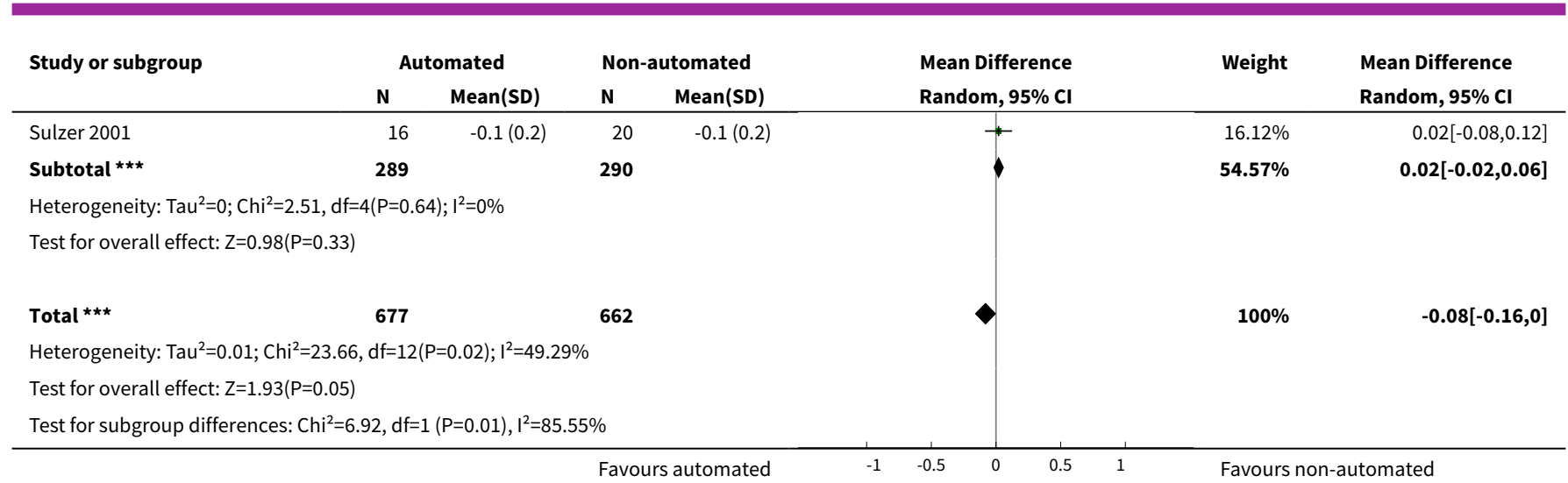

Analysis 1.12. Comparison 1 Primary analysis: automated closed loop system versus non-automated system, Outcome 12 ICU length of stay by automated system.

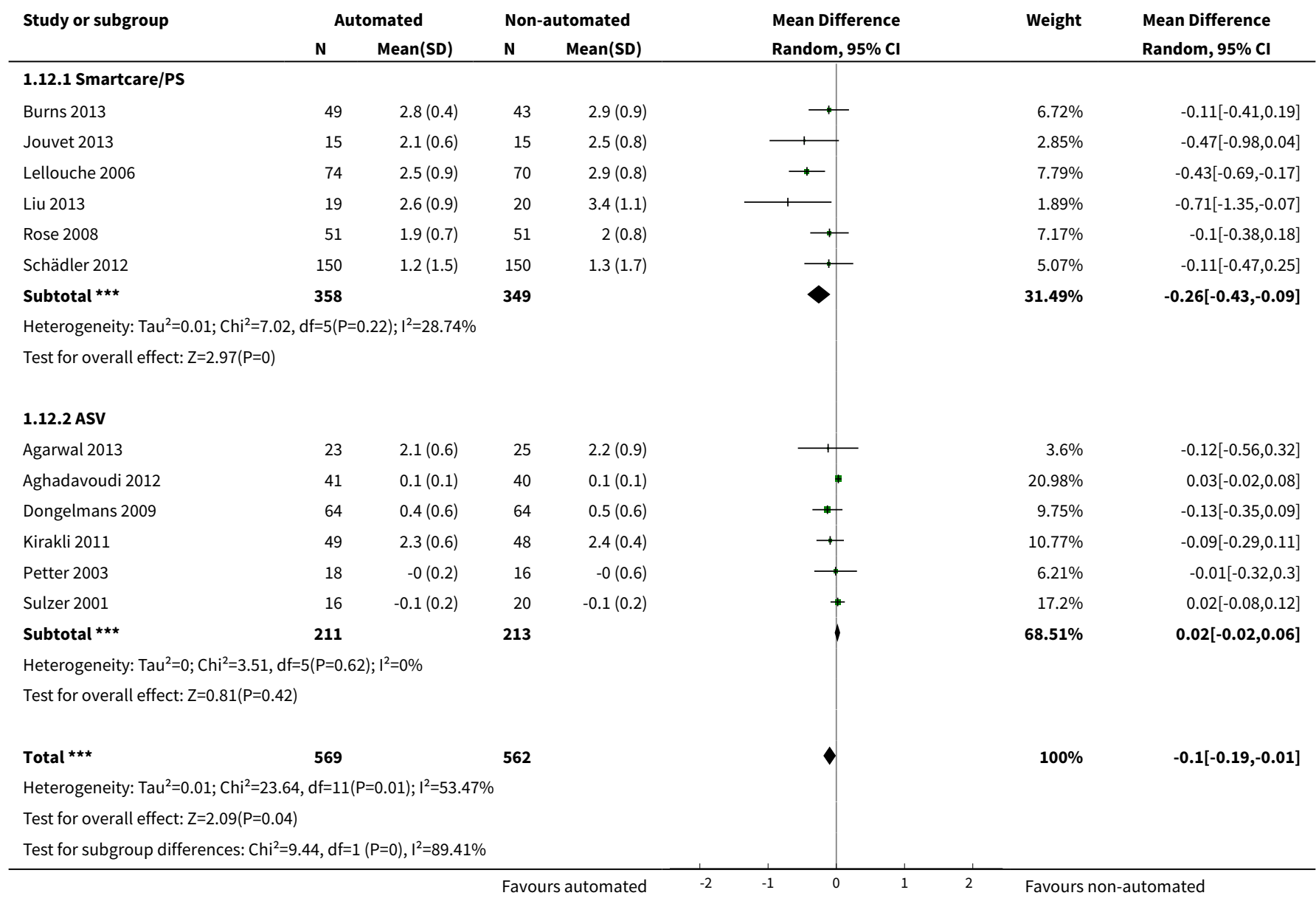


Analysis 1.13. Comparison 1 Primary analysis: automated closed loop system versus non-automated system, Outcome 13 Reintubation.

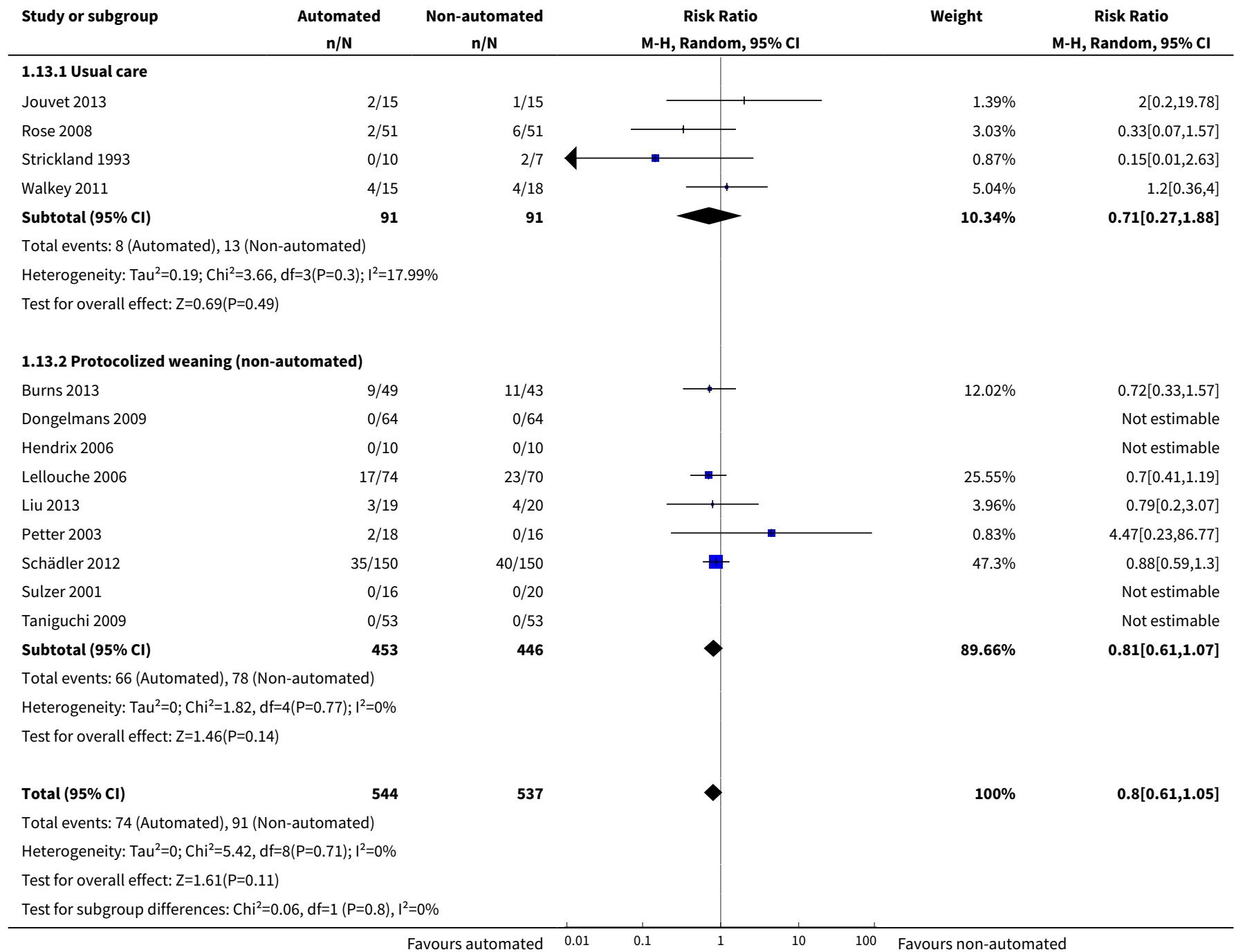

Analysis 1.14. Comparison 1 Primary analysis: automated closed loop system versus non-automated system, Outcome 14 Self-extubation.

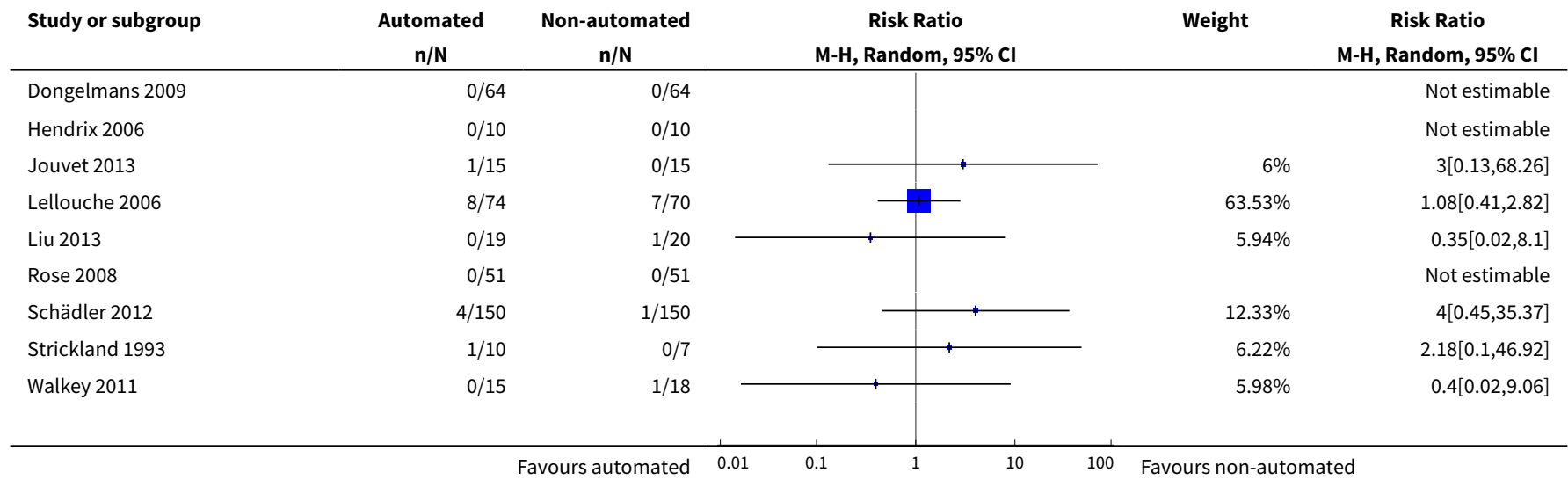

Automated versus non-automated weaning for reducing the duration of mechanical ventilation for critically ill adults and children 69 (Review)

Copyright (c) 2018 The Cochrane Collaboration. Published by John Wiley \& Sons, Ltd. 


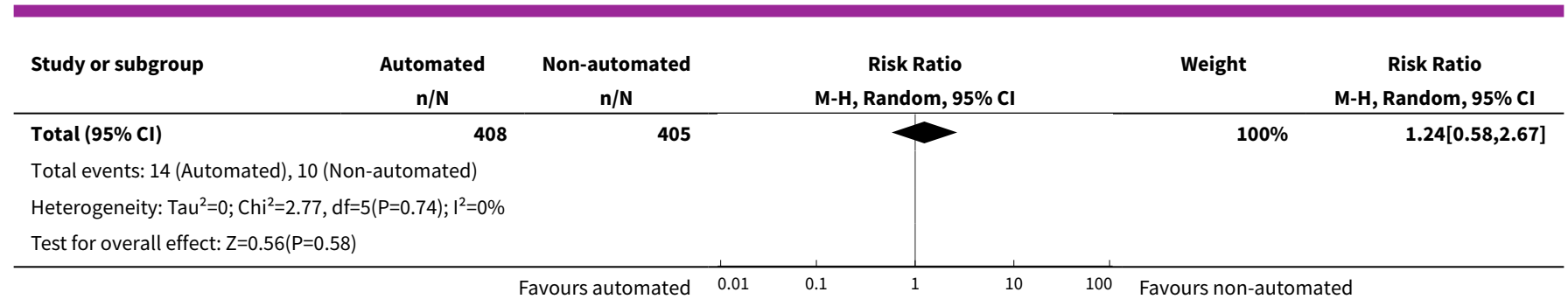

Analysis 1.15. Comparison 1 Primary analysis: automated closed loop system versus non-automated system, Outcome 15 Non invasive ventilation.

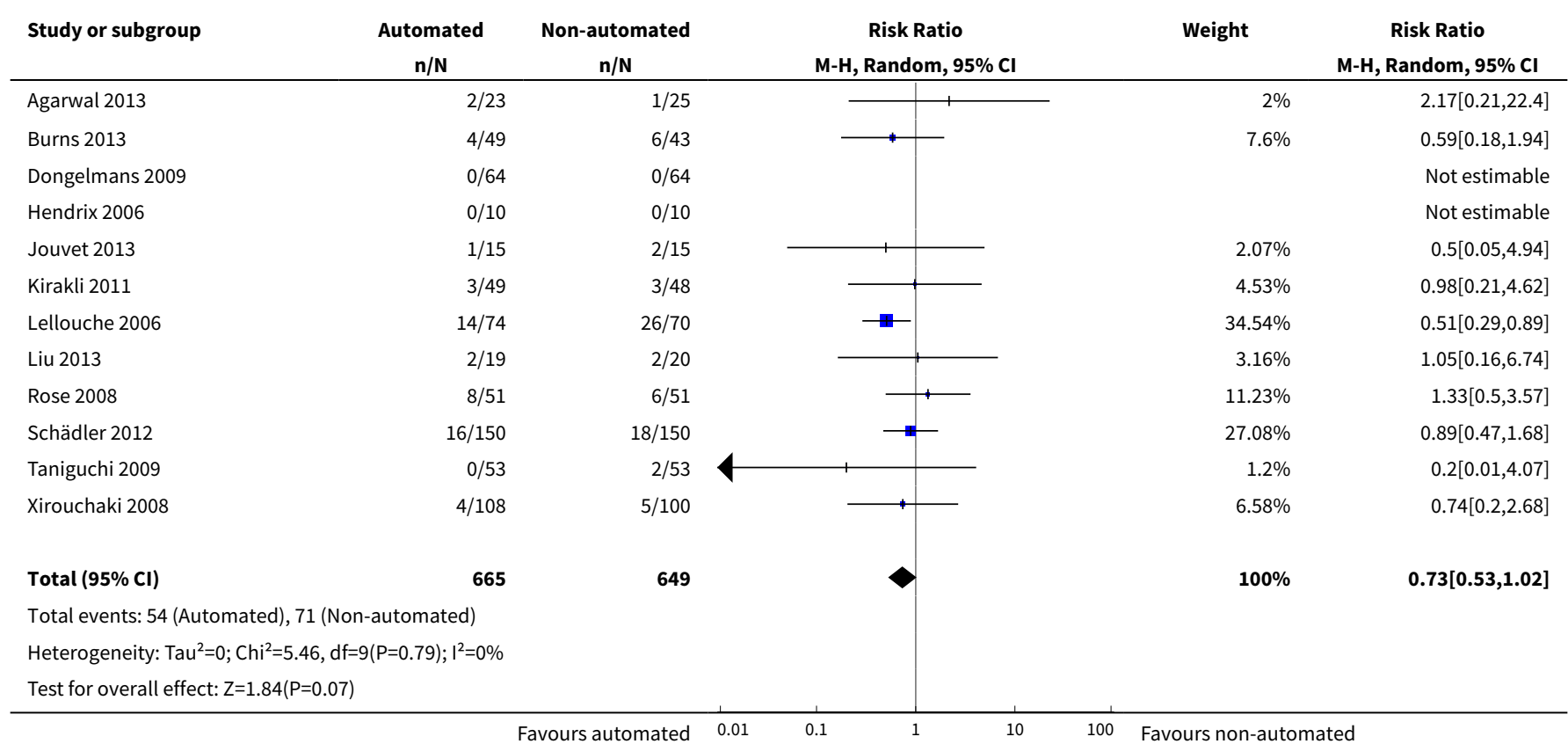

Analysis 1.16. Comparison 1 Primary analysis: automated closed loop system versus non-automated system, Outcome 16 Prolonged mechanical ventilation.

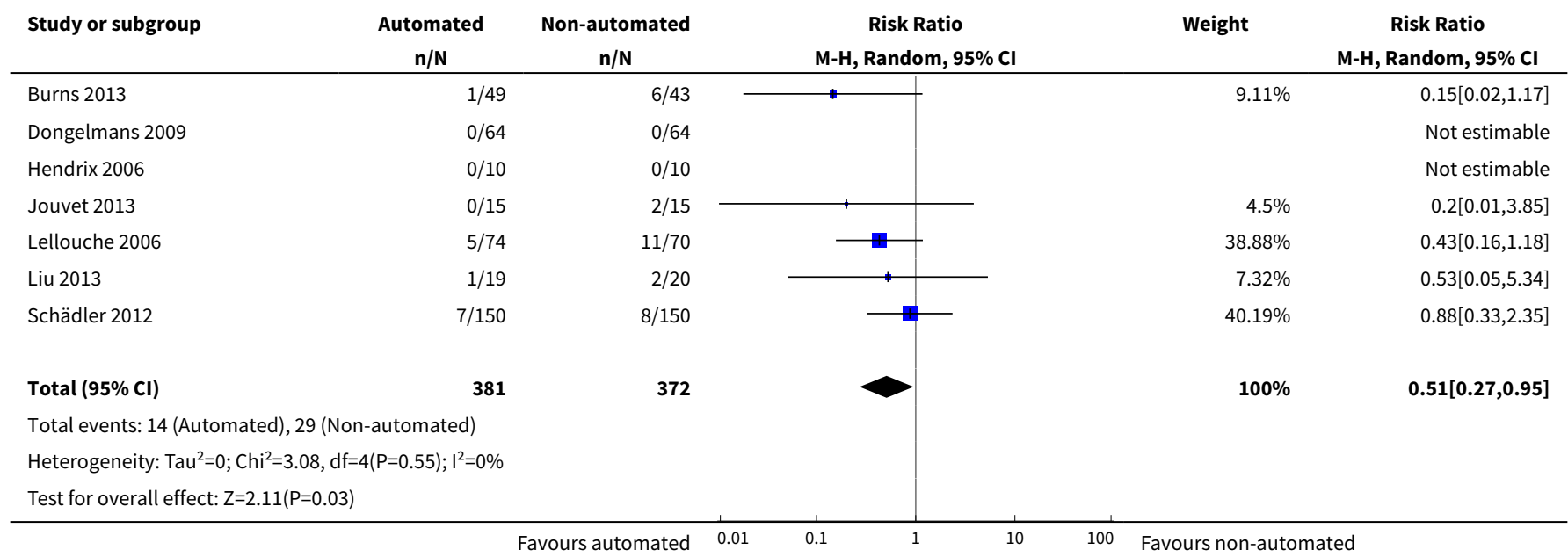


Analysis 1.17. Comparison 1 Primary analysis: automated closed loop system versus non-automated system, Outcome 17 Tracheostomy.

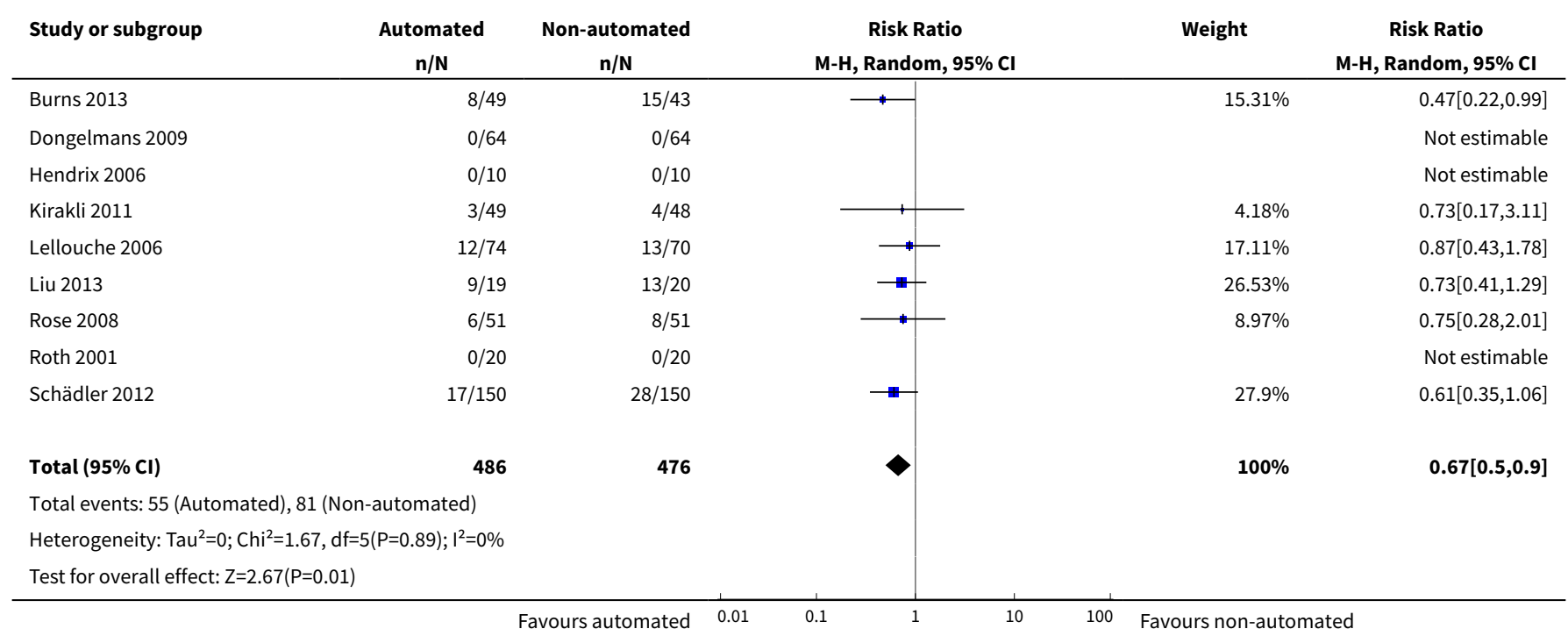

Comparison 2. Sensitivity analysis: automated closed loop system versus non-automated system, un-logged data duration of weaning

\begin{tabular}{|c|c|c|c|c|}
\hline Outcome or subgroup title & No. of studies & $\begin{array}{l}\text { No. of partici- } \\
\text { pants }\end{array}$ & Statistical method & Effect size \\
\hline $\begin{array}{l}1 \text { Weaning duration by ICU } \\
\text { population }\end{array}$ & 16 & 1246 & $\begin{array}{l}\text { Mean Difference (IV, Random, 95\% } \\
\text { CI) }\end{array}$ & $-0.75[-1.85,0.34]$ \\
\hline $\begin{array}{l}\text { 1.1 Mixed or medical ICU } \\
\text { population }\end{array}$ & 9 & 542 & $\begin{array}{l}\text { Mean Difference (IV, Random, 95\% } \\
\text { CI) }\end{array}$ & $-18.75[-32.30,-5.20]$ \\
\hline 1.2 Surgical ICU population & 7 & 704 & $\begin{array}{l}\text { Mean Difference (IV, Random, 95\% } \\
\text { CI) }\end{array}$ & $-0.15[-0.70,0.39]$ \\
\hline $\begin{array}{l}2 \text { Weaning duration by au- } \\
\text { tomated system [hours] }\end{array}$ & 16 & 1246 & $\begin{array}{l}\text { Mean Difference (IV, Random, 95\% } \\
\mathrm{Cl})\end{array}$ & $-0.75[-1.85,0.34]$ \\
\hline 2.1 Smartcare/PS & 7 & 744 & $\begin{array}{l}\text { Mean Difference (IV, Random, 95\% } \\
\mathrm{CI})\end{array}$ & $-38.46[-58.11,-18.81]$ \\
\hline 2.2 ASV & 4 & 295 & $\begin{array}{l}\text { Mean Difference (IV, Random, 95\% } \\
\mathrm{CI})\end{array}$ & $-0.00[-0.07,0.06]$ \\
\hline 2.3 Other & 5 & 207 & $\begin{array}{l}\text { Mean Difference (IV, Random, 95\% } \\
\mathrm{CI})\end{array}$ & $-3.89[-7.71,-0.07]$ \\
\hline $\begin{array}{l}3 \text { Weaning duration by non- } \\
\text { automated strategy (con- } \\
\text { trol arm) }\end{array}$ & 16 & 1246 & $\begin{array}{l}\text { Mean Difference (IV, Random, 95\% } \\
\mathrm{CI})\end{array}$ & $-0.75[-1.85,0.34]$ \\
\hline
\end{tabular}




\begin{tabular}{|c|c|c|c|c|}
\hline Outcome or subgroup title & No. of studies & $\begin{array}{l}\text { No. of partici- } \\
\text { pants }\end{array}$ & Statistical method & Effect size \\
\hline 3.1 usual care & 5 & 238 & $\begin{array}{l}\text { Mean Difference (IV, Random, 95\% } \\
\mathrm{CI})\end{array}$ & $-30.49[-60.63,-0.35]$ \\
\hline $\begin{array}{l}3.2 \text { protocolized (non-auto- } \\
\text { mated) }\end{array}$ & 11 & 1008 & $\begin{array}{l}\text { Mean Difference (IV, Random, 95\% } \\
\mathrm{CI})\end{array}$ & $-0.44[-1.42,0.54]$ \\
\hline $\begin{array}{l}4 \text { Randomization to first ex- } \\
\text { tubation }\end{array}$ & 11 & 1039 & $\begin{array}{l}\text { Mean Difference (IV, Random, 95\% } \\
\mathrm{CI})\end{array}$ & $-0.61[-1.61,0.39]$ \\
\hline 5 Ventilation duration & 14 & 1248 & $\begin{array}{l}\text { Mean Difference (IV, Random, 95\% } \\
\mathrm{Cl} \text { ) }\end{array}$ & $-0.55[-1.38,0.28]$ \\
\hline $\begin{array}{l}6 \text { Intubation to randomiza- } \\
\text { tion }\end{array}$ & 11 & 664 & $\begin{array}{l}\text { Mean Difference (IV, Random, 95\% } \\
\text { CI) }\end{array}$ & $-0.16[-0.69,0.36]$ \\
\hline 7 Hospital length of stay & 7 & 749 & $\begin{array}{l}\text { Mean Difference (IV, Random, 95\% } \\
\mathrm{CI})\end{array}$ & $-2.20[-4.91,0.52]$ \\
\hline $8 \mathrm{ICU}$ length of stay & 13 & 1339 & $\begin{array}{l}\text { Mean Difference (IV, Random, 95\% } \\
\mathrm{CI})\end{array}$ & $0.01[-0.09,0.11]$ \\
\hline
\end{tabular}

\section{Analysis 2.1. Comparison 2 Sensitivity analysis: automated closed loop system versus non-automated system, un-logged data duration of weaning, Outcome 1 Weaning duration by ICU population.}

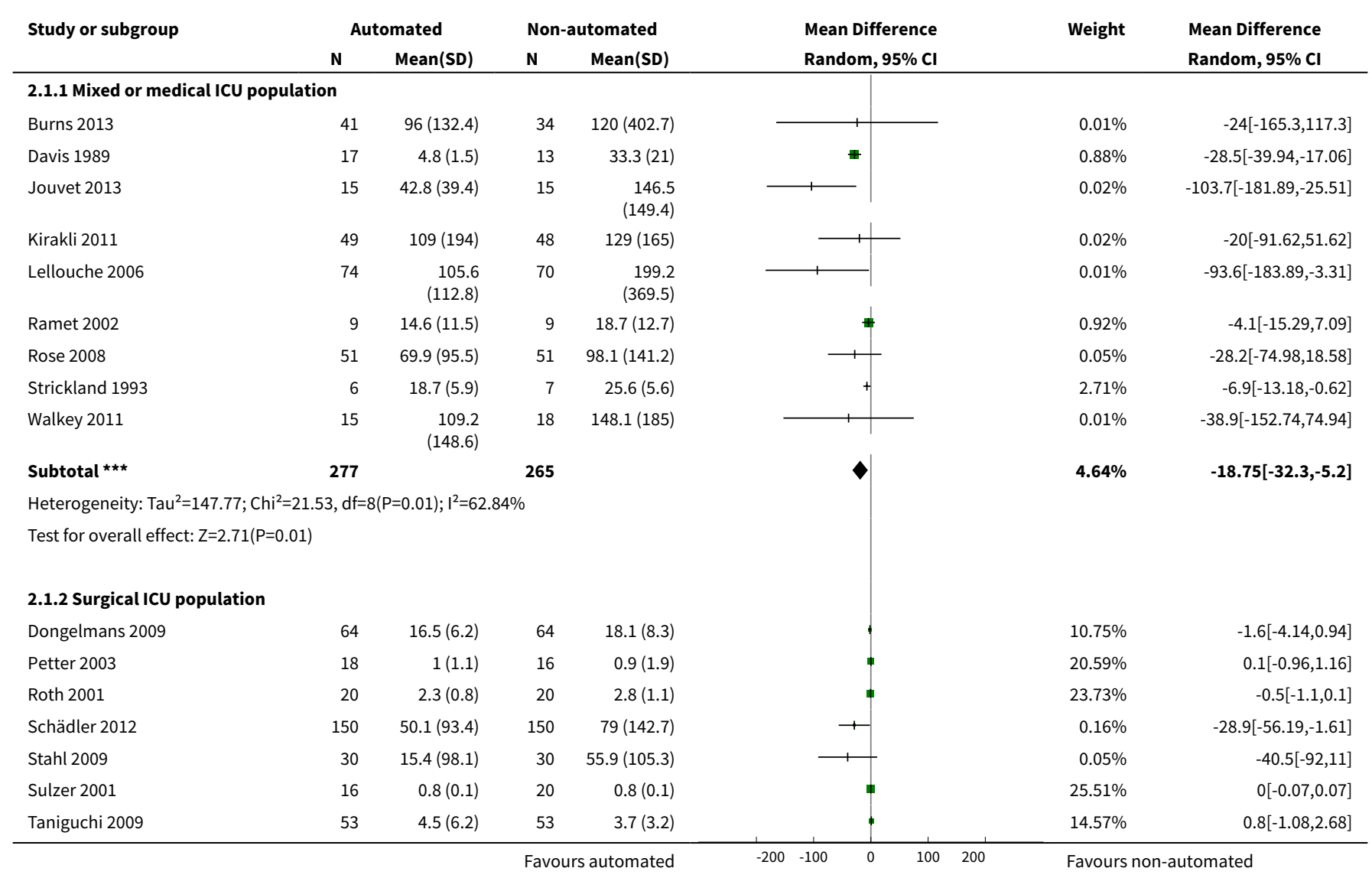

Automated versus non-automated weaning for reducing the duration of mechanical ventilation for critically ill adults and children 72 


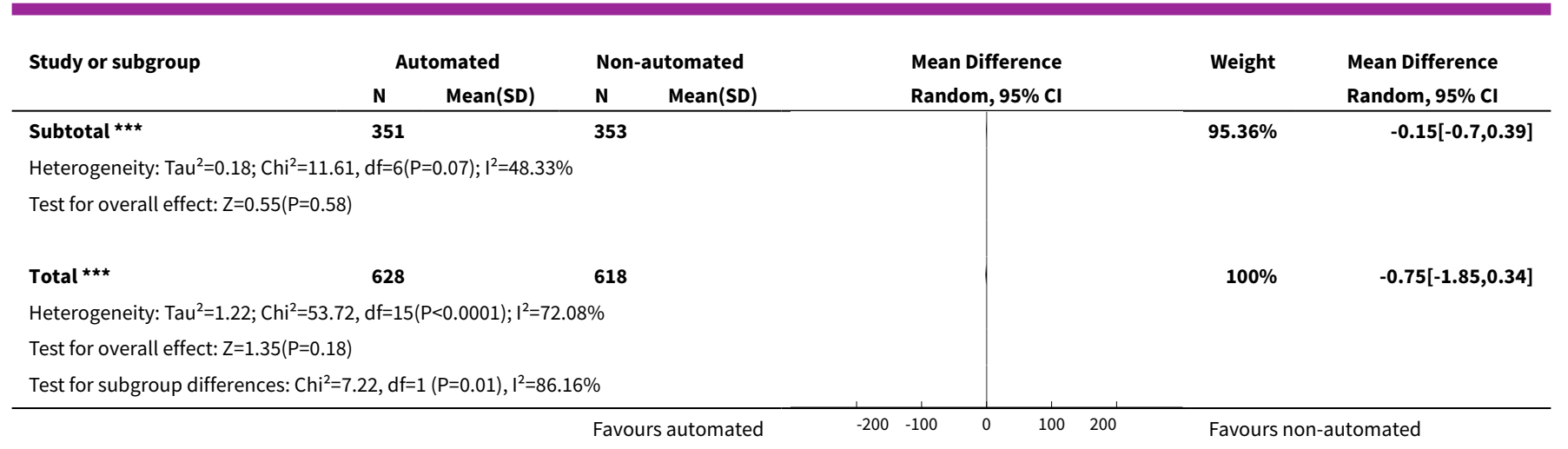

\section{Analysis 2.2. Comparison 2 Sensitivity analysis: automated closed loop system versus non-automated system, un-logged data duration of weaning, Outcome 2 Weaning duration by automated system [hours].}

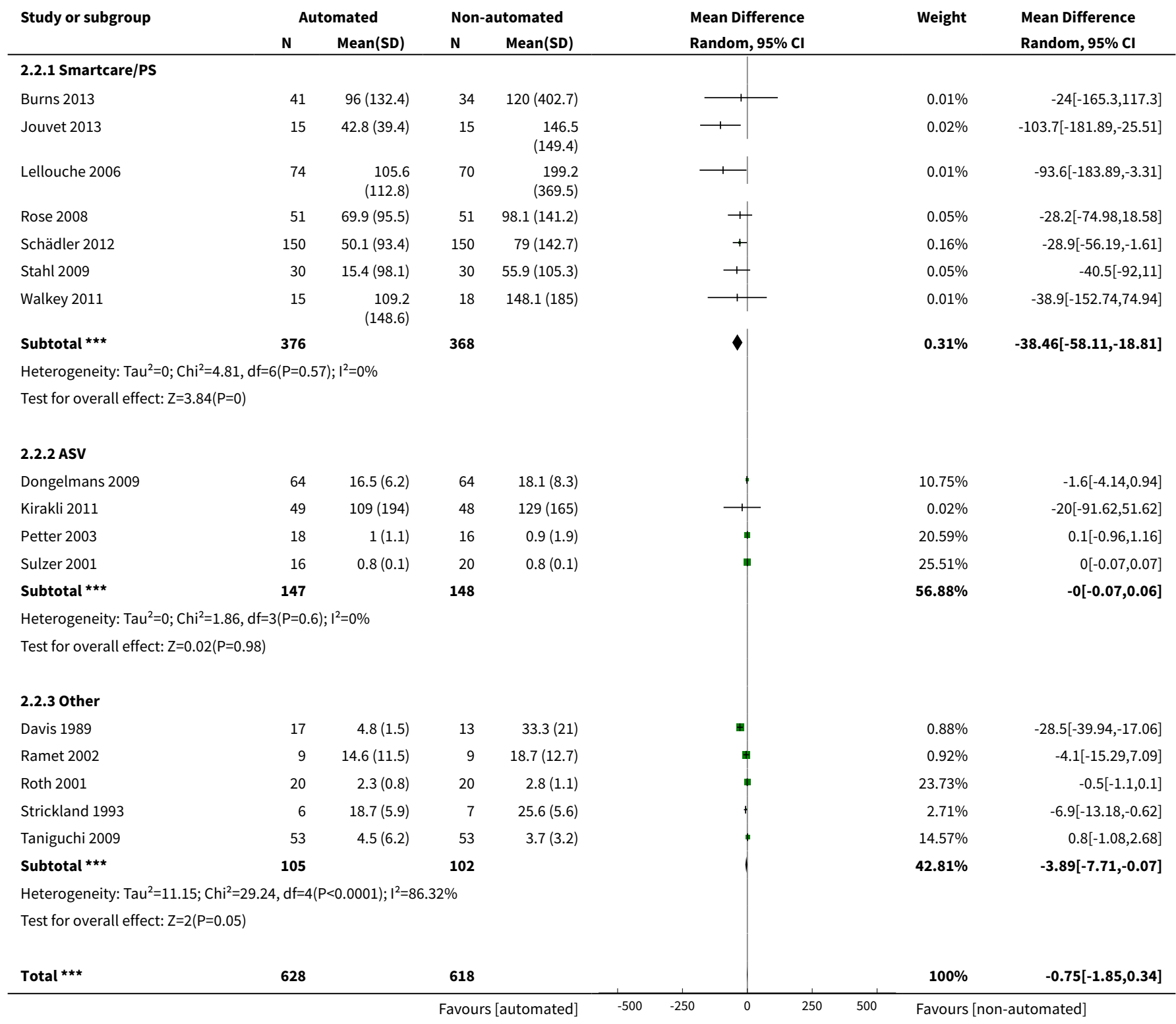

Automated versus non-automated weaning for reducing the duration of mechanical ventilation for critically ill adults and children 73 (Review)

Copyright (c) 2018 The Cochrane Collaboration. Published by John Wiley \& Sons, Ltd. 


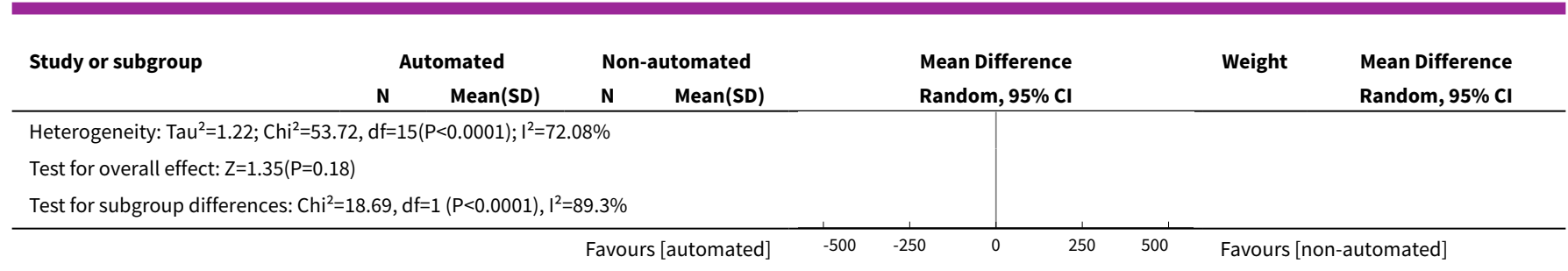

\section{Analysis 2.3. Comparison 2 Sensitivity analysis: automated closed loop system versus non-automated system, un-logged data duration of weaning, Outcome 3 Weaning duration by non-automated strategy (control arm).}

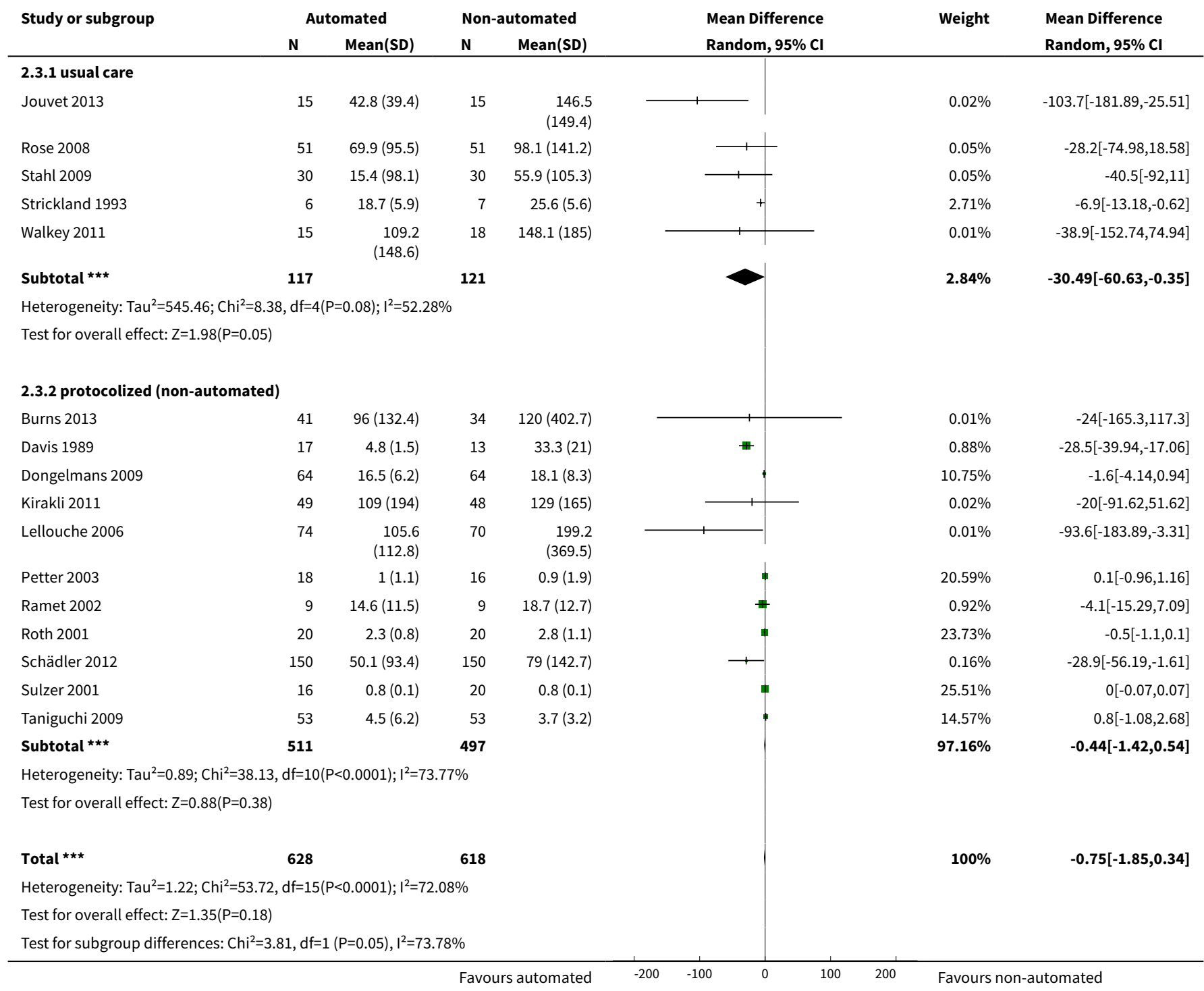


Analysis 2.4. Comparison 2 Sensitivity analysis: automated closed loop system versus nonautomated system, un-logged data duration of weaning, Outcome 4 Randomization to first extubation.

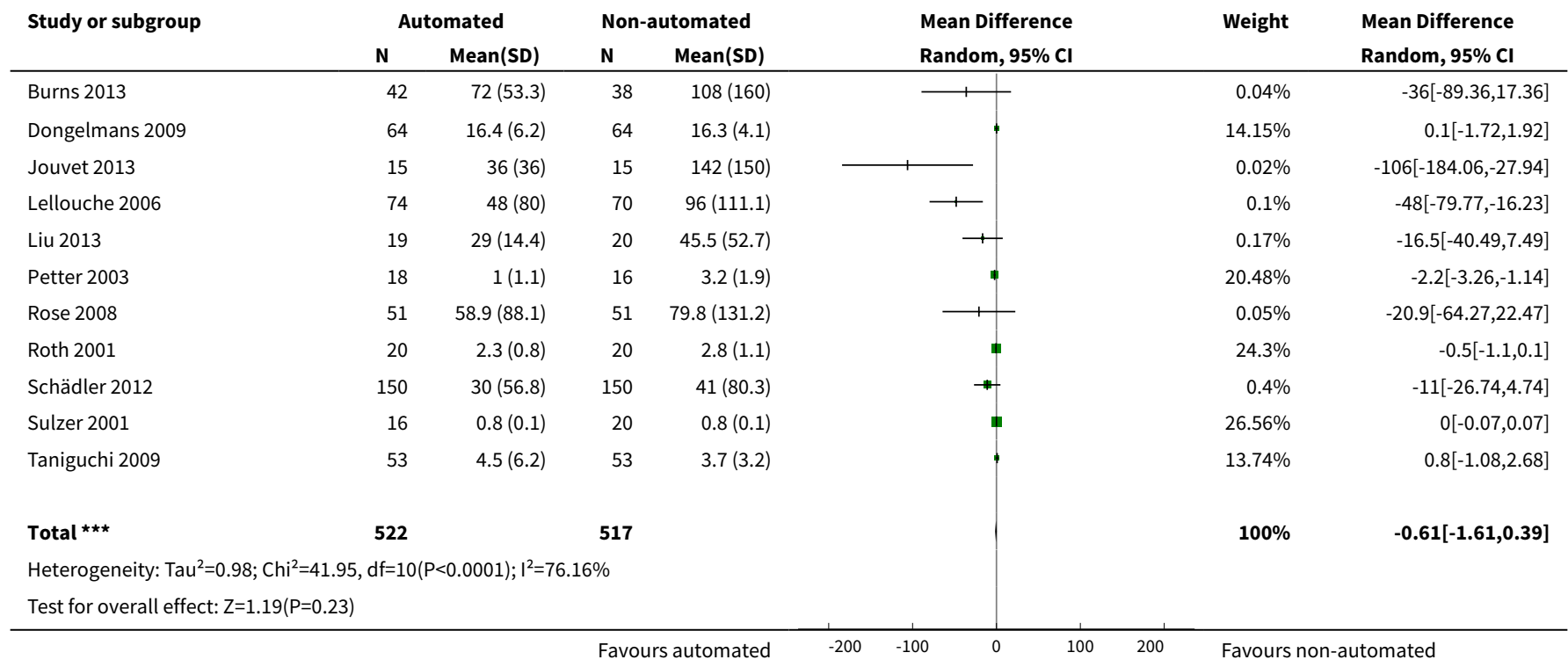

\section{Analysis 2.5. Comparison 2 Sensitivity analysis: automated closed loop system versus non- automated system, un-logged data duration of weaning, Outcome 5 Ventilation duration.}

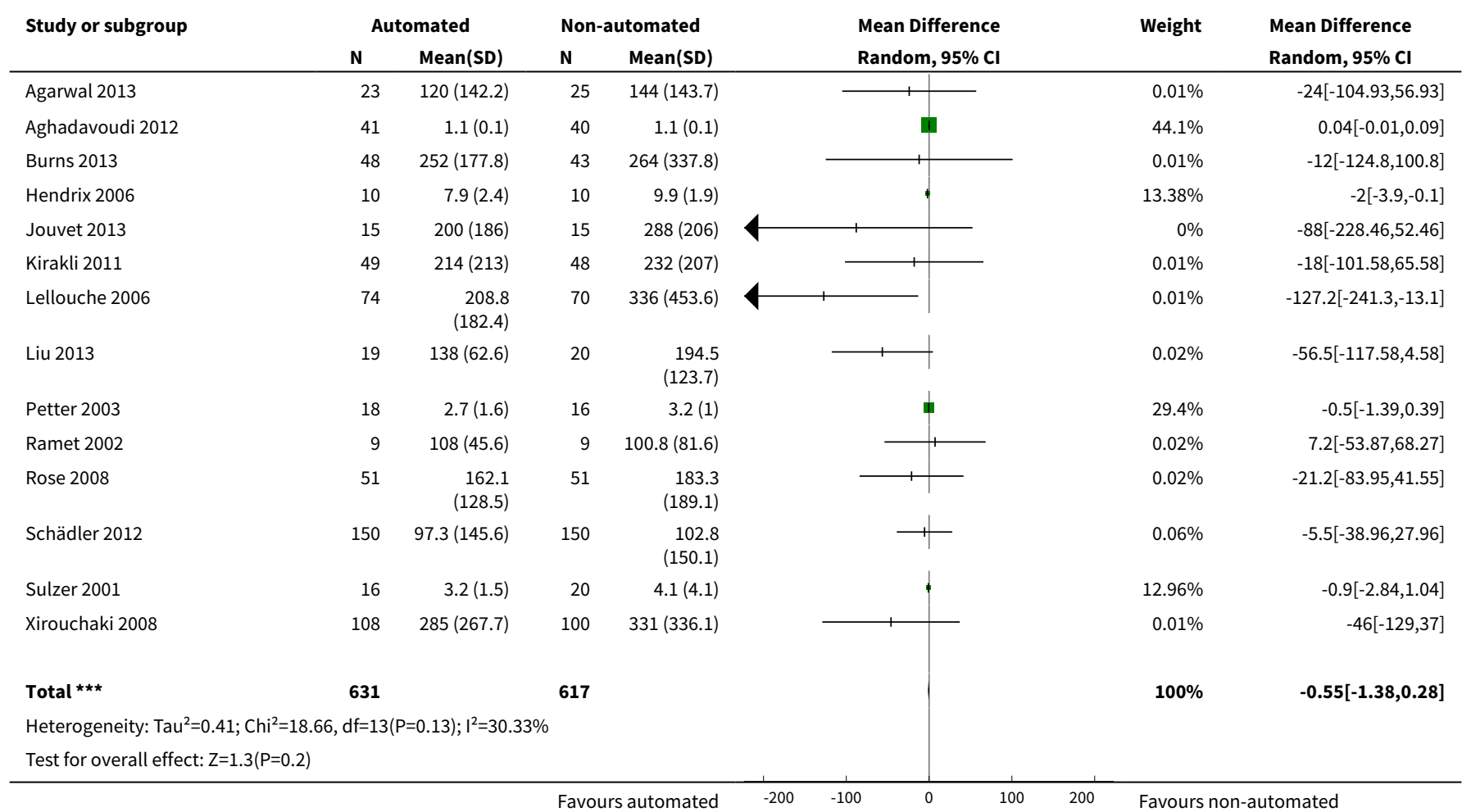


Analysis 2.6. Comparison 2 Sensitivity analysis: automated closed loop system versus nonautomated system, un-logged data duration of weaning, Outcome 6 Intubation to randomization.

\begin{tabular}{|c|c|c|c|c|c|c|c|}
\hline \multirow{3}{*}{$\begin{array}{l}\text { Study or subgroup } \\
\text { Burns } 2013\end{array}$} & \multicolumn{2}{|c|}{ Automated } & \multicolumn{2}{|c|}{ Non-automated } & \multirow{2}{*}{$\begin{array}{l}\text { Mean Difference } \\
\text { Random, 95\% Cl }\end{array}$} & \multirow[t]{2}{*}{ Weight } & \multirow{2}{*}{$\begin{array}{l}\text { Mean Difference } \\
\text { Random, } 95 \% \mathrm{Cl}\end{array}$} \\
\hline & $\mathbf{N}$ & Mean(SD) & $\mathbf{N}$ & Mean(SD) & & & \\
\hline & 49 & $114(124.4)$ & 43 & $120(106.7)$ & - & $0.01 \%$ & $-6[-53.23,41.23]$ \\
\hline Jouvet 2013 & 15 & $157(189)$ & 15 & $141(104)$ & & $0 \%$ & $16[-93.17,125.17]$ \\
\hline Kirakli 2011 & 49 & $93(93)$ & 48 & $83(72)$ & 1 & $0.02 \%$ & $10[-23.06,43.06]$ \\
\hline Lellouche 2006 & 74 & $84(71.1)$ & 70 & $96(71.1)$ & + & $0.05 \%$ & $-12[-35.23,11.23]$ \\
\hline Liu 2013 & 19 & $85.7(53.3)$ & 20 & $\begin{array}{r}121.5 \\
(113.6)\end{array}$ & + & $0.01 \%$ & $-35.8[-91.05,19.45]$ \\
\hline Petter 2003 & 18 & $5.1(0.5)$ & 16 & $4.7(0.5)$ & 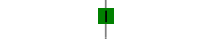 & $37.98 \%$ & $0.4[0.06,0.74]$ \\
\hline Rose 2008 & 51 & $93(75.8)$ & 51 & $90.7(66.9)$ & 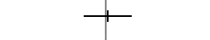 & $0.04 \%$ & $2.3[-25.45,30.05]$ \\
\hline Roth 2001 & 20 & $2.3(0.8)$ & 20 & $2.8(1.1)$ & 申 & $28.39 \%$ & $-0.5[-1.1,0.1]$ \\
\hline Strickland 1993 & 10 & $\begin{array}{r}321.6 \\
(187.2)\end{array}$ & 7 & $348(266.4)$ & 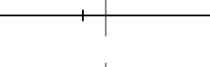 & $0 \%$ & $-26.4[-255.33,202.53]$ \\
\hline Sulzer 2001 & 16 & $4.7(0.6)$ & 20 & $5.2(0.8)$ & $\phi$ & $33.49 \%$ & $-0.5[-0.96,-0.04]$ \\
\hline Walkey 2011 & 15 & $\begin{array}{r}151.4 \\
(104.9)\end{array}$ & 18 & $147.1(88.8)$ & & $0.01 \%$ & $4.3[-62.79,71.39]$ \\
\hline Total $\star \star \star ~$ & 336 & & 328 & & & $100 \%$ & $-0.16[-0.69,0.36]$ \\
\hline \multicolumn{8}{|c|}{ Heterogeneity: Tau $^{2}=0.16 ; \mathrm{Chi}^{2}=15.92, \mathrm{df}=10(\mathrm{P}=0.1) ; \mathrm{I}^{2}=37.18 \%$} \\
\hline Test for overall effect & & & & & & & \\
\hline
\end{tabular}

Analysis 2.7. Comparison 2 Sensitivity analysis: automated closed loop system versus nonautomated system, un-logged data duration of weaning, Outcome 7 Hospital length of stay.

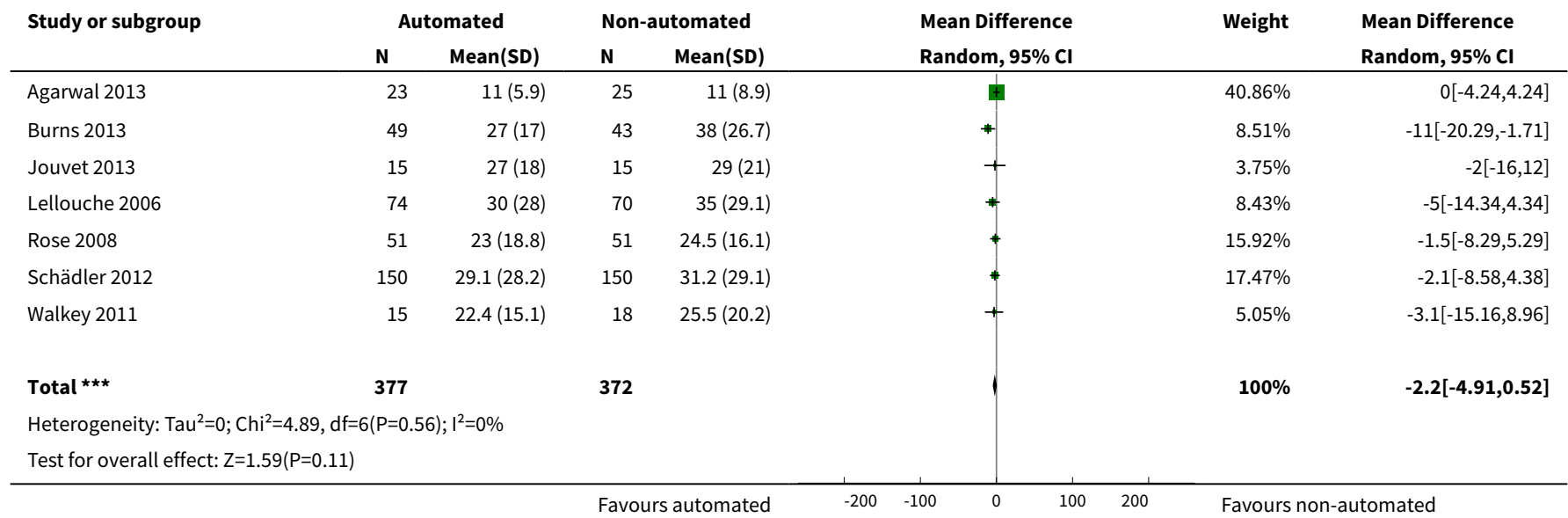

Analysis 2.8. Comparison 2 Sensitivity analysis: automated closed loop system versus nonautomated system, un-logged data duration of weaning, Outcome 8 ICU length of stay.

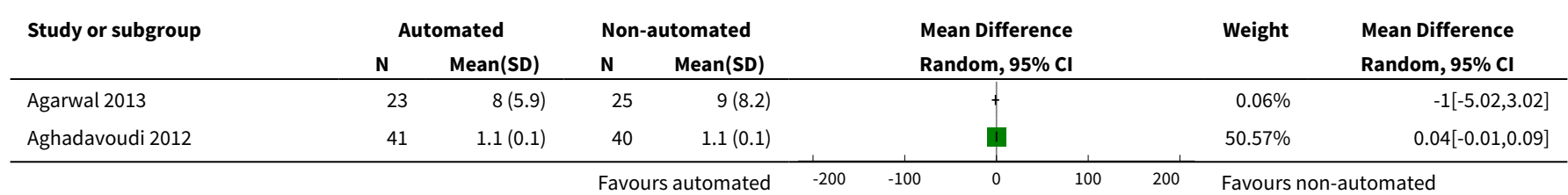

Automated versus non-automated weaning for reducing the duration of mechanical ventilation for critically ill adults and children 76 


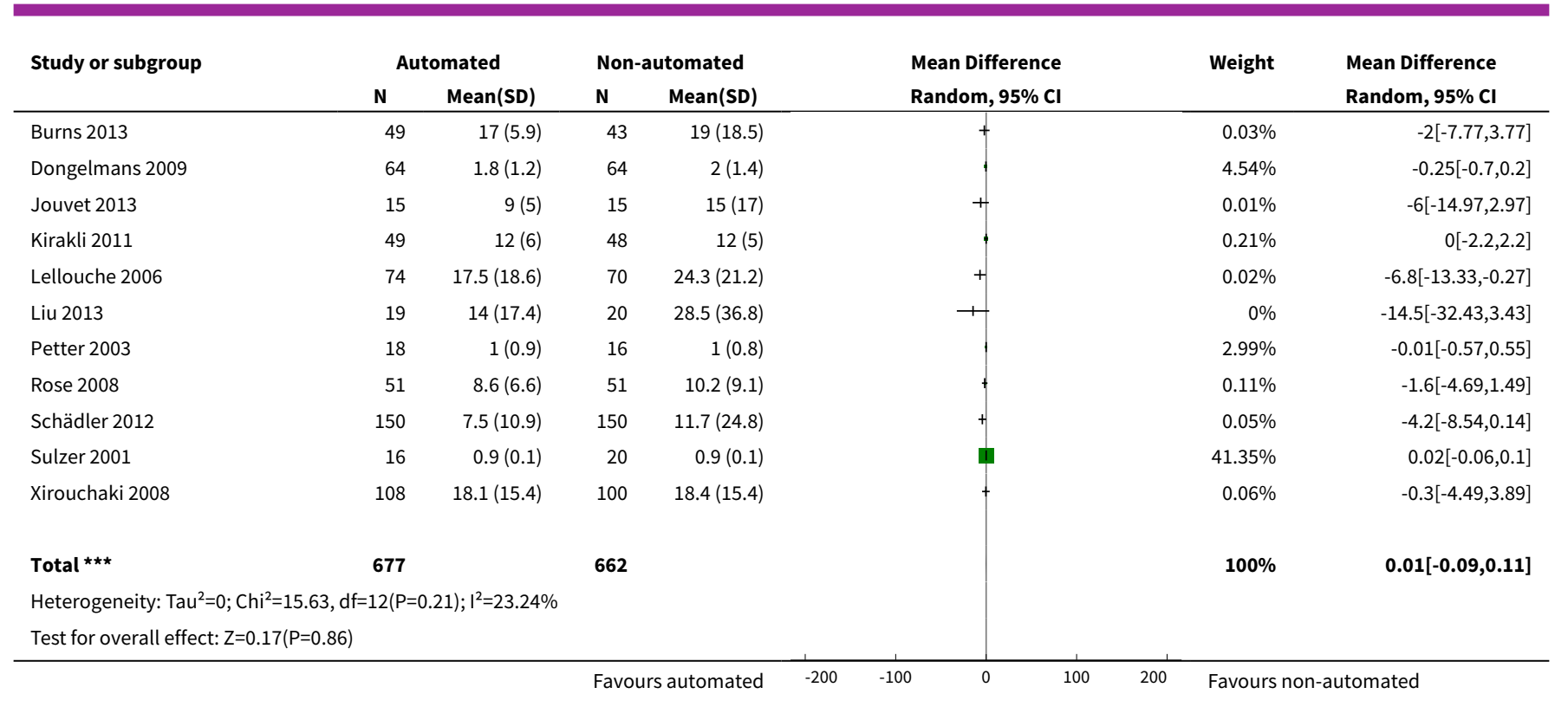

Comparison 3. Sensitivity analysis: automated closed loop system versus non-automated system excluding high risk of bias studies

\begin{tabular}{lllll}
\hline Outcome or subgroup title & No. of studies & $\begin{array}{l}\text { No. of partici- } \\
\text { pants }\end{array}$ & Statistical method & Effect size \\
\hline 1 Weaning duration & 14 & 1195 & $\begin{array}{l}\text { Mean Difference (IV, Random, 95\% } \\
\text { Cl) }\end{array}$ & $-0.37[-0.61,-0.13]$ \\
\hline
\end{tabular}

Analysis 3.1. Comparison 3 Sensitivity analysis: automated closed loop system versus non-automated system excluding high risk of bias studies, Outcome 1 Weaning duration.

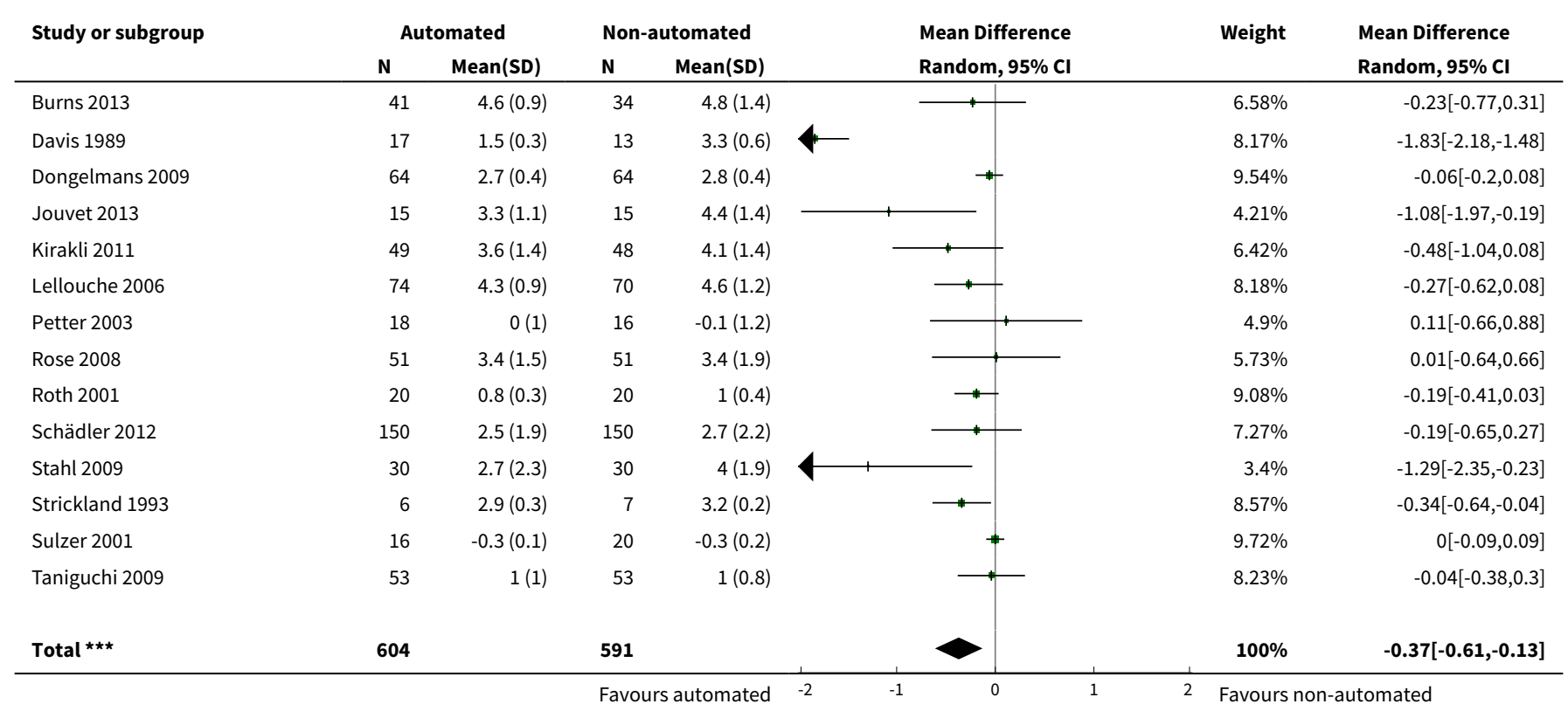




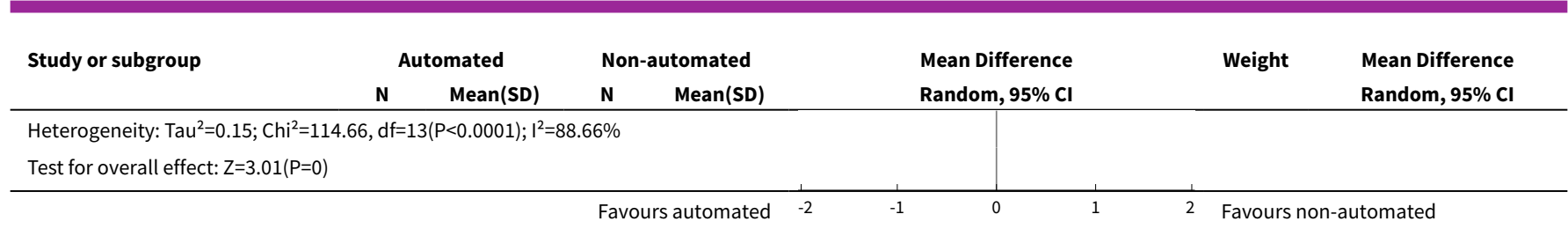

\section{APPENDICES}

\section{Appendix 1. MEDLINE (OvidSP) search strategy}

1 ventilator weaning/

2 (exp positive-pressure respiration/ or Ventilators, Mechanical/ or respiration, artificial/ or exp Respiratory Mechanics/ or ventilat*.ti,ab.) and $\left(\right.$ wean $^{\star}$ or liberat $^{\star}$ or extubat $\left.^{\star}\right)$.mp.

31 or $2(6423)$

4 exp Therapy, Computer-Assisted/ or (((computer or proportion ${ }^{\star}$ ) adj3 assist* ${ }^{\star}$ ) or (automat ${ }^{\star}$ adj3 system ${ }^{\star}$ ) or (smart adj3 care) or automat ${ }^{\star}$ or closed-loop or (closed adj3 loop) or smartcare or automode or adaptive support ventilation or (adaptive adj3 (support* or assist*)) or mandatory minute ventilation or (mandatory adj3 minute*) or neurally adjusted ventilat ${ }^{\star}$ assist or (neurally adj3 adjust*) or nava or volume support ventilation or intellivent or(volume adj3 support adj3 ventilation) or proportional pressure support or (proportional adj3 pressure adj3 support)).mp.

53 and 4

6 (controlled clinical trial or meta analysis or multicenter study or randomized controlled trial).pt. or randomized control trials as topic/ or controlled clinical trials as topic/ or multicenter studies as topic/ or metaanalysis as topic/ or double-blind method/ or single-blind method/ or (rct or rcts or random ${ }^{\star}$ or multicent ${ }^{\star}$ or placebo* or metanalys* or sham or effectiveness or efficacy or compar*).mp. or (meta adj5 analys?s).mp. or ((sing|* or doubl* or tripl* or trebl*) adj5 (mask* or blind $\left.\left.{ }^{\star}\right)\right) . m p . ~(4119912)$

75 and 6

\section{Appendix 2. EMBASE (OvidSP) search strategy}

1 (exp artificial ventilation/ or artificial ventilation/or positive end expiratory pressure/ or ventilator/ or breathing mechanics/or ((respirat* or breathing) adj2 (ventilat ${ }^{\star}$ or movement $\left.{ }^{\star}\right)$ ).ti,ab. or ventilat ${ }^{\star}$.mp.) and (wean ${ }^{\star}$ or liberat $^{\star}$ or extubat $^{\star}$ ).mp.

2 exp computer assisted therapy/ or (((computer or proportion $\left.{ }^{\star}\right)$ adj3 assist*) or (automat ${ }^{\star}$ adj3 system $\left.{ }^{\star}\right)$ or automat ${ }^{\star}$ or closed-loop or (closed adj3 loop) or (smart adj3 care) or smartcare or automode or "adaptive support ventilation" or (adaptive adj3 (support* or assist*)) or "mandatory minute ventilation" or (mandatory adj3 minute*) or "neurally adjusted ventilat* assist*" or (neurally adj3 adjust*) or nava or "volume support ventilation" or intellivent or (volume adj3 support adj3 ventilation) or "proportional pressure support" or (proportional adj3 pressure adj3 support)).mp.

\section{1 and 2}

4 ct.fs. or controlled clinical trial/ or randomized controlled trial/ or multicenter study/ or meta analysis/ or (random* or (doubl ${ }^{\star}$ adj2 dummy) or ((Singl ${ }^{\star}$ or doubl* or trebl $l^{\star}$ or tripl ${ }^{\star}$ ) adj5 (blind ${ }^{\star}$ or mask $\left.{ }^{\star}\right)$ ) or RCT or RCTs or (control ${ }^{\star}$ adj5 trial ${ }^{\star}$ ) or multicent ${ }^{\star}$ or placebo* or metaanalys ${ }^{\star}$ or (meta adj5 analys*) or sham or effectiveness or efficacy or compar*).ti,ab.

\section{3 and 4}

\section{Appendix 3. Cochrane Central Register of Controlled Trials search strategy}

\#1 MeSH descriptor Ventilator Weaning explode all trees

\#2 MeSH descriptor Positive-Pressure Respiration explode all trees

\#3 MeSH descriptor Ventilators, Mechanical explode all trees

\#4 MeSH descriptor Respiration, Artificial explode all trees

\#5 MeSH descriptor Respiratory Mechanics explode all trees

\#6 ((respirat ${ }^{\star}$ or breathing) near (ventilat ${ }^{\star}$ or movement $\left.{ }^{\star}\right)$ ):ti,ab or ventilat*:ti,ab

\#7 (positive? end expirat* pressure) or (breathing mechanic ${ }^{\star}$ )

\#8 wean* $^{\star}$ or liberat* ${ }^{\star}$ or extubat ${ }^{\star}$

Automated versus non-automated weaning for reducing the duration of mechanical ventilation for critically ill adults and children 
\#9 (\#8 AND ( \#1 OR \#2 OR \#3 OR \#4 OR \#5 OR \#6 OR \#7 ))

\#10 (\#1 OR \#9)

\#11 MeSH descriptor Therapy, Computer-Assisted explode all trees

\#12 ((computer or proportion*) near assist ${ }^{\star}$ ) or (automat ${ }^{\star}$ near system ${ }^{\star}$ ) or (smart near care) or smartcare or automode or (adaptive near (support* or assist $\left.{ }^{\star}\right)$ ) or (mandatory near minute*) or (neurally adjusted ventilat* assist ${ }^{\star}$ ) or (neurally near adjust ${ }^{\star}$ ) or nava or (volume near support near ventilation) or (proportional near pressure near support) or intellivent

\#13 (\#11 OR\#12)

\#14 (\#10 AND \#13)

\section{Appendix 4. Database of Abstracts of Reviews of Effects (DARE) search strategy}

1 ((ventilat* and (wean* or liberat* ${ }^{\star}$ or extubat* $\left.{ }^{\star}\right)$ or "ventilator weaning").mp.

2 (("positive pressure respiration" or "artificial ventilation" or "Respiratory Mechanics") and (wean* or liberat* or extubat*)).mp.

31 or 2

$4 \quad\left(\left(\left(\right.\right.\right.$ computer or proportion $\left.^{\star}\right)$ adj3 assist $\left.{ }^{\star}\right)$ or (automat* adj3 system $\left.{ }^{\star}\right)$ or (smart adj3 care) or smartcare or automode or "adaptive support ventilation" or (adaptive adj3 (support* or assist*)) or "mandatory minute ventilation" or (mandatory adj3 minute*) or "neurally adjusted ventilat* assist*" or (neurally adj3 adjust*) or nava or "volume support ventilation" or (volume adj3 support adj3 ventilation) or "proportional pressure support" or (proportional adj3 pressure adj3 support)).mp.

$5 \quad 3$ and 4

\section{Appendix 5. Health Technology Assessment search strategy}

1 ventilator weaning/

2 (exp positive-pressure respiration/ or Ventilators, Mechanical/ or respiration, artificial/ or exp Respiratory Mechanics/ or artificial ventilation/ or positive end expiratory pressure/ or ventilator/ or breathing mechanics/ or ((respirat* or breathing) adj2 (ventilat* or

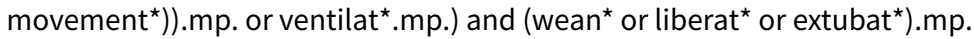

\section{1 or 2}

4 exp Therapy, Computer-Assisted/ or exp Therapy, Computer-Assisted/ or (((computer or proportion*) adj3 assist*) or (automat* adj3 system $^{\star}$ ) or (smart adj3 care) or smartcare or automode or "adaptive support ventilation" or (adaptive adj3 (support* or assist*)) or "mandatory minute ventilation" or (mandatory adj3 minute*) or "neurally adjusted ventilat* assist*" or (neurally adj3 adjust*) or nava or "volume support ventilation" or (volume adj3 support adj3 ventilation) or "proportional pressure support" or (proportional adj3 pressure adj3 support)).mp.

\section{3 and 4}

\section{Appendix 6. CINAHL search strategy}

1 (MH "Ventilator Weaning")

2 ((MH "Respiration, Artificial") OR (MH "Positive Pressure Ventilation+") OR (MH "Ventilators, Mechanical") OR (MH "Respiratory Mechanics") OR ventilat*) AND (wean* or liberat* or extubat*)

$3(1$ or 2$)$

$4 \quad$ (MH "Therapy, Computer Assisted+")

5 (TX computer N3 assist ${ }^{\star}$ )

6 (TX proportion N3 assist ${ }^{\star}$ )

7 (TX automat* N3 system ${ }^{\star}$ )

$8 \quad$ (TX smart N3 care)

9 (TX smartcare OR automode OR nava OR intellivent)

10 (TX adaptive N3 support ${ }^{\star}$ )

11 (TX adaptive N3 assist ${ }^{\star}$ )

Automated versus non-automated weaning for reducing the duration of mechanical ventilation for critically ill adults and children 
12 (TX mandatory N3 minute*)

13 (TX neurally N3 adjust ${ }^{\star}$ )

14 (TX volume N3 support N3 ventilation)

15 (TX proportional N3 pressure N3 support*)

16 (TX closed N3 loop)

17 (TX automat $\left.{ }^{\star}\right)$

184 or 5 or 6 or 7 or 8 or 9 or 10 or 11 or 12 or 13 or 14 or 15 or 16 or 17

$19 \quad 3$ and 18

20 (MH "Randomized Controlled Trials") OR (MH "Double-Blind Studies")OR (MH "Single-Blind Studies") OR (MH "Triple-Blind Studies") OR (MH "Meta Analysis") OR (MH "Multicenter Studies") OR (MH "Random Sample")

21 (TX singl ${ }^{*}$ N5 mask $\left.{ }^{\star}\right)$ OR (TX doubl* N5 mask $\left.{ }^{\star}\right)$ OR (TX tripl* N5 mask ${ }^{\star}$ ) OR (TX trebl* N5 mask $\left.{ }^{\star}\right)$

22 (TX singl* N5 blind*) OR (TX doubl* N5 blind*) OR (TX tripl ${ }^{\star}$ N5 blind*) OR (TX trebl* N5 blind*)

23 (TX meta N5 analysis)

24 (TX rct OR rcts OR random* OR multicent* OR placebo* OR metanalysis ${ }^{\star}$ OR sham OR effectiveness OR efficacy OR compare*

2518 or 19 or 20 or 21 or 22

$26 \quad 17$ and 23

\section{Appendix 7. LILACS search strategy}

"VENTILATOR" or "VENTILATION" or "VENTILATION-PERFUSION" or "VENTILATIONFOR" or "VENTILATIONIN" or "VENTILATIONS" or "VENTILATOR" or "VENTILATOR-ASSOCIATED" or "VENTILATOR-INDUCED" or "VENTILATORIA" or "VENTILATORIAMENTE" or "VENTILATORIAS" or "VENTILATORIES" or "VENTILATORIO" or "VENTILATORIODEPENDENTE" or "VENTILATORIOS" or "VENTILATORS" or "VENTILATORY" or "VENTILATORYSTRATEGIES" or "VENTILATORYTHRESHOLD" [Words] and "WEAN" or "WEANALYZED" or "WEANED" or "WEANER" or "WEANING" or "WEANLING" or "WEANNING" or "WEANS" or "WEANSO" and automated or automated/ or automates or automatic or automatic control or automatic control/ or automatically or automaticament or automaticamente or automaticidad or automaticidade or automatizados or automaticos or closed loop or smartcare or nava or computer or proportional or mandatory or neurally [Words] 


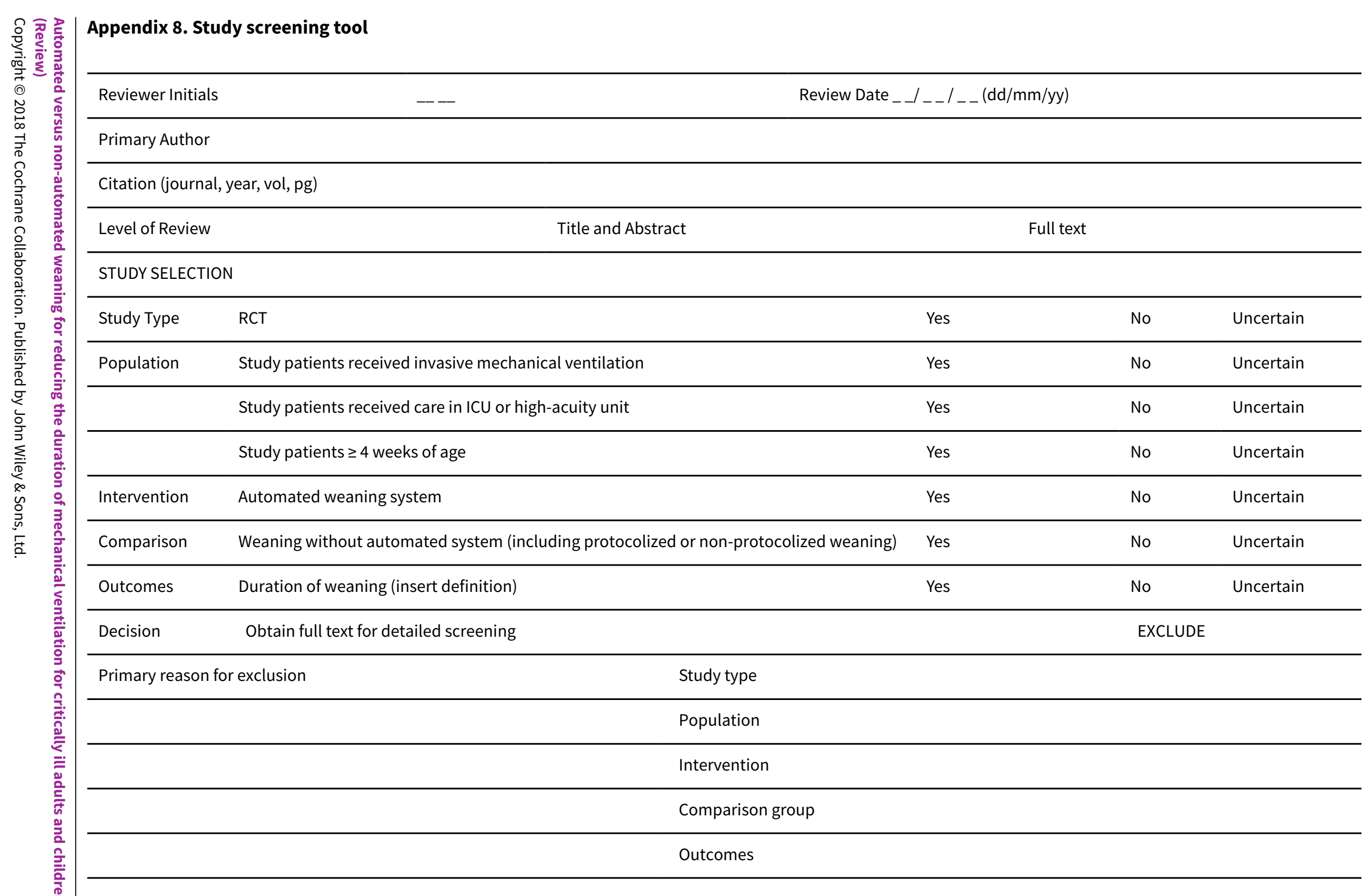




\section{Appendix 9. Data extraction form}

Data extraction form

Reviewer Initials

\section{Review Date (dd/mm/yy)}

Study ID

Primary author

Citation (journal, year, vol, pg)

Confirm study eligibility $\quad$ Yes

No (if No, list reason for exclusion on screening tool

Study type

Simple RCT

Cluster RCT

Factorial RCT

General Notes:

\section{Participant inclusion criteria (please list):}

Exclusion criteria (please list):

\section{PARTICIPANTS}

\begin{tabular}{lll}
\hline INTERVENTION: & $\mathrm{N}=$ & CONTROL: \\
\hline Age, mean (SD) & $\begin{array}{l}\text { Age, mean (SD) } \\
\text { med (IQR) }\end{array}$ \\
med (IQR) & Male n (\%) \\
\hline Male n (\%) & Name severity of illness measure (e.g. \\
\hline $\begin{array}{l}\text { Name severity of illness measure (e.g. } \\
\text { APACHE, SAPS, PELOD) }\end{array}$ & APACHE, SAPS, PELOD) \\
mean (SD) & mean (SD) \\
med (IQR) & med (IQR) \\
\hline
\end{tabular}

Setting 
Participating site country (ies):

Academic hospital

Non-teaching hospital

\section{Not reported}

Urban

Regional

Rural

Mixed ICU

MICU

SICU

Closed ICU structure

Open ICU structure

\section{Not reported}

Nurse staffing for vent pts.

Not reported

\section{Physician staffing (describe)}

Not reported

\section{INTERVENTION}

Describe automated weaning system and protocol (verbatim)

Describe sedation strategies in intervention arm (tick all that apply):

sedation score

sedation protocol

daily interruption

not reported 
(Continued)

\section{CONTROL}

Describe weaning method used for control group (verbatim)

Describe sedation strategies in control arm (tick all that apply):

sedation score

sedation protocol

daily interruption

not reported

\section{OUTCOMES}

PLEASE RECORD UNIT of MEASUREMENT for ALL OUTCOMES (days/hours)

\begin{tabular}{|c|c|}
\hline INTERVENTION & CONTROL \\
\hline $\begin{array}{l}\text { Study randomization to successful extuba- } \\
\text { tion }\end{array}$ & $\begin{array}{l}\text { Study randomization to successful ex- } \\
\text { tubation }\end{array}$ \\
\hline $\mathrm{n}(\%)$ & $\mathrm{n}(\%)$ \\
\hline mean (SD) & mean (SD) \\
\hline median (IQR) & median (IQR) \\
\hline mean diff ( $95 \% \mathrm{Cl}, \mathrm{P}$ value) & mean diff (95\% Cl, P value) \\
\hline
\end{tabular}

$\begin{array}{ll}\begin{array}{l}\text { Successful extubation/discontinuation of } \\ \text { mechanical ventilation }\end{array} & 24 \mathrm{hrs} \\ & 48 \mathrm{hrs} \\ \begin{array}{l}\text { defined as no requirement for reintubation } \\ \text { at (tick interval that applies) }\end{array} & 72 \mathrm{hrs} \\ & 96 \mathrm{hrs} \\ & 7 \text { days }\end{array}$

\begin{tabular}{ll}
\hline Study randomization to first extubation & $\underline{\underline{\text { Study randomization to first extuba- }}}$ \\
\hline $\mathrm{n}(\%)$ & $\mathrm{n}(\%)$ \\
mean (SD) & mean (SD) \\
median (IQR) & median (IQR) \\
mean diff (95\% Cl, P value) & mean diff (95\% Cl, P value) \\
\hline Intubation to successful extubation & $\underline{\text { Intubation to successful extubation }}$ \\
\hline $\mathrm{n}(\%)$ & $\mathrm{n}(\%)$ \\
mean (SD) & mean (SD)
\end{tabular}

Automated versus non-automated weaning for reducing the duration of mechanical ventilation for critically ill adults and children 
(Continued) median (IQR)

mean diff ( $95 \% \mathrm{Cl}$, P value) median (IQR)

mean diff (95\% Cl, P value)

\begin{tabular}{|c|c|}
\hline Intubation to study randomization & $\underline{\text { Intubation to study randomization }}$ \\
\hline $\mathrm{n}(\%)$ & $\mathrm{n}(\%)$ \\
\hline mean (SD) & mean (SD) \\
\hline median (IQR) & median (IQR) \\
\hline mean diff (95\% Cl, P value) & mean diff (95\% Cl, P value) \\
\hline $\begin{array}{l}\text { Satisfying extubation criteria and actual ex- } \\
\text { tubation }\end{array}$ & $\begin{array}{l}\text { Satisfying extubation criteria and actu- } \\
\underline{\text { al extubation }}\end{array}$ \\
\hline $\mathrm{n}(\%)$ & $\mathrm{n}(\%)$ \\
\hline median (IQR) & median (IQR) \\
\hline mean diff ( $95 \% \mathrm{Cl}, \mathrm{P}$ value) & mean diff (95\% Cl, P value) \\
\hline ICU length of stay & ICU length of stay \\
\hline $\mathrm{n}(\%)$ & $\mathrm{n}(\%)$ \\
\hline mean (SD) & mean (SD) \\
\hline median (IQR) & median (IQR) \\
\hline mean diff (95\% Cl, P value) & mean diff ( $95 \% \mathrm{Cl}, \mathrm{P}$ value) \\
\hline $\mathrm{n}(\%)$ & $\mathrm{n}(\%)$ \\
\hline mean (SD) & mean (SD) \\
\hline median (IQR) & median (IQR) \\
\hline mean diff (95\% Cl, P value) & mean diff (95\% Cl, $\mathrm{P}$ value) \\
\hline
\end{tabular}

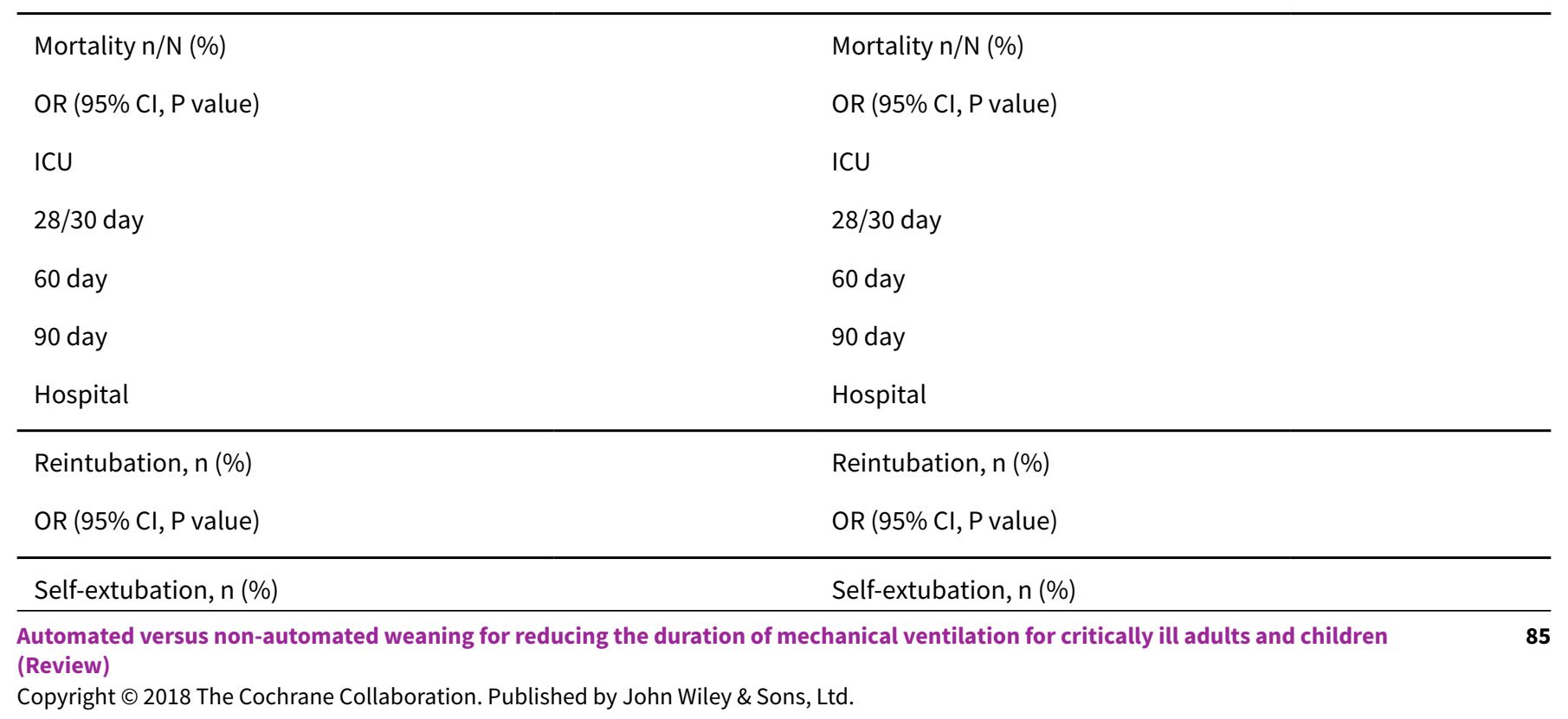


(Continued)
OR (95\% CI, P value)
OR (95\% Cl, P value)

\begin{tabular}{lc}
\hline Post-extubation NIV, $\mathrm{n}(\%)$ & Post-extubation NIV, $\mathrm{n}(\%)$ \\
OR $(95 \% \mathrm{Cl}, \mathrm{P}$ value) & OR $(95 \% \mathrm{Cl}, \mathrm{P}$ value $)$ \\
\hline 21 days vented, $\mathrm{n}(\%)$ & $\geq 21$ days vented, $\mathrm{n}(\%)$ \\
OR $(95 \% \mathrm{Cl}, \mathrm{P}$ value) & $\mathrm{OR}(95 \% \mathrm{Cl}, \mathrm{P}$ value $)$
\end{tabular}

\section{CONCLUSIONS}

Key Conclusions made by authors

\section{PERSONAL COMMUNICATION}

List any personal communication with authors \& corresponding dates.

\section{WHAT'S NEW}

\begin{tabular}{lll}
\hline Date & Event & Description \\
\hline 20 December 2018 & Amended & Editorial team changed to Cochrane Emergency and Critical Care \\
\hline
\end{tabular}

\section{H I S T O R Y}

Protocol first published: Issue 7, 2011

Review first published: Issue 6, 2013

\begin{tabular}{lll}
\hline Date & Event & Description \\
\hline 3 June 2014 & New search has been performed & Review updated including search to 30 September 2013 \\
\hline 3 June 2014 & $\begin{array}{l}\text { New citation required but conclusions } \\
\text { have not changed }\end{array}$ & $\begin{array}{l}\text { This review is an update of the previous Cochrane systematic re- } \\
\text { view (Rose 2013). We found and included six new trials. In gener- } \\
\text { al our review reaches the same conclusions as our previous re- } \\
\text { view that included 15 trials. However, we included more trials } \\
\text { and thus have more precise estimates for the effects of automat- } \\
\text { ed systems on our primary and secondary outcomes. }\end{array}$ \\
\hline 18 January 2012 & Amended & Contact details updated. \\
\hline
\end{tabular}




\section{CONTRIBUTIONS OF AUTHORS}

Louise Rose (LR), Marcus J Schultz (MS), Chris R Cardwell (CC), Philippe Jouvet (PJ), Danny F McAuley (DM), Bronagh Blackwood (BB)

Conceiving the review: $\mathrm{LR}, \mathrm{BB}$

Co-ordinating the review: LR

Undertaking manual searches: LR, PJ

Screening search results: LR, PJ

Organizing retrieval of papers: LR

Screening retrieved papers against inclusion criteria: LR, PJ, DM (arbiter)

Appraising quality of papers: BB, MS, DM (arbiter)

Abstracting data from papers: $\mathrm{BB}, \mathrm{MS}$

Writing to authors of papers for additional information: LR

Providing additional data about papers: LR, BB

Obtaining and screening data on unpublished studies: LR, BB

Data management for the review: LR

Entering data into Review Manager (RevMan 5.2): LR

RevMan statistical data: CC

Other statistical analysis not using RevMan: CC

Double entry of data: (data entered by person one: LR; data entered by person two: BB)

Interpretation of data: all authors

Statistical inferences: CC

Writing the review: LR, BB, all authors

Securing funding for the review: LR

Performing previous work that was the foundation of the present study: BB, CC (previous review that identified increased interest in automated studies)

Guarantor for the review (one author): LR

Person responsible for reading and checking review before submission: LR

\section{DECLARATIONS OF INTEREST}

Bronagh Blackwood, Chris R Cardwell, Danny F McAuley: none known.

Louise Rose has completed an RCT comparing automated weaning using SmartCare/PS ${ }^{\text {TM }}$ with usual care that was included in this systematic review. Dr Rose received no funding from Draeger Medical for this study. SmartCare/PS software, and associated technical upgrades for two ventilators, were provided free of charge to the Intensive Care Unit of The Royal Melbourne Hospital by Draeger Medical, Australia.

Marcus J Schultz received a research fund of EUR 12,000 for a study on weaning with ASV by Hamilton Medical, Switzerland. Hamilton Medical provided Professor Schultz's hospital research group with EUR 12,000 for performing a study of weaning with ASV in cardiac surgical patients. The money was used to buy equipment, a computer, statistician time, and to cover costs involved with the presentation of the results at a scientific meeting and publication of an article.

Philippe Jouvet has completed an RCT comparing automated weaning using SmartCare/PS ${ }^{\mathrm{TM}}$ with usual care, included in this systematic review. Dr Jouvet did not receive any funding from Draeger for this study though, for the purposes of the study, Draeger Medical provided one ventilator. Dr Jouvet received two grants as support from Hamilton Medical for two clinical studies, including a prospective trial on

Automated versus non-automated weaning for reducing the duration of mechanical ventilation for critically ill adults and children 
automation of weaning with ASV in children (NCT01095406) and a clinical study on criteria for mechanical ventilation adjustments in children. These two studies were not eligible for inclusion in the systematic review. Dr Jouvet also conducted a clinical trial on weaning with NAVA in infants (NCT00603174) that was not eligible for inclusion in the systematic review. Dr Jouvet did not receive any funding from Maquet for this study though, for the purposes of the study, Maquet provided one ventilator.

\section{SOURCES OF SUPPORT}

\section{Internal sources}

- No sources of support supplied

\section{External sources}

- Canadian Institutes of Health Research, Canada, Other.

CIHR Knowledge Synthesis 2011 grant

\section{NDEX TERMS}

\section{Medical Subject Headings (MeSH)}

${ }^{*}$ Critical Illness; Intensive Care Units; Length of Stay; Randomized Controlled Trials as Topic; Respiration, Artificial [ ${ }^{*}$ methods] [statistics \& numerical data]; Time Factors; Ventilator Weaning [*methods] [statistics \& numerical data]

\section{MeSH check words}

Adult; Child; Humans 